\title{
Covalently bonded Compounds of Heavy Group 15/16 Elements - Synthesis, Structure and Potential Application in Material Sciences
}

Stephan Schulz

Prof. Dr. Stephan Schulz, Institute of Inorganic Chemistry, University of Duisburg-Essen, 45117 Essen, Germany and Center for Nanointegration Duisburg-Essen (CENIDE); Phone: +49 0201-1834635; Fax: + 49 0201-1833830; e-mail: stephan.schulz@uni-due.de.

\begin{abstract}
Our understanding on the nature of weak intermolecular metal-metal interactions as well as of multiple bonding in group 15/16 chemistry, in particular of compounds containing the heaviest elements of both groups - $\mathrm{Sb}, \mathrm{Bi}, \mathrm{Se}$, and $\mathrm{Te}$ - is still scarce. These types of interactions are particularly important for the chemical and phyical properties of such main group element compounds. For instance, the formation and disruption of weak intermolecular metal-metal interactions are the origin of the so-called thermochroism. The structural characterization of compounds containing sterically less demanding organic substituents is therefore of particular interest, since the capability of small substituents to kinetically stabilize the respective metal centers - and hence to suppress intermolecular interactions - is expected to be rather less pronounced.

We will herein summarize the most recent results reported for the synthesis and structural characterization of group 15/16 compounds containg a direct (polar-covalent) elementelement bond including compounds containing a terminal, formally double bond. In addition, the capability of selected compounds to serve as single source precursor for the synthesis of the corresponding nanomaterials, in particular $\mathrm{Sb}_{2} \mathrm{Te}_{3}$ and $\mathrm{Bi}_{2} \mathrm{Te}_{3}$, by using wet chemical methods as well as gas phase approaches such as metal organic chemical vapor deposition (MOCVD) processes will be demonstrated.
\end{abstract}

\section{Keywords}

Antimony, Bismuth, Selenium, Tellurium, X-ray Crystal Structure, Intermolecular Interaction, Multiple Bonding, Single-Source-Precursor, Thermoelectric Materials, Nanoparticles, Thin Films, MOCVD. 


\section{Abbreviations}

AACVD, aerosol-assisted chemical vapor deposition; AFM, atomic force microscopy; $\mathrm{Bbt}=$ 2,6-bis[bis(trimethylsilyl)methyl]-4-[tris(trimethylsilyl)methyl]phenyl， $\quad$ DIPP， 2,6diisoporopyl phenyl; DSC, differential scanning calorimetry; EDX, energy-dispersive X-ray spectroscopy; HDA, hexadecylamine; PVP*, poly(1-vinylpyrolidone)-graft-(1-triacontene), SAED, selected area electron diffraction; SEM, scanning electron microscopy; TEM, transmission electron microscopy; TOPO, tri-n-octylphosphane oxide; Trip, 2,4,6-triisopropyl-phenyl, 2,4,6-i- $\mathrm{Pr}_{3}-\mathrm{C}_{6} \mathrm{H}_{2} ; \quad \mathrm{XRD}, \quad \mathrm{X}$-ray diffraction; 8-Seq, tris(quinoline-8selenolato)-stibine.

\section{Introduction}

Heteronuclear metal organic compounds with a direct bond between group 15 and group 16 elements, in particular those containing the heaviest homologues of both groups - $\mathrm{Sb}, \mathrm{Bi}, \mathrm{Se}$, and Te - have received a steadily growing interest over the last decades. This interest is mainly based on their potential to form weak intermolecular metal-metal contacts in the solid state, as is also typical for homonuclear compounds such as distibines $\left(\mathrm{Sb}_{2} \mathrm{R}_{4}\right)$ and dibismuthines $\left(\mathrm{Bi}_{2} \mathrm{R}_{4}\right)$ as well as in ditellanes $\left(\mathrm{Te}_{2} \mathrm{R}_{2}^{\prime}\right)$, respectively. The strength of the intermolecular interactions in these types of compounds are known to depend on the size of the organic substituents and their electronic properties. Sterically less demanding substituents force the formation of one- or two-dimensional polymeric networks, whereas sterically demanding substituents hamper the formation of intermolecular contacts (kinetic stabilization). Moreover, electron withdrawing substituents rather suppress the formation of intermolecular contacts, i.e. dimethylditellurane $\mathrm{Te}_{2} \mathrm{Me}_{2}$ forms a chain-like structure in the solid state, ${ }^{[1]}$ whereas the shortest intermolecular distance in bis(trifluormethyl)ditellurane $\mathrm{Te}_{2}\left(\mathrm{CF}_{3}\right)_{2}$ exceed the sum of the van-der-Waals radii of the metal atoms. ${ }^{[2]}$ Comparable findings were observed in tetraalkyldistibines and -dibismuthines, which often show chainlike structures in the solid state with weak intermolecular metal-metal interactions. ${ }^{[3,4,5]}$ The metal-metal interactions are typically interrupted upon melting, resulting in a bathochromic shift between fluid and solid phases, the so-called "thermochromic" effect. ${ }^{[6]}$

Group 15/16 compounds such as bis(dialkylstibanyl)chalcogenanes $\mathrm{R}_{2} \mathrm{Sb}-\mathrm{E}-\mathrm{SbR}_{2}(\mathrm{E}=\mathrm{S}, \mathrm{Se}$, $\mathrm{Te})^{[7,8,9]}$ and bis(dialkylbismuthanyl)chalcogenanes $\mathrm{R}_{2} \mathrm{Bi}-\mathrm{E}-\mathrm{BiR}_{2}(\mathrm{E}=\mathrm{S}, \mathrm{Se}, \mathrm{Te}){ }^{[10,11,12,13]}$ which are accessible by insertion reactions of elemental chalcogens into the metal-metal bonds of the corresponding distibines and dibismuthines, also exhibit weak intermolecular 
contacts in the solid state, resulting in thermochromic behavior upon melting. ${ }^{[14]}$ In addition, compounds of the general type $\mathrm{R}_{2} \mathrm{SbER}^{\prime}(\mathrm{E}=\mathrm{S}$, Se, Te; $\mathrm{R}=\mathrm{Me}$, Et, R' $=\mathrm{Me}, \mathrm{Ph}),{ }^{[15,16,17]}$ which were synthesized by reactions of distibines and dibismuthines with dichalcogenanes $\mathrm{E}_{2}^{\prime} \mathrm{R}_{2}\left(\mathrm{E}^{\prime}=\mathrm{S}, \mathrm{Se}, \mathrm{Te}\right),{ }^{\left[{ }_{8}, 10,18,19,20,21,22\right]}$ were reported to be thermochromic. $\mathrm{Me}_{2} \mathrm{SbTeMe}$ for instance is a red liquid at room temperature that solidifies at $-52{ }^{\circ} \mathrm{C}$ with formation of a red solid, which turns yellow-orange at $-80^{\circ} \mathrm{C}$. In addition, $\mathrm{Et}_{2} \mathrm{SbTeMe}$ is an orange liquid at room temperature that solidifies at $-80{ }^{\circ} \mathrm{C}$ to a green-yellow solid. Unfortunately, even though these types of compounds were well known for years, solid state structures of compounds containing sterically less demanding organic substituents such as methyl or ethyl groups, which are typically liquid at ambient temperature, remained almost unknown.

The second major point of interest in group 15/16 chemistry in the last decades was the synthesis and structural characterization of compounds containing hetero-multiple bonds between the group 15 and group 16 atoms. ${ }^{[23,24]}$ Compounds containing a formal double bond were successfully stabilized by either the introduction of sterically overcrowded ligands, which typically prevent the molecules from self-condensation and/or polymerization (ring formation), or by use of specific N,C,N-pincer-type ligands, which were successfully applied for the stabilization of monomeric antimony(III) chalcogenides of the general type LSbE (E = $\mathrm{S}, \mathrm{Se}) .{ }^{[25,26]}$ These compounds contain highly polar, terminal $\mathrm{Sb}-\mathrm{E}$ bonds $\left(\mathrm{Sb}^{{ }^{+}-}-\mathrm{E}^{\delta^{-}}(\mathrm{E}=\mathrm{Se}\right.$, $\mathrm{Te}$ ) due to the donation of electron density from the $\mathrm{N}$ atoms to the $\mathrm{Sb}$ atom, while according to theoretical studies, the terminal $\mathrm{Sb}-\mathrm{E}$ bonds in hypothetical $\mathrm{PhSb}=\mathrm{E}$ molecules are less polar and exhibit more double bond character due to the lack of extra donor atoms. Surprisingly, solid state structures of organoantimony(V) chalcogenides $\mathrm{R}_{3} \mathrm{SbE}$ bearing an unsupported terminal Sb-E bond are almost unknown, even though triethylchalcogenostiboranes $\mathrm{Et}_{3} \mathrm{SbS}$ and $\mathrm{Et}_{3} \mathrm{SbSe}$ have been initially prepared more than 150 years ago by Carl Jakob Löwig and Eduard Schweizer. ${ }^{[27]}$ Triphenylthiostiborane $\mathrm{Ph}_{3} \mathrm{SbS}$, aside from $\mathrm{p}-\mathrm{Tol}_{3} \mathrm{SbS}$ the only structurally characterized triorganylthiostiborane, ${ }^{[28,29,30,31,32]}$ shows a short Sb-S bond (2.244(1) Å), which was described by Pebler et al. as partial double bond due to $\mathrm{d} \pi-\mathrm{p} \pi$ interaction, whereas Otera et al. described the Sb-S bond in $\mathrm{Me}_{3} \mathrm{SbS}$ as highly polar single bond with some ionic stabilization due to the large electronegativity difference between $\mathrm{Sb}$ and S. ${ }^{[33]}$ Therefore, our knowledge on the nature of the bonding in these type of compounds is still rather sparce.

Finally, group 15/16 compounds have received growing interest in recent years as molecular precursors, so-called single source precursors, for the synthesis of the corresponding binary 
materials of the general type $\mathrm{M}_{2} \mathrm{E}_{3}(\mathrm{M}=\mathrm{Sb}, \mathrm{Bi} ; \mathrm{E}=\mathrm{S}, \mathrm{Se}, \mathrm{Te}) . \mathrm{Sb}_{2} \mathrm{~S}_{3}$ for instance is of particular interest for technical applications in sensitized solar cells (SSCs), ${ }^{[34,35,36]}$ in ferroelectric phase transition materials ${ }^{[37]}$ and in battery materials. ${ }^{[38,39,40]}$ In addition, nanoparticles as well as thin films of $\mathrm{Sb}_{2} \mathrm{Te}_{3}, \mathrm{Bi}_{2} \mathrm{Se}_{3}$ as well as $\mathrm{Bi}_{2} \mathrm{Te}_{3}$, which belong to the $\mathrm{M}_{2} \mathrm{E}_{3}$ layered materials $(\mathrm{M}=\mathrm{Sb}, \mathrm{Bi} ; \mathrm{E}=\mathrm{S}$, Se, Te) with tetradymite structure, are of particular interest for technical applications as thermoelectric materials. $\mathrm{Sb}_{2} \mathrm{Te}_{3}$ for instance is a narrow band-gap $\left(\mathrm{E}_{\mathrm{gap}}=0.26 \mathrm{eV}\right)$ semiconductor with good thermoelectric properties near room temperature. ${ }^{[11,42,43]}$ Although many promising thermoelectric materials have been discovered in recent years, antimony and bismuth chalcogenide-based materials are still the most widely used. In the last decade, the effect of nanostructuring on the enhancement of the thermoelectric figure of merit $\mathrm{zT}$, which is mainly based on the decoupling of thermal and electrical conductivity due to the different lengths scales of the mean free path of electrons and phonons, ${ }^{[44]}$ was demonstrated. Moreover, $\mathrm{Bi}_{2} \mathrm{Te}_{3}, \mathrm{Bi}_{2} \mathrm{Se}_{3}$, and $\mathrm{Sb}_{2} \mathrm{Te}_{3}$ are of particular technological interest since they are prototypical topological insulators - bulk insulators with metallic surfaces. In contrast, $\mathrm{Sb}_{2} \mathrm{Se}_{3}$ lacks a sufficiently strong spin-orbit interaction to develop the topological surface state. ${ }^{[45]}$ In order to generate technologically important $\mathrm{M}_{2} \mathrm{E}_{3}$ materials with defined optical and physical properties, bottom-up chemistry approaches are currently investigated. So-called single-source precursors are known to have a promising potential for the synthesis of nanostructured $\mathrm{M}_{2} \mathrm{E}_{3}$ materials. ${ }^{[36,46,47,48,49,50]}$

We herein summarize on the most recent progress made in the synthesis and structural characterization of molecular group 15/16 compounds of type I - VI (Scheme 1) of the heaviest elements of both groups, $\mathrm{Sb}, \mathrm{Bi}, \mathrm{Se}$ and $\mathrm{Te}$, as well as on their promising technical applications to serve as tailor-made single source precursors in material sciences.

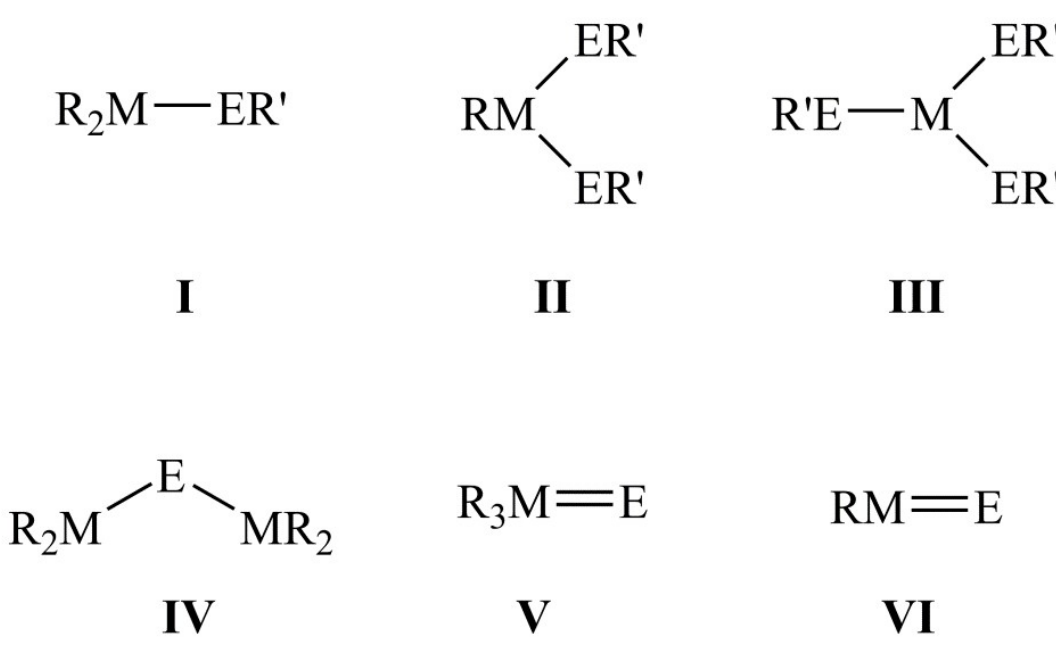


Scheme 1. Molecular group 15/16 compounds with potential technical applications as single source precursors in material sciences.

\section{Synthesis and Solid State Structures of Group 15 Chalcogenides of the types $\mathbf{R}_{2} \mathrm{MER}$, $\operatorname{RM}\left(E^{\prime}\right) 2$ and $M\left(E^{\prime}\right) 3$}

\section{$2.1 R_{2} M E R^{\prime}(M=S b, B i ; E=S e, T e)$}

Compounds of the general type $\mathrm{R}_{2}$ MER' (type I) have been synthesized by standard salt elimination reactions ${ }^{[51,52,53,54,55]}$ and were postulated as intermediates in reactions of $\mathrm{BiR}_{3}$ with Te. ${ }^{[56]}$ However, the most convenient route for such compounds including those containing sterically less demanding organic substituents, for which intermolecular interactions between adjacent molecules in the solid state are most likely, are reactions of low-valent dipentelanes $\mathrm{R}_{4} \mathrm{M}_{2} \quad(\mathrm{M}=\mathrm{Sb}$, Bi) containing weak $\mathrm{M}-\mathrm{M}$ bonds with dichalcogenanes $E_{2}^{\prime} R_{2}\left(E^{\prime}=S\right.$, Se, Te). ${ }^{\left[8^{, 10,18,19,20,21,22] ~}\right.}$ For instance, $\mathrm{R}_{2} \mathrm{SbER}^{\prime}(\mathrm{E}=\mathrm{S}, \mathrm{Se}, \mathrm{Te}$; $\mathrm{R}=\mathrm{Me}, \mathrm{Et}, \mathrm{R}^{\prime}=\mathrm{Me}, \mathrm{Ph}$ ) were obtained from reactions of $\mathrm{Sb}_{2} \mathrm{R}_{4}$ and $\mathrm{E}_{2} \mathrm{R}_{2}^{\prime}$ at ambient temperature $\left(\mathrm{Sb}_{2} \mathrm{Me}_{4}\right)$ and $-40{ }^{\circ} \mathrm{C}\left(\mathrm{Sb}_{2} \mathrm{Et}_{4}\right)$, respectively. ${ }^{[15,16,17]}$

$\mathrm{R}_{2} \mathrm{SbTeMe}(\mathrm{R}=\mathrm{Me}, \mathrm{Et})$, which decompose upon heating with formation of the corresponding trialkylstibine $\mathrm{SbR}_{3}$ and $\mathrm{RSb}\left(\mathrm{ER}^{\prime}\right)_{2}$, were reported to be thermochromic, indicating the presence of intermolecular contacts between the metal centers in the solid state. $\mathrm{Me}_{2} \mathrm{SbTeMe}$ is a red liquid at room temperature that solidifies at $-52{ }^{\circ} \mathrm{C}$ with formation of a red solid, which turns yellow-orange at $-80{ }^{\circ} \mathrm{C}$. A similar color change was observed when the compound was dissolved in $\mathrm{CDCl}_{3}$. $\mathrm{Et}_{2} \mathrm{SbTeMe}$ is an orange liquid at room temperature which solidified at $-80{ }^{\circ} \mathrm{C}$ with formation of a green-yellow solid. Freezing a solution of $\mathrm{Et}_{2} \mathrm{SbTeMe}$ in $\mathrm{CDCl}_{3}$ produced a similar change in color.

Recently, compounds of the type $\mathrm{RBi}(\mathrm{EAr})_{2}\left(\mathrm{R}=o-\mathrm{C}_{6} \mathrm{H}_{4}\left(\mathrm{CH}=\mathrm{NC}_{6} \mathrm{H}_{3}-2,6-i-\mathrm{Pr}_{2}\right), \mathrm{E}=\mathrm{Se}, \mathrm{Te}\right)$ were obtained by reactions of $\mathrm{RBiCl}_{2}$ with two equivalents of $\mathrm{K}\left[\mathrm{B}(s-\mathrm{Bu})_{3} \mathrm{H}\right]$ and subsequent reactions with diphenyldichalcogenanes $\mathrm{E}_{2} \mathrm{Ph}_{2}\left(\mathrm{E}=\mathrm{Se}\right.$, Te; Scheme 2). ${ }^{[57]}$ These compounds were found to decompose in solution with elimination of $\mathrm{Bi}(\mathrm{EPh})_{3}$ and subsequent formation of $\mathrm{R}_{2} \mathrm{BiEPh}$. This is a promising route for the synthesis of the desired class of compounds in the future. 


$$
\begin{aligned}
\mathrm{R}_{2} \mathrm{MCl}+\mathrm{LiER}^{\prime} & -\mathrm{R}_{2} \mathrm{MER}^{\prime} \\
\mathrm{R}_{2} \mathrm{M}^{\mathrm{M}} \mathrm{MR}_{2}+\mathrm{R}^{\prime} \mathrm{E}-\mathrm{EiCl} & \longrightarrow 2 \mathrm{R}_{2}^{\prime} \mathrm{MER}^{\prime}
\end{aligned}
$$

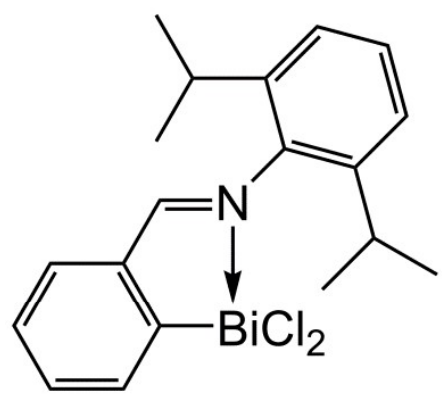

i) $+2 \mathrm{~K}\left[\mathrm{~B}(\mathrm{~s}-\mathrm{Bu})_{3} \mathrm{BH}\right]$

$-2 \mathrm{KCl},-\mathrm{H}_{2},-2 \mathrm{~B}(\mathrm{~s}-\mathrm{Bu})_{3}$

ii) $+\mathrm{PhE}-\mathrm{EPh}$

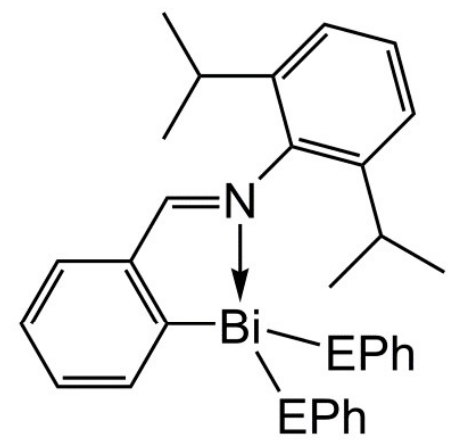

(3)
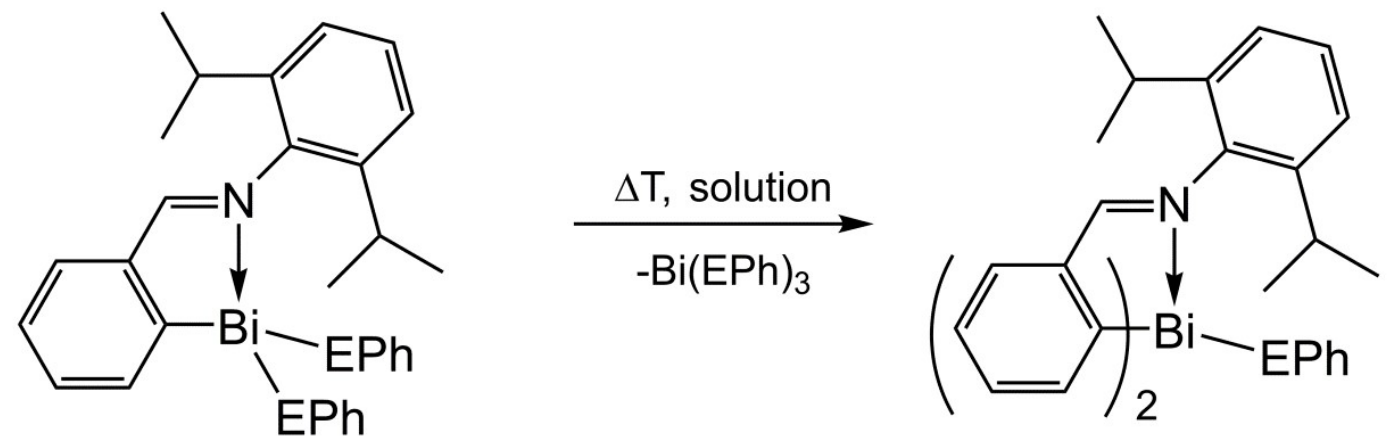

Scheme 2: Synthesis of compounds of the general type $\mathrm{R}_{2} \mathrm{MER}^{\prime}(\mathrm{M}=\mathrm{Sb}, \mathrm{Bi} ; \mathrm{E}=\mathrm{S}, \mathrm{Se}, \mathrm{Te})$ Unfortunately, structurally characterized compounds containing the heavier elements of both groups are rather scarce. While several antimony and bismuth alkoxides and sulfides, which typically show strong intermolecular contacts in the solid state, have been structurally characterized, only five structures containing the heaviest elements of both groups were reported to the best of our knowledge, most likely as a result of their enhanced sensitivity toward air-, moisture and light. Moreover, compound containing sterically less demanding alkyl ligands are often liquid at ambient temperature, which makes it rather difficult to grow single crystals.

Table 1. Bond lengths $[\AA]$ and angles $\left[^{\circ}\right]$ of structurally characterized compounds of the type $\mathrm{R}_{2} \mathrm{MER}$ ' containing the heaviest elements $(\mathrm{M}=\mathrm{Sb}, \mathrm{Bi} ; \mathrm{E}=\mathrm{Se}, \mathrm{Te})$

\begin{tabular}{llllll}
\hline & $\mathrm{Et}_{2} \mathrm{SbTeEt}^{[61]}$ & $\mathrm{Ph}_{2} \mathrm{BiSePh}^{[22]}$ & $\mathrm{Et}_{2} \mathrm{BiTeEt}^{[61]}$ & $\mathrm{R}_{2} \mathrm{BiSePh}^{[57]}$ & $\mathrm{R}_{2} \mathrm{BiTePh}^{[57]}$ \\
\hline M-E & $2.7834(4)$ & $2.6910(8)$, & $2.9116(5)$ & $2.7261(8)$ & $2.9084(4)$ \\
& & & & \\
& & $2.7049(9)$, & & &
\end{tabular}




$\begin{array}{llllll}\text { M } \cdots \text { E } & 3.5599(4) & 3.897 & 3.6217(6) & - & - \\ \angle \mathrm{C}-\mathrm{M}-\mathrm{C} & 92.93(12) & 90.8(4) & 96.6(4) & \text { a } & \text { a } \\ \angle \mathrm{M}-\mathrm{E}-\mathrm{C} & 94.94(11) & 87.4(3) & 92.9(2) & \text { a } & \text { a } \\ & & 97.4(3) & & & \text { a } \\ \Sigma \angle \mathrm{C}-\mathrm{M}-\mathrm{C} / \mathrm{E} & 286.0(3) & 275.6 & 282.3(8) & \text { a } & \end{array}$

a The metal center is fivefold-coordinated, so these values are meaningless. $\mathrm{R}=o$ $\left.\mathrm{C}_{6} \mathrm{H}_{4}\left(\mathrm{CH}=\mathrm{NC}_{6} \mathrm{H}_{3}-2,6-i-\mathrm{Pr}_{2}\right)\right)$

The central bismuth atoms in $\mathrm{R}_{2} \mathrm{BiSePh}$ and $\mathrm{R}_{2} \mathrm{BiTePh}$ adopt strongly distorted square pyramidal coordination spheres with one ipso-carbon atom located in the apical position, while two nitrogen atoms, one chalcogen atom and the second ipso-carbon atom occupy basal positions (Fig. 1). The remaining electron lone pair of the central Bi atom may adopt the trans position to the apical ipso-carbon atom, even though it should exhibit a rather high s-orbital character. The Bi-N bond lengths significantly differ within each compound (2.801(6), 3.029(5) $\AA$ in $\mathrm{R}_{2} \mathrm{BiSePh} ; 2.824(4), 3.045(4) \AA$ in $\mathrm{R}_{2} \mathrm{BiTePh}$ ) indicating different strengths of the intramolecular $\mathrm{Bi} \cdots \mathrm{N}$ interactions. The Bi-E bond lengths (2.7261(8) $\AA$ in $\mathrm{R}_{2} \mathrm{BiSePh}$, 2.9084(4) $\AA$ in $\mathrm{R}_{2} \mathrm{BiTePh}$ ) increase with increasing atomic number of the chalcogen atom as was expected. The Bi-Se bond length in $\mathrm{R}_{2} \mathrm{BiSePh}$ agrees well with those reported for $\mathrm{Ph}_{2} \mathrm{BiSePh}$ (2.704(3) $\AA$ ), which was synthesized by reaction of $\mathrm{Bi}_{2} \mathrm{Ph}_{4}$ with $\mathrm{Se}_{2} \mathrm{Ph}_{2},{ }^{[22]}$ and $\operatorname{Bi}(\operatorname{SeR})_{3}(\mathrm{R}=2$-(4,4-dimethyloxazolino)phenyl, 2.6910(8), 2.7049(9), 2.7454(9) $\AA),{ }^{[58]}$ the only structurally characterized compounds containing a Bi-Se single bond, as well as with the sum of the covalent radii $\sum_{\mathrm{cov}}(\mathrm{Bi}, \mathrm{E})=2.67(\mathrm{E}=\mathrm{Se})$, and $2.87 \AA(\mathrm{E}=\mathrm{Te})$ as reported by Pyykkö et al. ${ }^{[59]}$ In contrast, the shortest $\mathrm{Bi}-\mathrm{Se}$ bond in $\mathrm{Bi}_{2} \mathrm{Se}_{3}$ (2.97) is significantly elongated. ${ }^{[60]}$ 


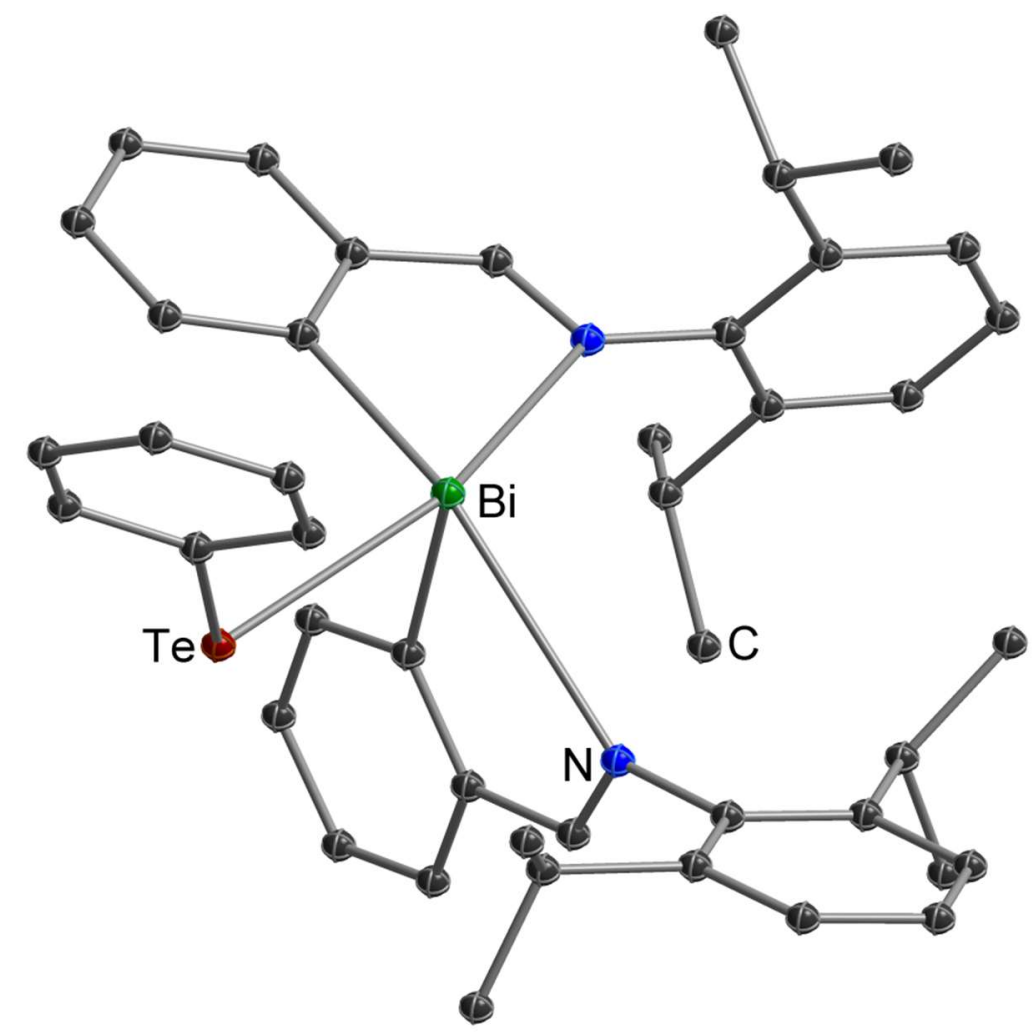

Figure 1. Solid state structure of $\mathrm{R}_{2} \mathrm{BiTePh}\left(\mathrm{R}=o-\mathrm{C}_{6} \mathrm{H}_{4}\left(\mathrm{CH}=\mathrm{NC}_{6} \mathrm{H}_{3}-2,6-i-\mathrm{Pr}_{2}\right){ }^{[57]}\right.$

The M-Te bond length in $\mathrm{Et}_{2} \mathrm{SbTeEt}(2.7834(4) \AA)$ ) and $\mathrm{Et}_{2} \mathrm{BiTeEt}(2.9116(5) \AA)$ (Figs. 2, $3)^{[61]}$ are slightly elongated compared to the sum of the covalent radii $\left(\left(\sum_{\operatorname{cov}}(\mathrm{M}, \mathrm{Te})=2.76 \AA\right.\right.$ $(\mathrm{M}=\mathrm{Sb}), 2.87 \AA(\mathrm{M}=\mathrm{Bi})) \cdot{ }^{[59]}$ The Sb-Te bond length of $\mathrm{Et}_{2} \mathrm{SbTeEt}$ is comparable to the telluradistibirane $\mathrm{Bbt}_{2} \mathrm{Sb}_{2} \mathrm{Te}$ (Sb-Te 2.7607(7), 2.7719(6) $\left.\AA\right)^{[62]}$ and the Bi-Te bond length in $\mathrm{Et}_{2} \mathrm{BiTeEt}$ is slightly elongated compared to the Bi-Te bond distances observed in $\left\{\left[\left(\mathrm{Me}_{3} \mathrm{Si}\right)_{2} \mathrm{CH}\right]_{2} \mathrm{Bi}\right\}_{2} \mathrm{Te}(2.872(3), 2.889(2) \AA),{ }^{[63]}\left[\left\{\left(\mathrm{Me}_{3} \mathrm{Si}\right)_{3} \mathrm{SiTe}\right\}_{2} \mathrm{BiR}\right]\left(\mathrm{R}=\mathbf{C H}\left(\mathrm{SiMe}_{3}\right)_{2}\right.$ : 2.8378(8), 2.8617(8) A; C(SiMe3)3: 2.8638(11), 2.8826(14) $\AA),{ }^{[64]} \mathrm{R}_{2} \mathrm{BiTePh}(\mathrm{R}=o-$ $\left.\mathrm{C}_{6} \mathrm{H}_{4}\left(\mathrm{CH}=\mathrm{NC}_{6} \mathrm{H}_{3}-2,6-i-\mathrm{Pr}_{2}\right)\right)$ 2.9084(4) $\AA$ ) and $\mathrm{RBi}(\mathrm{TePh})_{2} \quad(2.8949(3), 2.9545(3) \AA)$, respectively. ${ }^{[57]}$ In contrast, the $\mathrm{Bi}-\mathrm{Te}$ bond length of $\mathrm{Et}_{2} \mathrm{BiTeEt}$ is slightly shorter than the shortest Bi-Te distance observed in the crystal of $\mathrm{Bi}_{2} \mathrm{Te}_{3}(3.066(2) \AA) .{ }^{[65]}$ The slightly bigger sum of the bond angles at the $\mathrm{Sb}$ atom of $\mathrm{Et}_{2} \mathrm{SbTeEt}\left(286.0(3)^{\circ}\right)$ compared to the $\mathrm{Bi}$ atom in $\mathrm{Et}_{2} \mathrm{BiTeEt}\left(282.3(8)^{\circ}\right)$ points to a slightly higher p-character of the bonding electron pairs in $\mathrm{Et}_{2} \mathrm{BiTeEt}$ compared to $\mathrm{Et}_{2} \mathrm{SbTeEt}$. Surprisingly, $\mathrm{Ph}_{2} \mathrm{BiSePh}$ showed an even smaller bond angular sum at the $\mathrm{Bi}$ center $\left(275.6^{\circ}\right) .{ }^{[22]}$ 


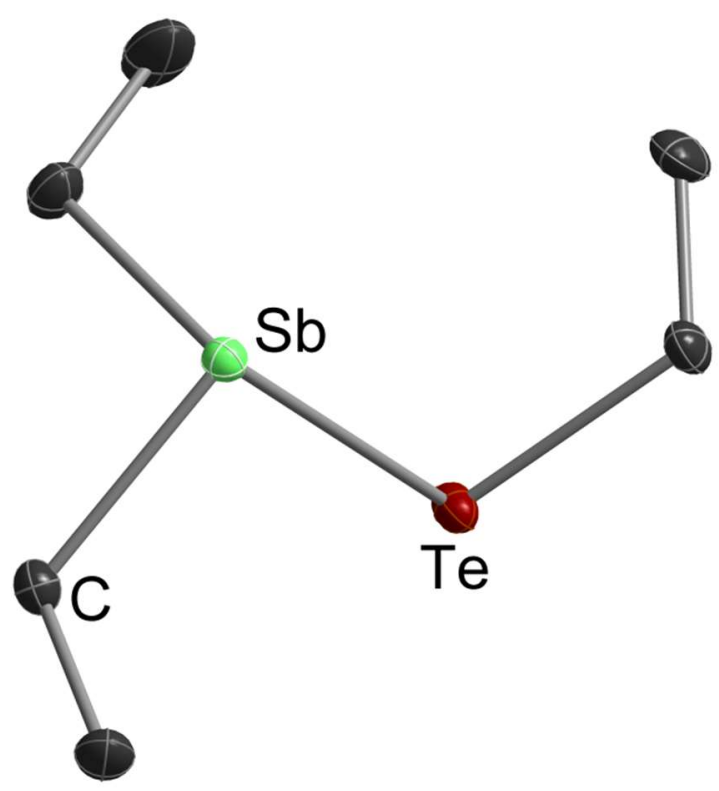

Figure 2. Solid state structure of $\mathrm{Et}_{2} \mathrm{SbTeEt}$; thermal ellipsoids are shown at $50 \%$ probability levels. ${ }^{[61]}$

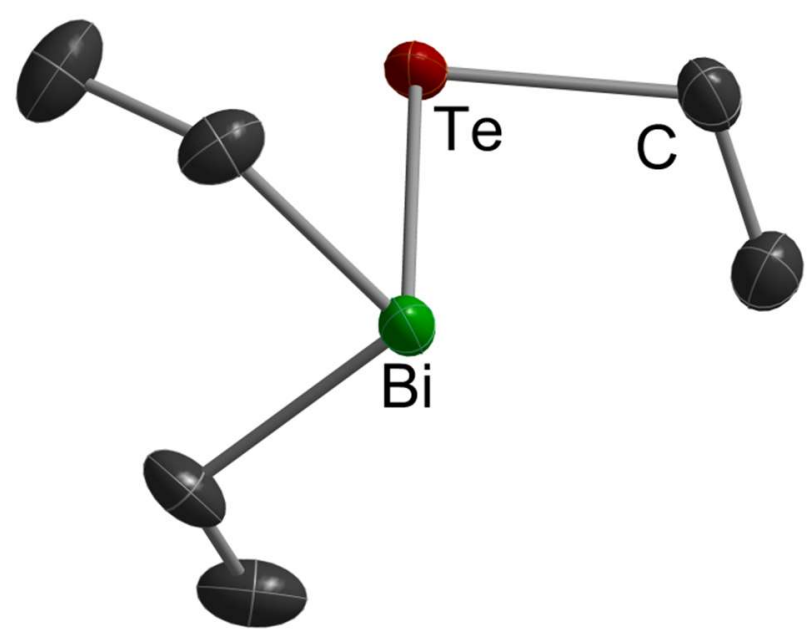

Figure 3. Solid state structure of $\mathrm{Et}_{2} \mathrm{BiTeEt}$; thermal ellipsoids are shown at $50 \%$ probability levels. ${ }^{[61]}$

Concerning the conformation of the molecules the most noticeable difference is the torsion angles about the E-Te bond. The orientation of the ethyl groups in $\mathrm{Et}_{2} \mathrm{SbTeEt}$ is $\mathrm{T}$-shaped as was previously observed for $\mathrm{Ph}_{2} \mathrm{BiSePh}^{[22]}$ whereas it is $\mathrm{Y}$-shaped in $\mathrm{Et}_{2} \mathrm{BiTeEt}$ (figure 2, table 1). Furthermore the $\mathrm{SbEt}_{2}$ group of $\mathrm{Et}_{2} \mathrm{SbTeEt}$ is arranged in a transoid $\mathrm{W}$-shaped manner (C-Sb-C-C 176.8(3) $\left.{ }^{\circ}, 150.6(3)^{\circ}\right)$, whereas the $\mathrm{BiEt}_{2}$ group in $\mathrm{Et}_{2} \mathrm{BiTeEt}$ shows a cisoid conformation (C-Bi-C-C 165.5(7) $\left.{ }^{\circ}, 45.0(9)^{\circ}\right)$.

\section{Intermolecular Interactions}

While $\mathrm{R}_{2} \mathrm{BiEPh}\left(\mathrm{E}=\mathrm{S}\right.$, Se, Te; $\left.\mathrm{R}=o-\mathrm{C}_{6} \mathrm{H}_{4}\left(\mathrm{CH}=\mathrm{NC}_{6} \mathrm{H}_{3}-2,6-i-\mathrm{Pr}_{2}\right)\right)$ are essentially monomeric in the solids state without any remarkable intermolecular contacts, $\mathrm{Ph}_{2} \mathrm{BiSePh}$ shows close 
intermolecular Bi $\cdots$ Se distances (3.897 $\AA$ ) fairly below the sum of the van-der-Waals radii $\left(\left(\sum_{\mathrm{vdw}}(\mathrm{Be}, \mathrm{Se})=3.97 \AA\right),{ }^{[3]}\right.$ indicating weak intermolecular Bi $\cdots$ Se interactions. ${ }^{[22]} \mathrm{Et}_{2} \mathrm{SbTeEt}$ and $\mathrm{Et}_{2} \mathrm{BiTeEt}$ also show weak intermolecular $\mathrm{M} \cdots$ Te contacts $(\mathrm{M}=\mathrm{Sb}$ 3.5599(4) $\AA$; Bi $3.6217(6) \AA)$ well below the sum of the van der Waals radii $\left(\left(\sum_{\mathrm{vdw}}(\mathrm{M}, \mathrm{Te})=4.12 \AA(\mathrm{M}=\mathrm{Sb})\right.\right.$, $4.13 \AA(\mathrm{M}=\mathrm{Bi})) .{ }^{\left[3^{]}\right.}$leading to the formation of endless chains in the solid state (Fig. 4). In contrast, intermolecular $\mathrm{Sb} \cdots \mathrm{Sb}$ as well as $\mathrm{Bi} \cdots \mathrm{Bi}$ contacts below the sum of the van der Waals radii were not observed. The different symmetry of the chains leads to a different orientations of the $\mathrm{EEt}_{2}(\mathrm{E}=\mathrm{Sb}, \mathrm{Bi})$ groups, hence influencing the arrangement of the chains in the packing (Fig. 5).

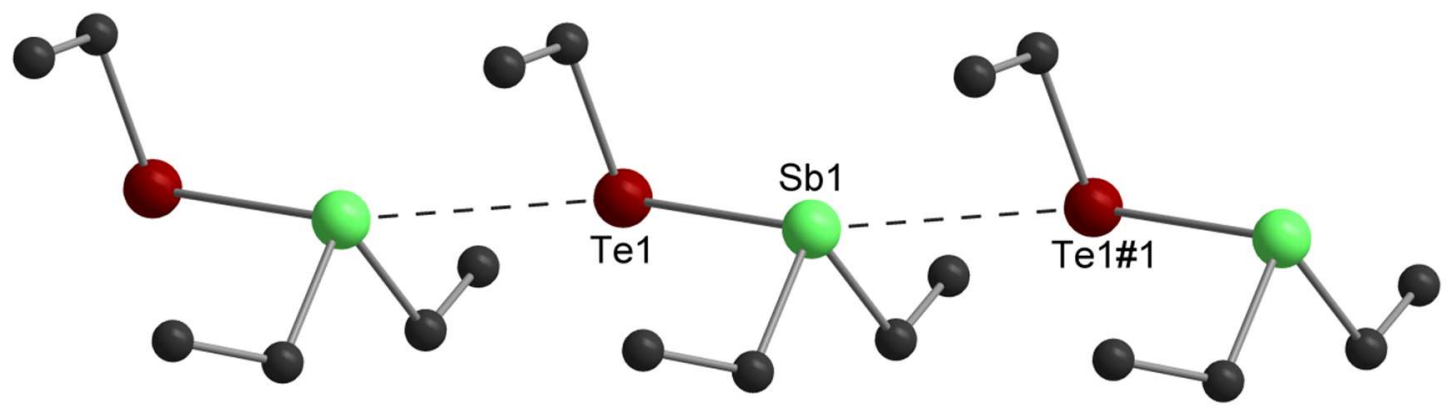

Figure 4. Chains in the packing of $\mathrm{Et}_{2} \mathrm{SbTeEt}$ (a: formed by translation parallel to a, linear). $\mathrm{H}$ atoms omitted for clarity, \#1: $1+\mathrm{x}, \mathrm{y}, \mathrm{z} ; \# 2: 2-\mathrm{x}, 1 / 2+\mathrm{y}, 1 / 2-\mathrm{z}){ }^{[61]}$

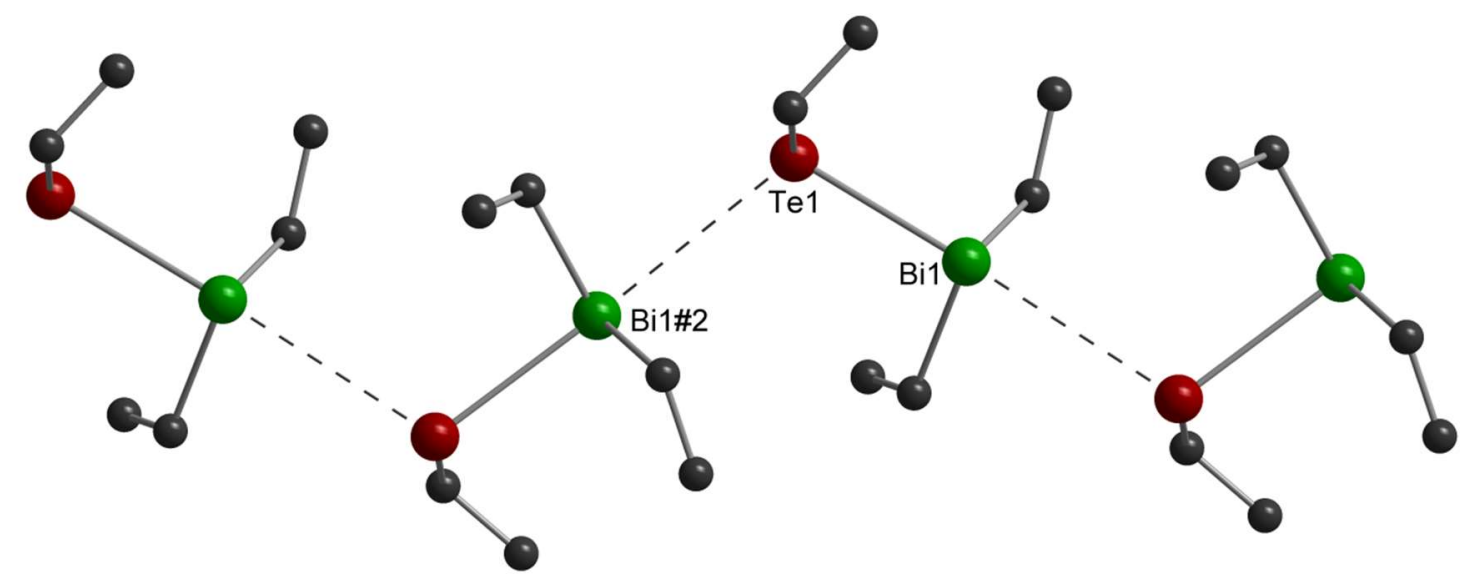

Figure 5. Chains in the packing of $\mathrm{Et}_{2} \mathrm{BiTeEt}$ (b: formed by $2_{1}$-axis parallel to b, zig-zag). $\mathrm{H}$ atoms omitted for clarity, \#1: 1+x, y, z; \#2: 2-x, 1/2+y, 1/2-z). ${ }^{[61]}$

The origin of the structural differences as observed in the crystals structures of $\mathrm{Et}_{2} \mathrm{SbTeEt}_{\mathrm{T}} \mathrm{and}$ $\mathrm{Et}_{2} \mathrm{BiTeEt}$ (linear vs. zig-zag chain orientation) was investigated by quantum chemical calculations. DFT+D3 calculations gave a slight intrinsic preference of the linear chain motif for $\mathrm{Et}_{2} \mathrm{SbTeEt}$ and a slight intrinsic preference of the zig-zag chain motif for $\mathrm{Et}_{2} \mathrm{BiTeEt}$. The preference of the different motifs is not related to different orbital interactions between the 
metal centers of neighboring molecules, since for both species the highest occupied molecular orbital (HOMO) is essentially a pure $5 \mathrm{p}$ orbital of energy -474.7 and $-464.9 \mathrm{~kJ} / \mathrm{mol}$, respectively, while the lowest unoccupied molecular orbital (LUMO) in both cases is essentially an antibonding linear combination of a $5 \mathrm{p}$ orbital of Te with a $5 \mathrm{p}$ orbital of $\mathrm{Sb}$ or a $6 \mathrm{p}$ orbital of $\mathrm{Bi}$ as exemplarily shown for $\mathrm{R}_{2} \mathrm{BiTePh}$ (Fig. 6), with similar energies of -193.6 and $-196.5 \mathrm{~kJ} / \mathrm{mol}$, respectively.
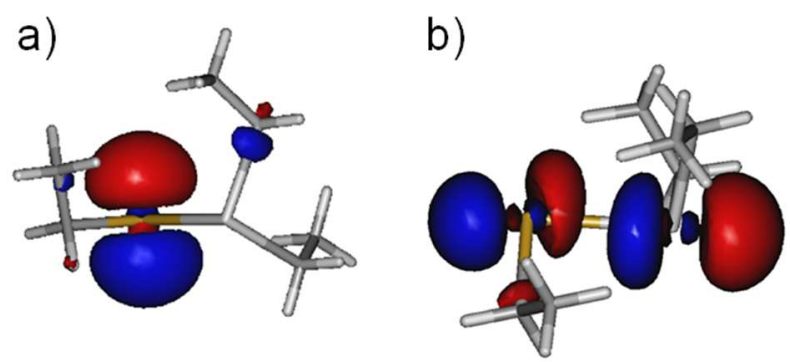

Figure 6. HOMO (a) and LUMO (b) of $\mathrm{Et}_{2} \mathrm{BiTeEt}^{[61]}$

Thus the aforementioned structural differences of the dimeric systems do not result from different HOMO-LUMO interactions between neighboring molecules or electrostatic interactions, but rather point to an interplay of several factors, for which not only metal-metal interactions but also interactions involving the ethyl-substituents play a significant role.

\section{$2.2 \operatorname{RM}\left(E R^{\prime}\right)_{2}(M=S b, B i ; E=S e, T e)$}

Known solid state structures of compounds of the general type $\mathrm{RM}\left(\mathrm{ER}^{\prime}\right)_{2}$ (type II) with threecoordinated group 15 atoms $(\mathrm{M})$ in the formal oxidation state +III and two-coordinated chalcogen (E) atoms are almost exclusively limited to the corresponding antimony sulfides $^{[66,67,68,69,70,71,72,73,74,75]}$ and bismuth sulfides. ${ }^{[76]}$ In contrast, only two compounds, $\left(\mathrm{Me}_{3} \mathrm{Si}\right)_{2} \mathrm{CHBi}\left\{\mathrm{TeSi}\left(\mathrm{SiMe}_{3}\right)_{3}\right\}_{2}$ and $\left(\mathrm{Me}_{3} \mathrm{Si}\right)_{3} \mathrm{CBi}\left\{\mathrm{TeSi}\left(\mathrm{SiMe}_{3}\right)_{3}\right\}_{2}$, of this type containing the heavier group 16 elements have been structurally characterized. ${ }^{[64]}$ $\left(\mathrm{Me}_{3} \mathrm{Si}\right)_{2} \mathrm{CHBi}\left\{\mathrm{TeSi}\left(\mathrm{SiMe}_{3}\right)_{3}\right\}_{2}$ and $\left.\left(\mathrm{Me}_{3} \mathrm{Si}\right)_{3} \mathrm{CBi}\left\{\mathrm{TeSi}\left(\mathrm{SiMe}_{3}\right)_{3}\right\}_{2}\right)$ were prepared in good yields by dehalosilylation reaction between $\mathrm{RBiCl}_{2}$ and $\left.\mathrm{Me}_{3} \mathrm{SiTeSi}_{(\mathrm{SiMe}}\right)_{3}$ ( $\mathrm{Scheme}_{3}$ ). 


$$
\begin{array}{lll}
\mathrm{RBiCl}_{2}+2 \mathrm{Me}_{3} \mathrm{SiTeR}^{\prime} \underset{-\mathrm{Me}_{3} \mathrm{SiCl}}{\longrightarrow} & \mathrm{RBi}\left(\mathrm{TeR}^{\prime}\right)_{2} \\
& \mathrm{R}=\mathrm{CH}\left(\mathrm{SiMe}_{3}\right)_{2}, \mathrm{C}\left(\mathrm{SiMe}_{3}\right)_{3}
\end{array}
$$
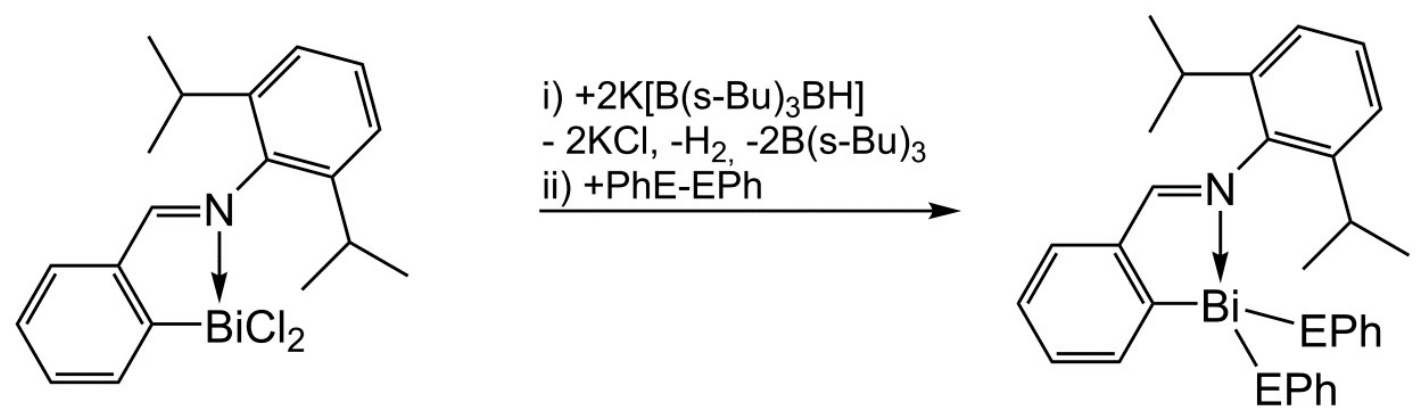

$$
\mathrm{E}=\mathrm{S}, \mathrm{Se}, \mathrm{Te}
$$

Scheme 3: Synthesis of compounds of the general type RBi(ER') $)_{2}$.

In both molecules, the three-coordinated bismuth atoms adopt a corner of a trigonal pyramid as is exemplarily shown for $\left.\left(\mathrm{Me}_{3} \mathrm{Si}\right)_{2} \mathrm{CHBi}\left\{\mathrm{TeSi}_{(} \mathrm{SiMe}_{3}\right)_{3}\right\}_{2}$ (Fig. 7). The basal corners of the pyramid are occupied with two $\left(\mathrm{Me}_{3} \mathrm{Si}\right)_{3} \mathrm{SiTe}$ moieties and the organosilyl group. The sum of the angles at the bismuth atom is roughly $299^{\circ}$ despite the sterically very demanding substituents, indicating a high p-orbital contribution to the bonding electron pairs and as a consequence, the electron lone pair on bismuth exhibits a high s-orbital character. The Bi-Te

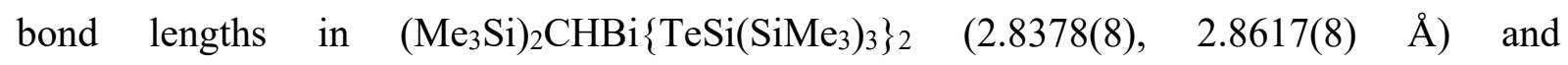
$\left.\left(\mathrm{Me}_{3} \mathrm{Si}\right)_{3} \mathrm{CBi}\left\{\mathrm{TeSi}\left(\mathrm{SiMe}_{3}\right)_{3}\right\}_{2}\right)(2.8638(11), 2.8826(14) \AA)$ are comparable to those observed in $\left\{\left[\left(\mathrm{Me}_{3} \mathrm{Si}\right)_{2} \mathrm{CH}\right]_{2} \mathrm{Bi}\right\}_{2} \mathrm{Te}(2.872(3) \AA, 2.889(2) \AA),{ }^{[63]}$ while the Bi-Te bond lengths in $\left.\mathrm{Et}_{2} \mathrm{BiTeEt}(2.9116(5) \AA),{ }^{[61]} \mathrm{R}_{2} \mathrm{BiTePh}\left(\mathrm{R}=o-\mathrm{C}_{6} \mathrm{H}_{4}\left(\mathrm{CH}=\mathrm{NC}_{6} \mathrm{H}_{3}(i-\mathrm{Pr})_{2}-2,6\right)\right) 2.9084(4) \AA\right)$ and $\mathrm{RBi}(\mathrm{TePh})_{2}(2.8949(3), 2.9545(3) \AA)$ are slightly elongated. ${ }^{[57]}$ 


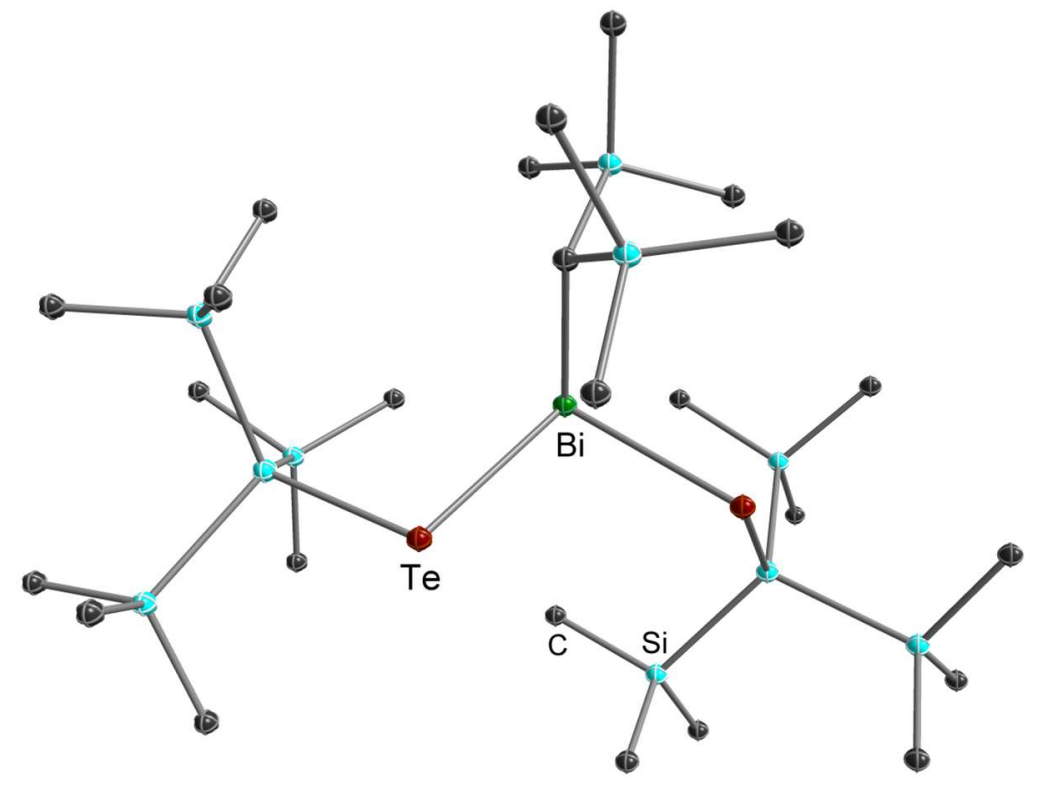

Figure 7. Solid state structure of $\left(\mathrm{Me}_{3} \mathrm{Si}\right)_{2} \mathrm{CHBi}\left\{\mathrm{TeSi}\left(\mathrm{SiMe}_{3}\right)_{3}\right\}_{2}{ }^{[64]}$

In addition to the compounds mentioned before, several intermolecular stabilized compounds of the type $\mathrm{RM}\left(\mathrm{ER}^{\prime}\right)_{2}$ have been synthesized, ${ }^{[77,78]}$ often by reactions of donor-stabilized lowvalent organoantimony and -bismuth compounds of the type $\mathrm{MR}(\mathrm{M}=\mathrm{Sb}, \mathrm{Bi})$, in which the metal centers adopt the formal oxidation state $+\mathrm{I}$, with diaryldichalcogenanes $\mathrm{E}_{2}^{\prime} \mathrm{Ar}_{2}\left(\mathrm{E}^{\prime}=\mathrm{S}\right.$, Se, Te). ${ }^{[57,79]}$

While the majority of these compounds adopt monomeric structures in the solid state, most likely a result of the steric demand of the bulky organic substituent as well as the intramolecular stabilization by the pendant donor group, some compounds were found to form intermolecular contacts, resulting in the formation of weakly bonded dimers in the solid state. These intermolecular interactions typically occur between the group 15 and group 16 elements as can be seen in $\mathrm{RBi}(\mathrm{EPh})_{2}\left(\mathrm{E}=\mathrm{S}\right.$, Se, Te; $\mathrm{R}=o-\mathrm{C}_{6} \mathrm{H}_{4}\left(\mathrm{CH}=\mathrm{NC}_{6} \mathrm{H}_{3}(i-\mathrm{Pr})_{2}-2,6\right)$ The bismuth-chalcogen contacts lead to weakly bonded dimers with central $\mathrm{Bi}_{2} \mathrm{E}_{2}$ four-membered rings as is shown for $\mathrm{RBi}(\mathrm{SePh})_{2}$ (Fig. 8). The intermolecular Bi-S (3.4513(18), 3.4895(17) $\AA$ in $\left.\mathrm{RBi}(\mathrm{SPh})_{2}\right)$, $\mathrm{Bi}-\mathrm{Se}\left(3.5059(10), 3.5521(10) \AA\right.$ in $\left.\mathrm{RBi}(\mathrm{SePh})_{2}\right)$ and $\mathrm{Bi}-\mathrm{Te}$ distances (3.8642(3) $\AA$ in $\left.\mathrm{RBi}(\mathrm{TePh})_{2}\right)$ are well below the sum of the van-der Waals radii $\left(\sum \mathrm{vdw}(\mathrm{Bi}, \mathrm{E})\right.$ $=3.80(\mathrm{~S}), 3.90(\mathrm{Se}), 4.06 \AA(\mathrm{Te})),{ }^{[3]}$ while the corresponding bond lengths of the primary Bi-E bonds (Bi-S 2.5591(18)-2.6430(17) $\AA$ in RBi(SPh)2, Bi-Se 2.6798(11)-2.7557(9) $\AA$ in $\mathrm{RBi}(\mathrm{SePh})_{2}, \mathrm{Bi}-\mathrm{Te} 2.8949(3)-2.9545(3) \AA$ in $\left.\mathrm{RBi}(\mathrm{TePh})_{2}\right)$ correspond nicely to the sum of the covalent radii $\left(\sum \operatorname{cov}(\mathrm{Bi}, \mathrm{E})=2.54(\mathrm{~S}), 2.67(\mathrm{Se})\right.$ and $\left.2.87 \AA(\mathrm{Te})\right) .{ }^{[59]}$ The resulting coordination polyhedra around each bismuth atom in $\mathrm{RBi}(\mathrm{EPh})_{2}$ are best described as distorted square pyramids, in which the ipso-carbon atom is located in the apical position and 
the nitrogen and chalcogen atoms occupy the basal positions. As a consequence, the electron lone pair of the central bismuth atoms is located in trans position to the ipso-carbon atoms.

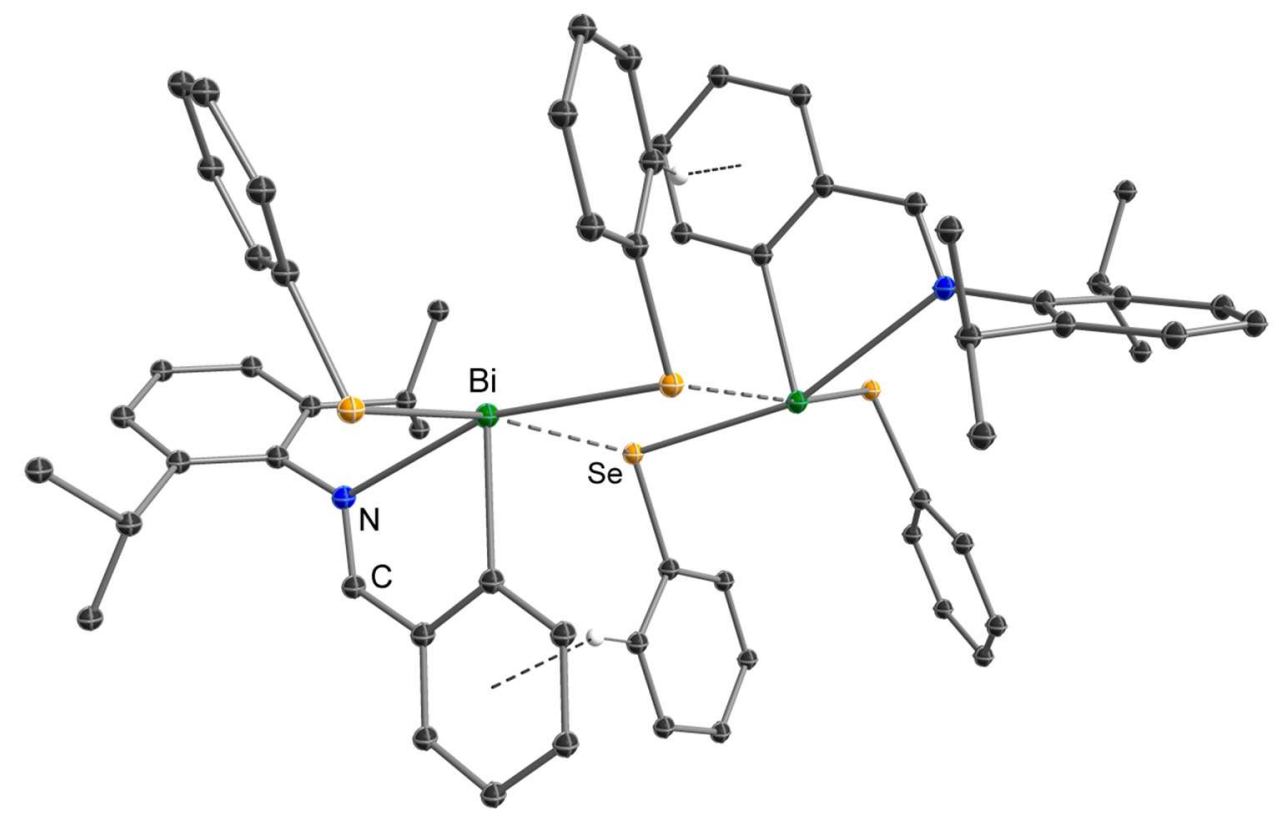

Figure 8. ORTEP plot of $\mathrm{RBi}(\mathrm{SePh})_{2}\left(\mathrm{R}=\mathrm{R}=o-\mathrm{C}_{6} \mathrm{H}_{4}\left(\mathrm{CH}=\mathrm{NC}_{6} \mathrm{H}_{3}(i-\mathrm{Pr})_{2}-2,6\right)\right.$ and the weak intermolecular $\mathrm{Bi} \cdots$ Se interactions. ${ }^{[57]}$

\section{$2.3 M\left(E R^{\prime}\right)_{3}(M=S b, B i ; E=S e, T e)$}

Homoleptic compounds of the general type $\mathrm{M}\left(\mathrm{ER}^{\prime}\right)_{3}$ (type III) are well known for the lightest homologues of group 16, O and S. For instance, the Cambridge structure database lists 27 homoleptic antimony trisulfides of the type $\mathrm{Sb}(\mathrm{SR})_{3}$ and 17 bismuth trisulfides of the type $\mathrm{Bi}(\mathrm{SR})_{3}$ containing threefold-coordinated $\mathrm{Sb} / \mathrm{Bi}$ atoms and alkyl or aryl groups bound to the sulfur atoms. In contrast, only three compounds containing the heavier group 16 elements have been structurally characterized, to date: $\mathrm{Sb}(\mathrm{SeMe})_{3}$ (Fig. 9), ${ }^{[80]} \mathrm{Bi}(\mathrm{SePh})_{3},{ }^{\left[{ }^{[81}\right]}$ and $\mathrm{Bi}\left(\right.$ SeTrip) ${ }_{3}{ }^{[46]}$

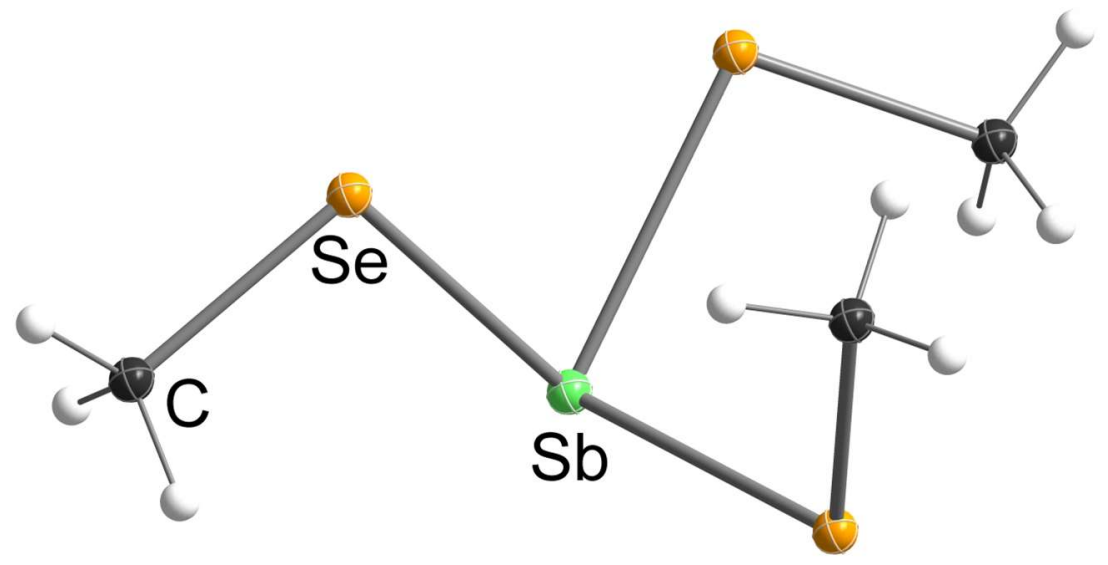


Figure 9. Solid state structure of $\mathrm{Sb}(\mathrm{SeMe})_{3} \cdot{ }^{[80]}$

$\mathrm{Sb}(\mathrm{SeMe})_{3}$ was initially prepared by thermal decomposition of $\mathrm{Et}_{2} \mathrm{SbSeMe}$, yielding $\mathrm{Et}_{3} \mathrm{Sb}$, $\mathrm{EtSb}(\mathrm{SeMe})_{2}$ and $\mathrm{Sb}(\mathrm{SeMe})_{3}{ }^{[82]}$ In addition, the reaction of $\mathrm{Me}_{2} \mathrm{Se}_{2}$ with antimony powder in refluxing toluene gave $\mathrm{Sb}(\mathrm{SeMe})_{3}$ in high yield. ${ }^{[80]} \mathrm{Sb}(\mathrm{SeMe})_{3}$ forms a trigonal pyramidal structure, in which the $\mathrm{Sb}$ atom is located in one corner of the tetrahedron. Including the sterochemically active electron lone pair, the $\mathrm{Sb}$ atoms adopts a tetrahedral coordination sphere. The Sb-Se bond distances (2.568(1), 2.581(1), 2.588(1) A) are almost identical and compare well with those reported for $\mathrm{Sb}[(8-\mathrm{Seq})]_{3}(2.618 \AA),{ }^{[83]} \mathrm{Sb}\left[2-\mathrm{CH}_{3}(8-\mathrm{Seq})\right]_{3}(2.6097$ (7) $\AA)^{[84]}$ and $\left[\mathrm{Sb}\left\{\mathrm{Se}-\mathrm{C}_{5} \mathrm{H}_{3}(\mathrm{Me}-3) \mathrm{N}\right\}_{3}\right] \quad(2.5843(13)-2.6643(12) \quad \AA),{ }^{[85]}$ respectively. $\mathrm{Sb}(\mathrm{SeMe})_{3}$ significantly deviates from $\mathrm{C}_{3 \mathrm{v}}$ symmetry as is reflected by the wide range of the Se-Sb-Se bond angles $\left(82.5(1)-102.1(1)^{\circ}\right)$. The bond angle sum at the $\mathrm{Sb}$ atom $\left(279.6^{\circ}\right)$ indicates a high p-orbital contribution to the bonding electron pairs, hence resulting in a high s-orbital character of the electron lone pair as is typical for heavy main group elements. Weak intermolecular contacts were observed in the solid state structure of $\mathrm{Sb}(\mathrm{SeMe})_{3}$. Each $\mathrm{Sb}$ atom

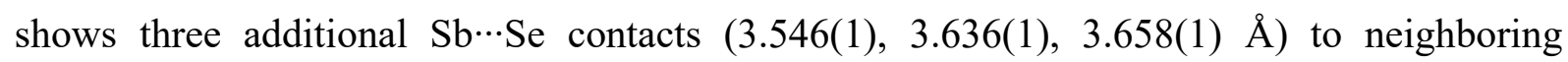
molecules, resulting in the formation of layers perpendicular to the c-axis, in which the $\mathrm{Sb}$ atoms adopt distorted octahedral coordination geometries. Comparable findings were reported for the intramolecularly stabilized homoleptic tris-2-pyridyl selenolate compounds of the general formula $\left[\mathrm{M}\left\{\mathrm{Se}-\mathrm{C}_{5} \mathrm{H}_{3}(\mathrm{R}-3) \mathrm{N}\right\}_{3}\right](\mathrm{M}=\mathrm{Sb}, \mathrm{Bi}),{ }^{[85]}$ in which also weak intermolecular contacts between $\mathrm{Sb} / \mathrm{Bi}$ and one $\mathrm{Se}$ atom of a neighboring molecule ( $\mathrm{Sb}-\mathrm{Se} 3.665 \AA$; $\mathrm{Bi}-\mathrm{Se}$ $3.523 \AA$ ). These interactions clearly exceed the sum of their covalent radii $\sum_{\operatorname{cov}}(\mathrm{M}, \mathrm{Se})=2.56$ $\AA(\mathrm{M}=\mathrm{Sb}), 2.67 \AA(\mathrm{M}=\mathrm{Bi})),{ }^{[59]}$ but are less than the sum of their van der Waals radii $\left(\sum_{\mathrm{vdW}}(\mathrm{M}, \mathrm{Se})=3.96 \AA, \mathrm{M}=\mathrm{Sb} ; 3.97 \AA, \mathrm{M}=\mathrm{Bi}\right),{ }^{\left[{ }^{]}\right]}$respectively.

$\mathrm{Bi}\left(\mathrm{SeC}_{6} \mathrm{H}_{5}\right)_{3}$ was synthesized by dehalosilylation reaction of $\mathrm{BiX}_{3}(\mathrm{X}=\mathrm{Cl}, \mathrm{Br})$ with $\mathrm{Se}\left(\mathrm{C}_{6} \mathrm{H}_{5}\right) \mathrm{SiMe}_{3}$, whereas $\mathrm{Bi}(\mathrm{SeTrip})_{3}$ can be prepared by either protolysis of the amides $\mathrm{Bi}\left[\mathrm{N}\left(\mathrm{SiMe}_{3}\right)_{2}\right]_{3}$ with $\mathrm{TripSeH}$ or by salt elimination reaction between $\mathrm{BiCl}_{3}$ and $\mathrm{TripSeLi}$ (Scheme 4), respectively. ${ }^{[81,46]}$ 


$$
\begin{aligned}
& \mathrm{Et}_{2} \mathrm{SbSeMe} \underset{-\mathrm{Et}_{3} \mathrm{Sb}}{\longrightarrow} \mathrm{EtSb}(\mathrm{SeMe})_{2}+\mathrm{Sb}(\mathrm{SeMe})_{3} \\
& 2 \mathrm{Sb}+3 \mathrm{Me}_{2} \mathrm{Se}_{2} \longrightarrow 2 \mathrm{Sb}(\mathrm{SeMe})_{3} \\
& \mathrm{BiCl}_{3}+3 \mathrm{Me}_{3} \mathrm{SiSePh} \underset{-3 \mathrm{Me}_{3} \mathrm{SiCl}}{\longrightarrow} \mathrm{Bi}(\mathrm{SePh})_{3} \\
& \mathrm{Bi}\left(\mathrm{NMe}_{2}\right)_{3}+\mathrm{HSeTrip} \underset{-3 \mathrm{Me}_{2} \mathrm{NH}}{\longrightarrow} \mathrm{Bi}(\text { SeTrip })_{3} \\
& \mathrm{BiCl}_{3}+\text { LiSeTrip } \underset{-3 \mathrm{LiCl}}{\longrightarrow} \mathrm{Bi}(\text { SeTrip })_{3}
\end{aligned}
$$

Scheme 4: Synthesis of $M(E R)_{3}$.

Unfortunately, the crystal quality of $\mathrm{Bi}(\operatorname{SeTrip})_{3}$ was too low to allow a detailed structure discussion. $\mathrm{Bi}(\mathrm{SePh})_{3}$ crystallizes with two independent molecules in the asymmetric unit and forms a trigonal-pyramidal structure as was observed for $\mathrm{Sb}(\mathrm{SeMe})_{3}$. The Bi-Se bond lengths (av. values for both molecules: $2.699 \AA, 2.695 \AA$ ) compare well to those reported for $\left.\mathrm{R}_{2} \mathrm{BiSePh}\left(\mathrm{R}=o-\mathrm{C}_{6} \mathrm{H}_{4}\left(\mathrm{CH}=\mathrm{NC}_{6} \mathrm{H}_{3}(i-\mathrm{Pr}){ }_{2}-2,6\right)\right) 2.7261(8) \AA\right),{ }^{[57]} \mathrm{Ph}_{2} \mathrm{BiSePh}(2.704(3) \AA),{ }_{[}^{[22]}$ and $\mathrm{Bi}(\mathrm{SeR})_{3}\left(\mathrm{R}=2\right.$-(4,4-dimethyloxazolino)phenyl, 2.6910(8), 2.7049(9), 2.7454(9) $\AA$ ). ${ }^{[58]}$ Moreover, the terminal Bi-Se bond lengths as-observed in the polynuclear bismuthselenolates, $\left[\mathrm{Bi}_{4}(\mu-\mathrm{SePh})_{5}(\mathrm{SePh})_{8}\right]^{-}(2.646(4)-2.737(4) \AA)$ and $\left[\mathrm{Bi}_{6}(\mu-\mathrm{SePh})_{6}(\mathrm{SePh})_{10} \mathrm{Br}_{2}\right]$ (2.666(2)-2.703(2) $\AA$ ), which were obtained from the reaction of $\mathrm{BiBr}_{3}$ with three equivalents of $\mathrm{Se}(\mathrm{Ph}) \mathrm{SiMe}_{3}$ in the presence of either two equivalents of $n-\mathrm{Pr}_{3} \mathrm{P}$ or $\mathrm{Ph}_{3} \mathrm{P}$, respectively, are also comparable. ${ }^{[86]}$ The Se-Bi-Se bond angles significantly deviate from each other (82.76(3)-100.66(3) ; 83.74(3)-101.27(3) ${ }^{\circ}$ ), most likely due to repulsive intramolecular interactions between the selenolate ligands as well as due to the presence of weak intermolecular contacts to neighboring molecules, resulting in a severely distorted $(3+3)$ coordination. As a consequence, $\mathrm{Bi}(\mathrm{SePh})_{3}$ forms a 1-dimensional chain in the crystal lattice via face-linked octahedra(Fig. 10). ${ }^{[81]}$ 


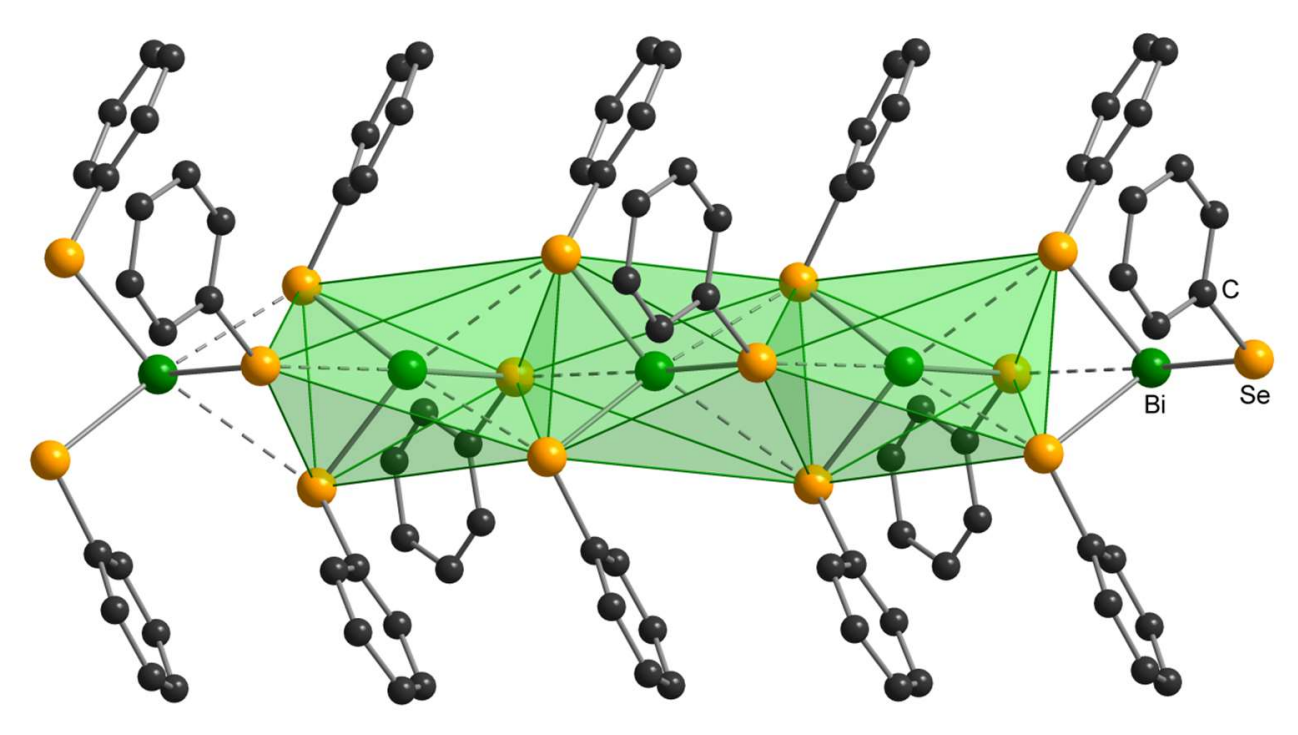

Figure 10. Chain-like structure of $\mathrm{Bi}(\mathrm{SePh})_{3}$

In addition, the solid state structures of three homoleptic antimony ${ }^{[83,84,85]}$ and bismuth triselenides ${ }^{[84,85,87]}$ containing 2-pyridyl selenolato and (2-methyl)quinoline selenolato ligands, have been reported (Figs. 11). Intramolecular stabilization of the $\mathrm{Sb} / \mathrm{Bi}$ atom through additional coordination of the N-donor sites results in coordination numbers 4 and 6 , respectively. Moreover, one bismuth triselenide containing the 2-(4,4dimethyloxazolino)phenyl selenolate ligand ${ }^{[58]}$ was structurally characterized.
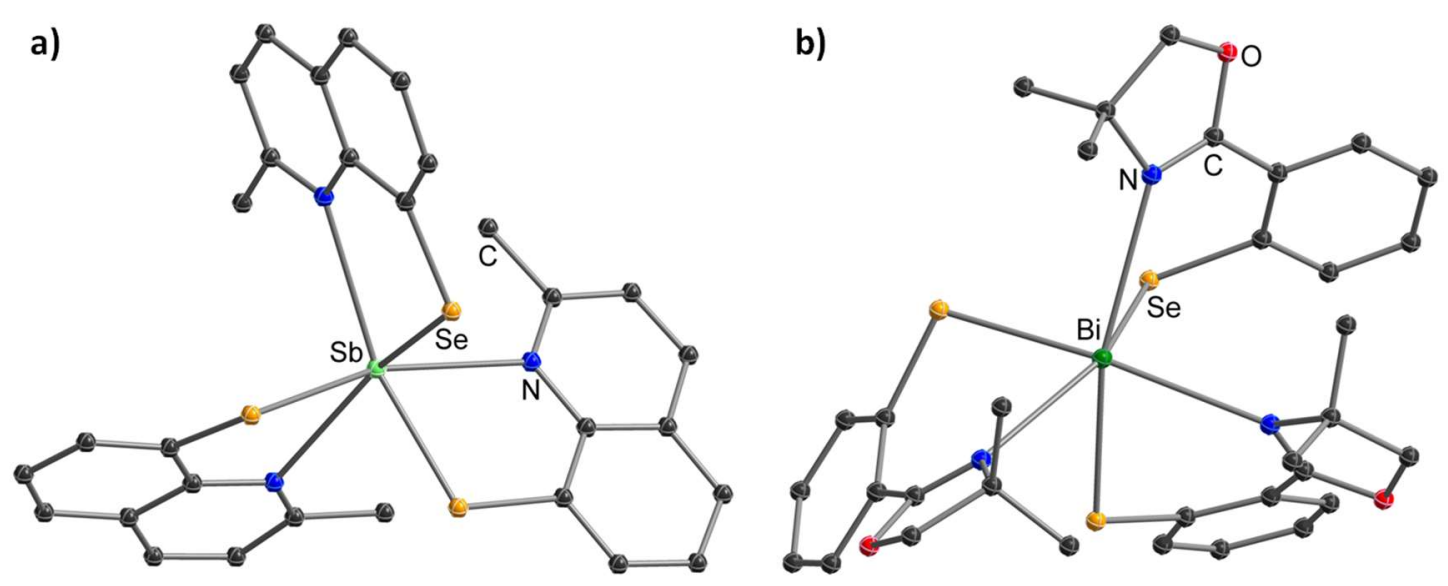

Figure 11. Intramolecular-stabilized heteroleptic antimony (a) and bismuth triselenides (b).

\section{Synthesis, Solid State Structures and Intermolecular Interactions in $\left(R_{2} M\right)_{2} E$}

Heteronuclear group 15-16 compounds of the type $\left(\mathrm{R}_{2} \mathrm{M}\right)_{2} \mathrm{E}(\mathrm{M}=\mathrm{Sb}, \mathrm{Bi}, \mathrm{E}=\mathrm{S}, \mathrm{Se}, \mathrm{Te}$, type IV), in which a central chalcogen atom adopts a bridging position between two group $15 \mathrm{MR}_{2}$ units, are well known for quite a long time. They are easily accessible by redox reactions of distibines and dibismuthines, in which the metal centers adopt the formal oxidation state +II, 
with elemental chalcogens, which easily insert into the rather weak $\mathrm{E}-\mathrm{E}$ bond $(\mathrm{E}=\mathrm{Sb}, \mathrm{Bi})$ with subsequent formation of the corresponding bis(dialkylstibanyl)chalcogenanes $\left(\mathrm{R}_{2} \mathrm{Sb}\right)_{2} \mathrm{E}^{[7,8,9]}$ and bis(dialkylbismuthanyl)chalcogenanes $\left(\mathrm{R}_{2} \mathrm{Bi}\right)_{2} \mathrm{E}$ (Scheme 5). ${ }^{[10,11,12,13]}$ Moreover, compounds of the desired type were obtained in standard salt elimination reaction between $\mathrm{R}_{2} \mathrm{MCl}$ and $\mathrm{Li}_{2} \mathrm{E}$, but complete removal of $\mathrm{LiCl}$ is sometimes problematic. ${ }^{[63]}$

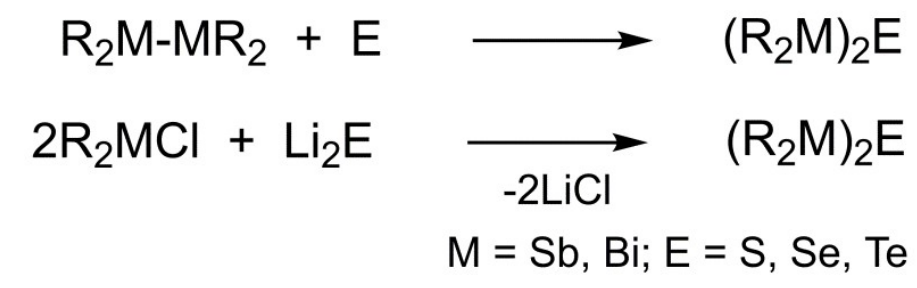

Scheme 5. Synthesis of $\left(\mathrm{R}_{2} \mathrm{M}\right)_{2} \mathrm{E}(\mathrm{M}=\mathrm{Sb}, \mathrm{Bi} ; \mathrm{E}=\mathrm{S}, \mathrm{Se}, \mathrm{Te})$.

Some of as-prepared chalcogen-bridged compounds show thermochromic behavior, pointing to weak intermolecular contacts in the solid state. ${ }^{[14]}$ Unfortunately, only limited information on their solid state structures are available. To the best of our knowledge, a very few sulfane derivatives $\left(\mathrm{R}_{2} \mathrm{Sb}\right)_{2} \mathrm{~S}\left(\mathrm{R}=\mathrm{Me},{ }^{[88]} 2-\mathrm{Me}_{2} \mathrm{NCH}_{2} \mathrm{C}_{6} \mathrm{H}_{4}{ }^{[89]}\right)$ and $\left(\mathrm{R}_{2} \mathrm{Bi}\right)_{2} \mathrm{~S}\left(\mathrm{R}=\left(\mathrm{Me}_{3} \mathrm{Si}\right)_{2} \mathrm{CH},{ }^{[63]}\right.$ 2,4,6- $\mathrm{Me}_{3} \mathrm{C}_{6} \mathrm{H}_{2},{ }^{[11]} 2-\left(\mathrm{Me}_{2} \mathrm{NCH}_{2}\right) \mathrm{C}_{6} \mathrm{H}_{4},{ }^{[13]} \mathrm{RN}\left(\mathrm{CH}_{2} \mathrm{C}_{6} \mathrm{H}_{4}\right)_{2}, \mathrm{R}=\mathrm{Ph}, \mathrm{Cy}, t$-Bu $\left.{ }^{[90]}\right)$ have been structurally characterized, whereas analogous compounds containing the heavier group 16 elements, Se and Te, remained unknown for a long time. Only recently, progress was made on the structural characterization of such compounds.

\section{$3.1\left(R_{2} S b\right)_{2} E(E=S e, T e)$}

Aside from the previously mentioned bis(dialkylstibanyl)sulfanes $\left(\mathrm{R}_{2} \mathrm{Sb}\right)_{2} \mathrm{~S},{ }^{[88,89]}$ four metal compounds containing $\left(\mathrm{R}_{2} \mathrm{Sb}\right)_{2} \mathrm{~S}$ and $\left(\mathrm{R}_{2} \mathrm{Sb}\right)_{2} \mathrm{Se}$ ligands were structurally characterized: $\left[\left(\mathrm{Me}_{2} \mathrm{Sb}\right)_{2} \mathrm{~S}\right]_{2} \mathrm{Cr}(\mathrm{CO})_{4},{ }^{[91]} \quad\left[\left(\mathrm{Ph}_{2} \mathrm{Sb}\right)_{2} \mathrm{~S}\right] \mathrm{Cr}(\mathrm{CO})_{5},{ }^{\left[{ }^{[92]}\right.} \quad\left[\left(\mathrm{Me}_{2} \mathrm{Sb}\right)_{2} \mathrm{Se}\right]_{2} \mathrm{Cr}(\mathrm{CO})_{4},{ }^{[93]} \quad$ and $\left[\left(\mathrm{Me}_{2} \mathrm{Sb}\right)_{2} \mathrm{Se}\right]\left[\mathrm{W}(\mathrm{CO})_{5}\right]_{2},{ }^{[93]}$ respectively. In addition, the structures of $\left(\mathrm{Me}_{2} \mathrm{Sb}\right)_{2} \mathrm{E}(\mathrm{E}=\mathrm{O}, \mathrm{S}$, $\mathrm{Se}, \mathrm{Te}$ ) were investigated by gas phase electron diffraction (GED) and computational calculations. ${ }^{[94,95,96]}$ Very recently, we reported on the synthesis of several bis(dialkylstibanyl)chalcogenanes $\left(\mathrm{R}_{2} \mathrm{Sb}\right)_{2} \mathrm{E}(\mathrm{R}=\mathrm{Me}, \mathrm{Et} ; \mathrm{E}=\mathrm{S}, \mathrm{Se}, \mathrm{Te})$ by insertion reactions of the chalcogenes into the weak Sb-Sb bond of tetramethyl- and tetraethyldistibines and their solid state structures, including the first bis(dialkylstibanyl)tellanes $\left(\mathrm{Me}_{2} \mathrm{Sb}\right)_{2} \mathrm{Te}$ and $\left(\mathrm{Et}_{2} \mathrm{Sb}\right)_{2} \mathrm{Te}^{\left[{ }^{[97]}\right.}$ Single-crystals of the compounds were grown on the diffractometer using a miniature zone melting procedure with focused infrared-laser-radiation. ${ }^{[98]}$ The crystal 
structures of $\left(\mathrm{Me}_{2} \mathrm{Sb}\right)_{2} \mathrm{Te}$ and $\left(\mathrm{Et}_{2} \mathrm{Sb}\right)_{2} \mathrm{Te}$ were determined by single-crystal X-ray diffraction (Figs. 12, 13).

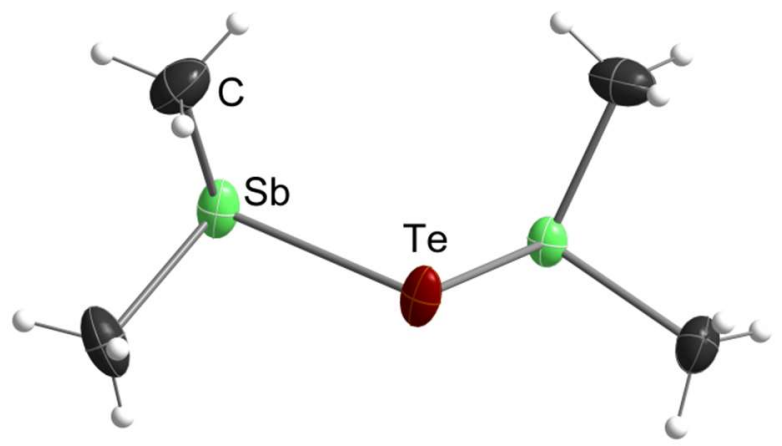

Figure 12. Solid state structure of $\left(\mathrm{Me}_{2} \mathrm{Sb}\right)_{2} \mathrm{Te}^{[97]}$

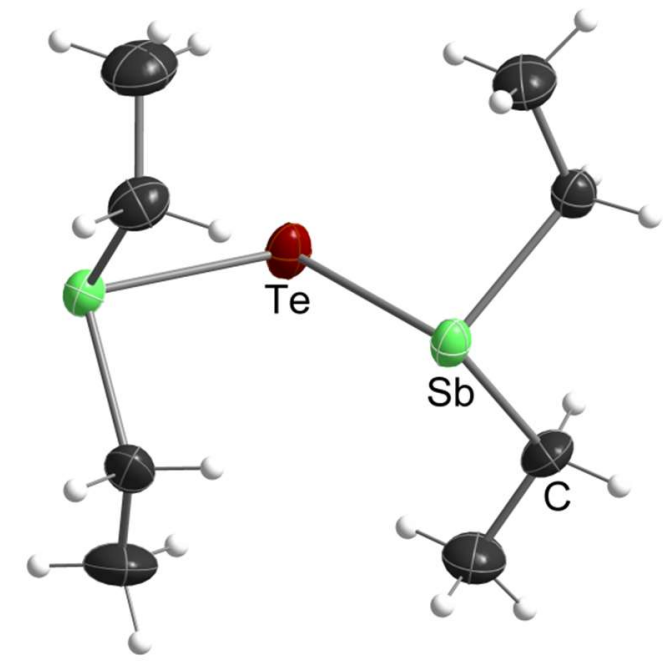

Figure 13. Solid state structure of $\left(\mathrm{Et}_{2} \mathrm{Sb}\right)_{2} \mathrm{Te}^{[97]}$

The average $\mathrm{Sb}-\mathrm{S}$ lengths observed for $\left(\mathrm{Et}_{2} \mathrm{Sb}\right)_{2} \mathrm{~S}(2.446 \AA)$ agree very well with the sum of the covalent radii $\left(\sum \operatorname{cov}(\mathrm{Sb}, \mathrm{S})=2.43 \AA\right)^{[59]}$ and with the value observed in the gas phase structure of $\left(\mathrm{Me}_{2} \mathrm{Sb}\right)_{2} \mathrm{~S}(2.414(4) \AA),{ }^{[94,95,96]}$ whereas those observed in the solid state structure of $\left(\mathrm{Me}_{2} \mathrm{Sb}\right)_{2} \mathrm{~S}$ are slightly elongated $(2.4983(12) \AA) .{ }^{[88]}$ The carbonylchromium complexes $\left[\left(\mathrm{Me}_{2} \mathrm{Sb}\right)_{2} \mathrm{~S}\right]_{2} \mathrm{Cr}(\mathrm{CO})_{4}(2.4239(19), 2.4209(15) \AA)^{[91]}$ and $\left[\left(\mathrm{Ph}_{2} \mathrm{Sb}\right)_{2} \mathrm{~S}\right] \mathrm{Cr}(\mathrm{CO})_{5}(\mathrm{Sb}-\mathrm{S} 2.402(1)$, $2.446(1) \AA)^{[92]}$ showed also comparable values. The $\mathrm{Sb}-\mathrm{S}-\mathrm{Sb}$ bond angles of $\left(\mathrm{Et}_{2} \mathrm{Sb}\right)_{2} \mathrm{~S}$ $\left(101.1(2)^{\circ}, 100.4(2)^{\circ}\right)$ agree very well with those observed for the syn-syn conformer of $\left(\mathrm{Me}_{2} \mathrm{Sb}\right)_{2} \mathrm{~S}$ in the gas phase $\left(98.7(5)^{\circ}\right)$ as well as with the calculated bond angle $\left(101.4^{\circ}\right)$ using density functional theory, ${ }^{[94,95,96]}$ but is significantly enlarged compared to that observed in the solid state structure of $\left(\mathrm{Me}_{2} \mathrm{Sb}\right)_{2} \mathrm{~S}\left(92.35(5)^{\circ}\right),{ }^{[88]}$ indicating different intermolecular interactions of $\left(\mathrm{Me}_{2} \mathrm{Sb}\right)_{2} \mathrm{~S}$ and $\left(\mathrm{Et}_{2} \mathrm{Sb}\right)_{2} \mathrm{~S}$ in the solid state.

The average Sb-Te lengths observed for $\left(\mathrm{Et}_{2} \mathrm{Sb}\right)_{2} \mathrm{Te}(2.777 \AA)$ and $\left(\mathrm{Me}_{2} \mathrm{Sb}\right)_{2} \mathrm{Te}(2.777 \AA)$ agree almost perfectly with the sum of the covalent radii $\left(\sum \operatorname{cov}(\mathrm{Sb}, \mathrm{Te})=2.76 \AA\right)^{[59]}$ as well as 
with the $\mathrm{Sb}-\mathrm{Te}$ bond lengths reported for the telluradistibirane $\mathrm{Bbt}_{2} \mathrm{Sb}_{2} \mathrm{Te}$ (2.7607(7), 2.7719(6) $\AA)^{[62]}$ and $\mathrm{Et}_{2} \mathrm{SbTeEt}\left(2.7834(4) \AA\right.$ ). In addition, several Zintl-ions such as $\left[\mathrm{SbTe}_{4}\right]^{3-}$ , $\left[\mathrm{Sb}_{2} \mathrm{Te}_{5}\right]^{4-},\left[\mathrm{Sb}_{4} \mathrm{Te}_{4}\right]^{4-}$ and $\left[\mathrm{Sb}_{9} \mathrm{Te}_{6}\right]^{3-}$ show comparable Sb-Te bond lengths. ${ }^{[99,100,101]}$ The SbTe-Sb bond angle of $\left(\mathrm{Me}_{2} \mathrm{Sb}\right)_{2} \mathrm{Te}\left(91.88(2)^{\circ}\right)$ is significantly smaller than that of $\left(\mathrm{Et}_{2} \mathrm{Sb}\right)_{2} \mathrm{Te}$ $\left(96.95(2)^{\circ}\right)$ as was observed for the corresponding sulfanes, pointing to more pronounced repulsive interactions between the $\mathrm{Et}_{2} \mathrm{Sb}$ groups in $\left(\mathrm{Et}_{2} \mathrm{Sb}\right)_{2} \mathrm{Te}$ compared to the sterically somewhat smaller $\left(\mathrm{Me}_{2} \mathrm{Sb}\right)_{2} \mathrm{Te}$ groups. In addition, the $\mathrm{Sb}-\mathrm{Te}-\mathrm{Sb}$ bond angle of $\left(\mathrm{Et}_{2} \mathrm{Sb}\right)_{2} \mathrm{Te}$ is significantly smaller than the $\mathrm{Sb}-\mathrm{S}-\mathrm{Sb}$ bond angle of $\left(\mathrm{Et}_{2} \mathrm{Sb}\right)_{2} \mathrm{~S}$, pointing to an increasing pcharacter of the Sb-E bonding electron pairs and hence an increasing s-character of the electron lone pairs at the chalcogen center, which is expected to increase with increasing atomic number of the bridging chalcogenide. Table 2 summarizes the central structural parameters for $\left(\mathrm{R}_{2} \mathrm{Sb}\right)_{2} \mathrm{E}$ derivatives $(\mathrm{R}=\mathrm{Me}, \mathrm{Et}, \mathrm{E}=\mathrm{S}, \mathrm{Se}, \mathrm{Te})$ and for transition metal carbonyl complexes $\left(\mathrm{R}_{2} \mathrm{Sb}\right)_{2} \mathrm{E}-\mathrm{M}(\mathrm{CO})_{\mathrm{x}}$.

Table 2. Structural parameters (interatomic distances, $\AA$, and angles, ${ }^{\circ}$ ) of alkyl-substituted compounds of the general type $\left(\mathrm{R}_{2} \mathrm{Sb}\right)_{2} \mathrm{E}(\mathrm{R}=\mathrm{Me}, \mathrm{Et}, \mathrm{E}=\mathrm{S}, \mathrm{Se}, \mathrm{Te})$ and their transition metal carbonyl complexes $\left(\mathrm{R}_{2} \mathrm{Sb}\right)_{2} \mathrm{E}-\mathrm{M}(\mathrm{CO})_{\mathrm{x}}$.

\begin{tabular}{|c|c|c|c|c|c|c|}
\hline $\mathbf{R}$ & Sb-E-Sb & C-Sb-C & $\Sigma(X-S b-X)$ & Sb-E & $\mathbf{S b} \cdots \mathbf{S b}^{\mathbf{a}}$ & Ref. \\
\hline$\left(\mathrm{Me}_{2} \mathrm{Sb}\right)_{2} \mathrm{~S}$ & $92.35(5)$ & $95.9(3)^{\mathrm{c}}$ & $283.3(6)$ & $2.498(1)$ & 3.605 & {$[88]^{\mathrm{c}}$} \\
\hline$\left(\mathrm{Me}_{2} \mathrm{Sb}\right)_{2} \mathrm{~S}^{\mathrm{b}}$ & $98.7(5)$ & $95(3)$ & 280.2 & $2.414(4)$ & $3.66(2)$ & {$[95]^{\mathrm{d}}$} \\
\hline$\left(\mathrm{Me}_{2} \mathrm{Sb}\right)_{2} \mathrm{Se}^{\mathrm{b}}$ & $96.3(11)$ & $92(7)$ & 282 & $2.551(5)$ & $3.80(6)$ & {$[95]^{\mathrm{d}}$} \\
\hline \multirow[t]{4}{*}{$\left(\mathrm{Et}_{2} \mathrm{Sb}\right)_{2} \mathrm{~S}$} & $101.1(2)$ & $95.0(10)$ & $288(2)$ & $2.429(5)$ & $3.7767(19)$ & {$[97]^{c}$} \\
\hline & & $98.8(10)$ & 289(3) & $2.462(7)$ & & \\
\hline & $100.4(2)$ & $93.4(10)$ & $283(2)$ & $2.427(5)$ & $3.7594(19)$ & \\
\hline & & $97.6(11)$ & $284(3)$ & $2.467(6)$ & & \\
\hline \multirow[t]{2}{*}{$\left(\mathrm{Me}_{2} \mathrm{Sb}\right)_{2} \mathrm{Te}$} & $91.875(14)$ & $93.6(2)$ & $285.7(5)$ & $2.7630(4)$ & $3.9908(4)$ & {$[97]^{\mathrm{c}}$} \\
\hline & & $94.1(3)$ & $287.1(6)$ & $2.7907(5)$ & & \\
\hline$\left(\mathrm{Me}_{2} \mathrm{Sb}\right)_{2} \mathrm{Te}^{\mathrm{b}}$ & $91(2)$ & $108(6)$ & 295.4 & $2.781(3)$ & $3.96(5)$ & {$[95]^{\mathrm{d}}$} \\
\hline \multirow[t]{2}{*}{$\left(\mathrm{Et}_{2} \mathrm{Sb}\right)_{2} \mathrm{Te}$} & $96.948(13)$ & $94.2(2)$ & $286.9(5)$ & $2.7695(9)$ & $4.1571(9)$ & {$[97]^{\mathrm{c}}$} \\
\hline & & $95.23(19)$ & $290.3(5)$ & $2.7833(7)$ & & \\
\hline $\begin{array}{l}{\left[\left(\mathrm{Me}_{2} \mathrm{Sb}\right)_{2} \mathrm{~S}\right]_{2-}} \\
{\left[\mathrm{Cr}(\mathrm{CO})_{4}\right]_{2}}\end{array}$ & $114.46(6)$ & $98.55(4)$ & $290.99(6)$ & $2.4239(19)$ & 4.074 & {$[91]^{\mathrm{c}}$} \\
\hline
\end{tabular}




\begin{tabular}{|c|c|c|c|c|c|c|}
\hline $\mathbf{R}$ & Sb-E-Sb & C-Sb-C & $\Sigma(X-S b-X)$ & Sb-E & $\mathbf{S b} \cdots \mathbf{S b}^{\mathbf{a}}$ & Ref. \\
\hline & & & & $2.4209(15)$ & & \\
\hline \multirow[t]{2}{*}{$\begin{array}{l}{\left[\left(\mathrm{Ph}_{2} \mathrm{Sb}\right)_{2} \mathrm{~S}\right]-} \\
\mathrm{Cr}(\mathrm{CO})_{5}\end{array}$} & $96.7(5)$ & $99.54(6)$ & 296.73 & $2.402(1)$ & & {$[92]^{\mathrm{c}}$} \\
\hline & & $98.15(7)$ & 289.93 & $2.446(1)$ & & \\
\hline \multirow[t]{2}{*}{$\begin{array}{l}{\left[\left(\mathrm{Me}_{2} \mathrm{Sb}\right)_{2} \mathrm{Se}\right]_{2}-} \\
\mathrm{Cr}(\mathrm{CO})_{4}\end{array}$} & 99.55 & $\begin{array}{l}98.14 \\
94.63\end{array}$ & $\begin{array}{l}302.55 \\
282.4\end{array}$ & $2.535 ; 2.589$ & & {$[93]^{\mathrm{c}}$} \\
\hline & 99.63 & $\begin{array}{l}99.21 \\
96.61\end{array}$ & $\begin{array}{l}292.94 \\
287.19\end{array}$ & $2.542 ; 2.569$ & & \\
\hline \multirow[t]{2}{*}{$\begin{array}{l}{\left[\left(\mathrm{Me}_{2} \mathrm{Sb}\right)_{2} \mathrm{Se}\right]-} \\
{\left[\mathrm{W}(\mathrm{CO})_{5}\right]_{2}}\end{array}$} & $106.38(4)$ & $98.69(5)$ & 293.77 & $2.5490(11)$ & 4.071 & {$[93]^{\mathrm{c}}$} \\
\hline & & $101.82(5)$ & 305.25 & $2.535(11)$ & & \\
\hline
\end{tabular}

${ }^{\mathrm{a}}$ Intramolecular $\mathrm{Sb} \cdots \mathrm{Sb}$ distance; ${ }^{\mathrm{b}}$ syn-syn conformer; ${ }^{\mathrm{c}}$ single crystal X-ray diffraction (XRD), ${ }^{\mathrm{d}}$ gas phase structure (GED).

The structurally characterized bis(dialkylstibanyl)chalcogenanes $\left(\mathrm{R}_{2} \mathrm{Sb}\right)_{2} \mathrm{E}$ show different conformations in the solid state and in the gas phase. $\left(\mathrm{Et}_{2} \mathrm{Sb}\right)_{2} \mathrm{~S}$ and $\left(\mathrm{Me}_{2} \mathrm{Sb}\right)_{2} \mathrm{Te}$ adopt $s y n-s y n$ orientations in the solid state (Sb-S-Sb-C: 147.9(7), 139.6(7) and 156.7(8), 158.1(8) (1), $166.8(1), 140.9(2)(4))$, whereas $\left(\mathrm{Et}_{2} \mathrm{Sb}\right)_{2} \mathrm{Te}$ crystallizes as syn-anti conformer (Sb-S-Sb-C: 131.3(1), 42.1(2)). Comparable findings were observed in the solid state structures of bis(dimethylstibanyl)oxane $\left(\mathrm{Me}_{2} \mathrm{Sb}\right)_{2} \mathrm{O}$ (syn-anti conformer) and -sulfane $\left(\mathrm{Me}_{2} \mathrm{Sb}\right)_{2} \mathrm{~S}($ syn-syn conformer). ${ }^{[88]}$ Moreover, GED studies by Haaland et al. showed that bis(dimethylstibanyl)oxane and -sulfane $\left(\mathrm{Me}_{2} \mathrm{Sb}\right)_{2} \mathrm{E}$ exist as mixtures of syn-syn and syn-anti conformers in the gas phase (syn-anti concentrations: $\mathrm{E}=\mathrm{O} 51(7) \% ; \mathrm{E}=\mathrm{S} 48(4) \%$ ), whereas the presence of syn-anti conformers for the heavier homologues $(\mathrm{E}=\mathrm{Se}, \mathrm{Te})$ was uncertain. ${ }^{[94,95,96]}$ The syn-syn conformers are about $4 \mathrm{~kJ} / \mathrm{mol}(\mathrm{E}=\mathrm{O}, \mathrm{S}, \mathrm{Se})$ less in energy than the syn-anti conformers according to DFT calculations, whereas the energy difference for the $\left(\mathrm{Me}_{2} \mathrm{Sb}\right)_{2} \mathrm{Te}$ conformers is roughly $1 \mathrm{~kJ} / \mathrm{mol}$. However, these small energy differences are low enough to be (over-)compensated by the energy gain in case of a more close packing or by the formation of weak intermolecular interactions of the energetically less favored conformer.

Table 3. Comparison of the central bond lengths $[\AA]$ and angles $\left[{ }^{\circ}\right]$ of $\left(\mathrm{Me}_{2} \mathrm{Sb}\right)_{2} \mathrm{Te}(s y n-s y n$ conformation) as obtained in the gas phase and in the solid state as well as by computational calculation. 


\begin{tabular}{llll}
\hline & DFT $^{[95][\mathrm{a}]}$ & $\mathrm{GED}^{[95]}$ & $\mathrm{XRD}^{[97]}$ \\
\hline $\mathrm{Sb}-\mathrm{Te}$ & 2.843 & $2.781(3)$ & $2.791(1) ; 2.763(1)$ \\
$\mathrm{Sb}-\mathrm{C}$ & 2.201 & $2.172(5)$ & $2.16(2) ; 2.150(5)$ \\
& & & $2.155(6) ; 2.156(6)$ \\
$\mathrm{C}-\mathrm{Sb}-\mathrm{C}$ & 94.3 & $108(6)$ & $93.6(2) ; 94.1(3)$ \\
$\mathrm{C}-\mathrm{Sb}-\mathrm{Te}$ & 96.1 & $93.7(11)$ & $97.3(2) ; 94.8(2)$ \\
& & & $96.9(2) ; 96.1(2)$ \\
$\mathrm{Sb}-\mathrm{Te}-\mathrm{Sb}$ & 94.8 & $91(2)$ & $91.9(1)$ \\
$\mathrm{Sb} \cdots \mathrm{Te}$ & - & - & $3.625(1) ; 4.298$ \\
$\mathrm{Te}-\mathrm{Sb} \cdots \mathrm{Sb}$ & - & - & 3.673 \\
\hline
\end{tabular}

[a] Standard deviations were not presented in the literature.

$\left(\mathrm{Me}_{2} \mathrm{Sb}\right)_{2} \mathrm{Se}$ and $\left(\mathrm{Me}_{2} \mathrm{Sb}\right)_{2} \mathrm{Te}$ were previously described as thermochromic compounds. $\left(\mathrm{Me}_{2} \mathrm{Sb}\right)_{2} \mathrm{Se}$ is an orange liquid in the liquid state, which turns red upon solidification and becomes finally purple at temperatures below $-20{ }^{\circ} \mathrm{C}$, whereas $\left(\mathrm{Me}_{2} \mathrm{Sb}\right)_{2} \mathrm{Te}$ was described as a purple solid, which melts at $8{ }^{\circ} \mathrm{C}$ to a red liquid. Since the thermochromic behavior of distibines $\mathrm{Sb}_{2} \mathrm{R}_{4}$ and dibismuthines is attributed to the disruption of short intermolecular $\mathrm{Sb} \cdots \mathrm{Sb}$ and $\mathrm{Bi} \cdots \mathrm{Bi}$ distances in the solid state, we carefully investigated the colors of liquid and solid $\left(\mathrm{Et}_{2} \mathrm{Sb}\right)_{2} \mathrm{~S},\left(\mathrm{Et}_{2} \mathrm{Sb}\right)_{2} \mathrm{Se},\left(\mathrm{Et}_{2} \mathrm{Sb}\right)_{2} \mathrm{Te}$ and $\left(\mathrm{Me}_{2} \mathrm{Sb}\right)_{2} \mathrm{Te}$, but could not observe any color change upon melting or freezing except for a slight bathochromic shift upon solidification from dark-orange to light red in liquid nitrogen for $\left(\mathrm{Me}_{2} \mathrm{Sb}\right)_{2} \mathrm{Te}$. We therefore investigated the packing of the bis(dialkylstibanyl)chalcogenanes $\left(\mathrm{R}_{2} \mathrm{Sb}\right)_{2} \mathrm{E}$ in more detail.

$\left(\mathrm{Et}_{2} \mathrm{Sb}\right)_{2} \mathrm{~S},\left(\mathrm{Et}_{2} \mathrm{Sb}\right)_{2} \mathrm{Te}$ and $\left(\mathrm{Me}_{2} \mathrm{Sb}\right)_{2} \mathrm{Te}$ show different intermolecular contacts in the solid state. $\left(\mathrm{Et}_{2} \mathrm{Sb}\right)_{2} \mathrm{~S}$ forms an endless chain-like structure as was previously reported for $\left(\mathrm{Me}_{2} \mathrm{Sb}\right)_{2} \mathrm{O}$ through the formation of $\mathrm{Sb} \cdots \mathrm{S}$ contacts $(3.501(6) ; 3.571(6) \AA),{ }^{[88]}$ which are clearly below the sum of the van-der-Waals radii $\left(\sum_{\mathrm{vdw}}(\mathrm{Sb}, \mathrm{S})=3.86 \AA\right)^{[3]}$ Only one $\mathrm{SbEt}_{2}$ group of each independent molecule is involved, resulting in a trigonal planar $(2+1)$ coordination sphere of the sulfur atoms (Fig. 14). The shortest intermolecular Sb $\cdots \mathrm{Sb}$ distance $(4.952(3) \AA)$ clearly exceeds the sum of the van-der-Waals radii $\left(\sum_{\mathrm{vdw}}(\mathrm{Sb}, \mathrm{S})=4.12 \AA\right) .{ }^{\left[3^{]} \mathrm{In}\right.}$ contrast, bis(dimethylstibanyl)sulfane $\left(\mathrm{Me}_{2} \mathrm{Sb}\right)_{2} \mathrm{~S}$ adopts a syn-syn conformation mode and the sulfur atoms are $(2+2)$ coordinated. Both antimony atoms are linked to two sulfur atoms, leading to a three-dimensional network instead of a one-dimensional chain as observed for 
$\left(\mathrm{Et}_{2} \mathrm{Sb}\right)_{2} \mathrm{~S}$. Repulsive interactions between the somewhat larger Et substituents in $\left(\mathrm{Et}_{2} \mathrm{Sb}\right)_{2} \mathrm{~S}$ most likely suppress the formation of a three-dimensional network.

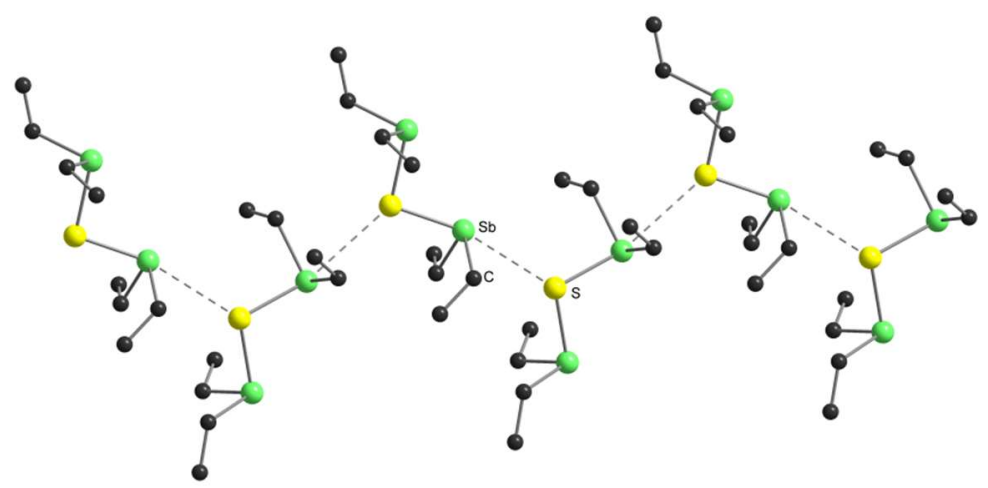

Figure 14. Intermolecular interactions in the solid state structure of $\left(\mathrm{Et}_{2} \mathrm{Sb}\right)_{2} \mathrm{~S}^{\left[{ }^{[97]}\right.}$

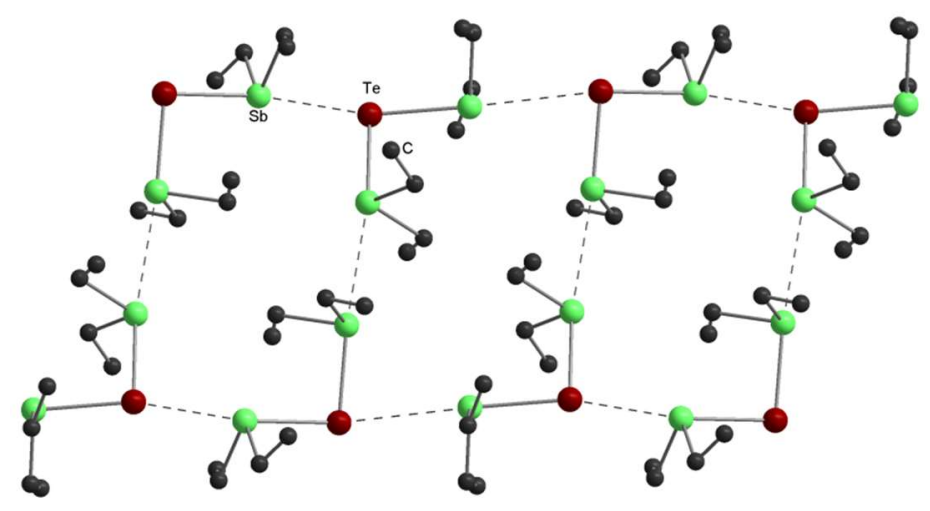

Figure 15. Intermolecular interactions in the solid state structure of $\left(\mathrm{Et}_{2} \mathrm{Sb}\right)_{2} \mathrm{Te}^{[97]}$

$\left(\mathrm{Et}_{2} \mathrm{Sb}\right)_{2} \mathrm{Te}$ and $\left(\mathrm{Me}_{2} \mathrm{Sb}\right)_{2} \mathrm{Te}$ show similar $\mathrm{T}$-shaped $(2+1)$ coordination modes of the $\mathrm{Te}$ atoms. Both form topologically identical ladder-like chain polymers, but those of $\left(\mathrm{Me}_{2} \mathrm{Sb}\right)_{2} \mathrm{Te}$ are are not corrugated (Fig. 15). The intermolecular $\mathrm{Sb} \cdots \mathrm{Sb}$ distances $\left(\left(\mathrm{Et}_{2} \mathrm{Sb}\right)_{2} \mathrm{Te} 3.686(1)\right.$, $\left(\mathrm{Me}_{2} \mathrm{Sb}\right)_{2} \mathrm{Te} 3.673(1) \AA$ ) within the ladders are almost identical, whereas the intermolecular $\mathrm{Sb} \cdots \mathrm{Te}$ distances $\left(\left(\mathrm{Et}_{2} \mathrm{Sb}\right)_{2} \mathrm{Te} 3.718(1),\left(\mathrm{Me}_{2} \mathrm{Sb}\right)_{2} \mathrm{Te} 3.625(1) \AA\right)$, which are considerably shorter than the sum of the van-der-Waals-radii $\left(\sum_{\mathrm{vdw}}(\mathrm{Sb}, \mathrm{Te})=4.12 \AA\right),{ }^{[3]}$ differ by almost $10 \mathrm{pm}$. However, the packing of the chains in $\left(\mathrm{Et}_{2} \mathrm{Sb}\right)_{2} \mathrm{Te}$ and $\left(\mathrm{Me}_{2} \mathrm{Sb}\right)_{2} \mathrm{Te}$ differs slightly. The somewhat sterically less demanding methyl groups in $\left(\mathrm{Me}_{2} \mathrm{Sb}\right)_{2} \mathrm{Te}$ allow closer distances between the metal atoms of the polymer chains, but the shortest contact ( $\mathrm{Sb} \cdots \mathrm{Te}$ 4.298(1) $\AA$ ) is still longer than the sum of the van der Waals radii. In contrast, no intermolecular metalmetal contacts between the polymer chains below $5 \AA$ are observed for $\left(\mathrm{Et}_{2} \mathrm{Sb}\right)_{2} \mathrm{Te}$. According to the structural results, the color change observed for $\left(\mathrm{Me}_{2} \mathrm{Sb}\right)_{2} \mathrm{Te}$ may be attributed to the breaking of either the short $\mathrm{Sb} \cdots$ Te distances (3.625(1) $\AA$ ) within the chain or the $\mathrm{Sb} \cdots \mathrm{Sb}$ distances (3.673(1) $\AA$ ) between the chains. In addition, breakage of the somewhat longer 
intermolecular $\mathrm{Sb} \cdots$ Te contacts $(4.298(1) \AA$ ) can play a role, even though these contacts are slightly longer than the van der Waals radii.

\section{$3.2\left(R_{2} \mathrm{Bi}\right)_{2} \mathrm{E}(\mathrm{E}=\mathrm{Se}, \mathrm{Te})$}

The number of structurally characterized bis(dialkylbismuthanyl)chalcogenanes $\left(\mathrm{R}_{2} \mathrm{Bi}\right)_{2} \mathrm{E}(\mathrm{E}=$ $\mathrm{S}, \mathrm{Se}, \mathrm{Te})$ is also small. While six sulfanes $\left(\mathrm{R}_{2} \mathrm{Bi}\right)_{2} \mathrm{~S}\left(\mathrm{R}=\left(\mathrm{Me}_{3} \mathrm{Si}\right)_{2} \mathrm{CH},{ }^{[63]} 2,4,6-\mathrm{Me}_{3} \mathrm{C}_{6} \mathrm{H}_{2},{ }^{[11]}\right.$ 2-( $\left.\left(\mathrm{Me}_{2} \mathrm{NCH}_{2}\right) \mathrm{C}_{6} \mathrm{H}_{4},{ }^{[13]} \mathrm{RN}\left(\mathrm{CH}_{2} \mathrm{C}_{6} \mathrm{H}_{4}\right)_{2}, \mathrm{R}=\mathrm{Ph}, \mathrm{Cy}, t-\mathrm{Bu}^{[90]}\right)$ have been investigated by single crystal X-ray diffraction, only one selenane $\left(\left[\left\{2,4,6-\mathrm{Me}_{3} \mathrm{C}_{6} \mathrm{H}_{2}\right\}_{2} \mathrm{Bi}\right]_{2} \mathrm{Se}\right)^{[11]}$ and one tellurane $\left(\left[\left\{\left(\mathrm{Me}_{3} \mathrm{Si}\right)_{2} \mathrm{CH}\right\}_{2} \mathrm{Bi}\right]_{2} \mathrm{Te}\right]^{[63]}$ have been structurally characterized, to date. All of them contain sterically demanding, sometimes donor-functionalized organic substituents, which kinetically stabilize the resulting monomeric compounds and effectively suppress the formation of intermolecular contacts. Very recently, we investigated the solid state structures of three bis(dialkylbismuthanyl)chalcogenanes $\left(\mathrm{Et}_{2} \mathrm{Bi}\right)_{2} \mathrm{~S}, \quad\left(\mathrm{Et}_{2} \mathrm{Bi}\right)_{2} \mathrm{Se}$, and $\left(\mathrm{Et}_{2} \mathrm{Bi}\right)_{2} \mathrm{Te}$ containing sterically less demanding Et substituents (Figs. 16, 17), ${ }^{[102]}$ which were prepared by reactions of $\mathrm{Bi}_{2} \mathrm{Et}_{4}$ with an excess of elemental $\mathrm{S}$, $\mathrm{Se}$ and Te, respectively. ${ }^{[11]}$ Table 4 summarizes selected structural data of structurally characterized bis(bismuthanyl)chalcogenanes $\left(\mathrm{R}_{2} \mathrm{Bi}\right)_{2} \mathrm{E}$.

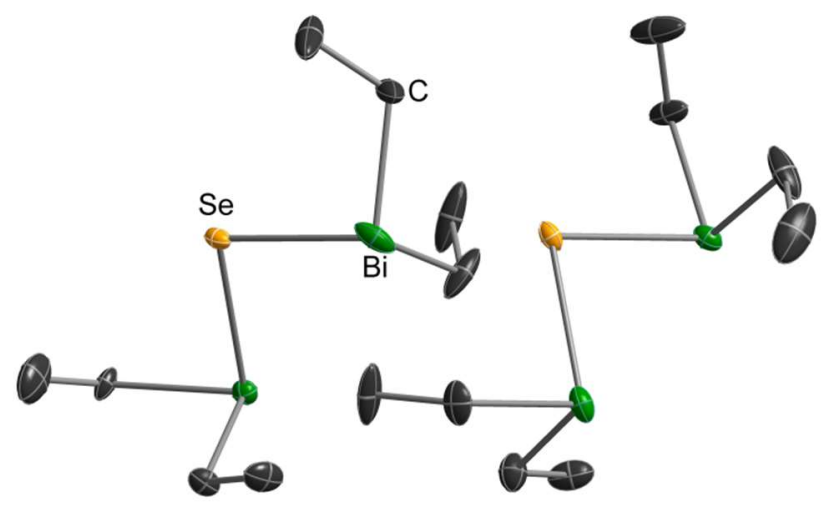

Figure 16. Solid state structure of $\left(\mathrm{Et}_{2} \mathrm{Bi}\right)_{2} \mathrm{Se}^{[102]}$

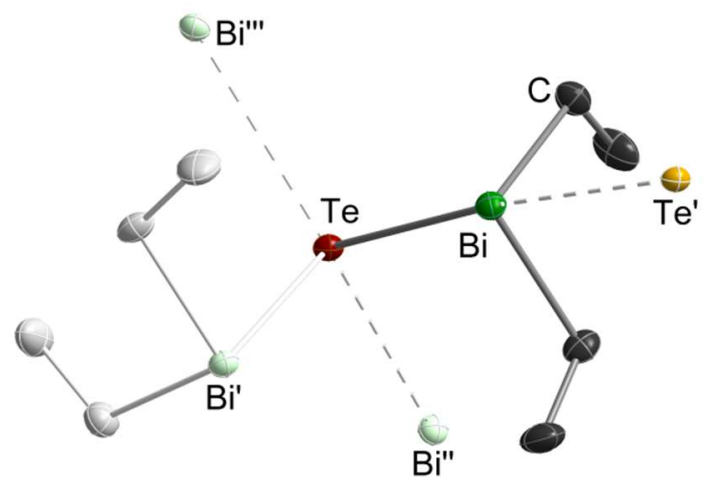

Figure 17. Solid state structure of $\left(\mathrm{Et}_{2} \mathrm{Bi}\right)_{2} \mathrm{Te}$ including weak intermolecular $\mathrm{Bi} \cdots \mathrm{Te}$ contacts in the distorted diamond-like networks. ${ }^{[102]}$ 
The $\mathrm{Bi}$ atoms adopt distorted trigonal pyramidal coordination environments. The $\mathrm{C}_{2}$ symmetric molecules of $\left(\mathrm{Et}_{2} \mathrm{Bi}\right)_{2} \mathrm{~S},\left(\mathrm{Et}_{2} \mathrm{Bi}\right)_{2} \mathrm{Se}$, and $\left(\mathrm{Et}_{2} \mathrm{Bi}\right)_{2} \mathrm{Te}$ form syn-anti conformers as was observed for $\left(\mathrm{Me}_{2} \mathrm{Sb}\right)_{2} \mathrm{Te}$. The sum of the $\mathrm{C}-\mathrm{Bi}-\mathrm{C}$ and $\mathrm{E}-\mathrm{Bi}-\mathrm{C}$ bond angles at each $\mathrm{Bi}$ atoms significantly deviates from tetrahedral, indicating a high s-character of the electron lone pair as is typical for trialkylbismuthines and tetraalkyldibismuthines $\left(\mathrm{BiR}_{3}: \mathrm{R}=\mathrm{Me}\right.$, 276.6(24) $)^{\circ} i$-Pr 290.6(9) $)$; $\left.\mathrm{Bi}_{2} \mathrm{Et}_{4} 281.8^{\circ}\right) .{ }^{[103,104]}$ The Bi-E-Bi bond angle of analogously substituted derivatives $\left(\mathrm{R}_{2} \mathrm{Bi}\right)_{2} \mathrm{E}$ steadily decreases with increasing atomic number of the chalcogen atom $\left(\mathrm{R}=\mathrm{Et}, \mathrm{E}=\mathrm{S}\right.$ 94.84(2) ${ }^{\circ}$; $\mathrm{Se} 91.69(2)^{\circ}$; $\mathrm{Te} 86.61(2)^{\circ} ;[102] \mathrm{R}=\left(\mathrm{Me}_{3} \mathrm{Si}\right)_{2} \mathrm{CH}$, $\mathrm{E}=\mathrm{S}$ 92.48(4) $;$ Te 88.00(7) ${ }^{\circ} ;{ }^{[63]} \mathrm{R}=2,4,6-\mathrm{Me}_{3} \mathrm{C}_{6} \mathrm{H}_{2}, \mathrm{E}=\mathrm{O} 117.1(8)^{\circ} ; \mathrm{S} 98.7(3)^{\circ} ; \mathrm{Te}$ $\left.91.2(1)^{\circ}{ }^{[11]}\right)$ as was expected due to the increasing s-character of the electron lone pairs and the increasing p-character of the E-Bi bonding electron pairs. The Bi-E bond distances in $\left(\mathrm{R}_{2} \mathrm{Bi}\right)_{2} \mathrm{E}$ (Table 4$)$, which increase with increasing atomic number of the central chalcogen atom, compare well with the sum of the covalent radii $\left(\sum \operatorname{cov}(B i, E)=2.54 \AA(E=S), 2.67 \AA(E\right.$ $=\mathrm{Se}), 2.87 \AA(\mathrm{E}=\mathrm{Te}))^{[59]}$ as well as with distances deposited in the Cambridge structure database, ${ }^{[105]}$ except for $\left(\mathrm{Et}_{2} \mathrm{Bi}\right)_{2} \mathrm{Se}$, and $\left(\mathrm{Et}_{2} \mathrm{Bi}\right)_{2} \mathrm{Te}$, which are significantly elongated by almost $10 \mathrm{pm}$ despite the sterically less demanding Et substituents. The Bi-Te bond length in $\left(\mathrm{Et}_{2} \mathrm{Bi}\right)_{2} \mathrm{Te}$ is also longer than those observed in $\mathrm{Et}_{2} \mathrm{BiTeEt}(2.9116(5) \AA),{ }^{[61]} \mathrm{R}_{2} \mathrm{BiTePh}(\mathrm{R}=$ $\left.\left.o-\mathrm{C}_{6} \mathrm{H}_{4}\left(\mathrm{CH}=\mathrm{NC}_{6} \mathrm{H}_{3}(i-\mathrm{Pr})_{2}-2,6\right)\right) \quad 2.9084(4) \quad \AA\right),{ }^{[57]} \quad\left\{\left[\left(\mathrm{Me}_{3} \mathrm{Si}\right)_{2} \mathrm{CH}\right]_{2} \mathrm{Bi}\right\}_{2} \mathrm{Te} \quad(2.872(3) \quad \AA$, $2.889(2) \AA),{ }^{[63]}\left[\left\{\left(\mathrm{Me}_{3} \mathrm{Si}\right)_{3} \mathrm{SiTe}\right\}_{2} \mathrm{BiR}\right]\left(\mathrm{R}=\mathrm{CH}\left(\mathrm{SiMe}_{3}\right)_{2}: 2.8378(8), 2.8617(8) \AA \AA \mathrm{C}\left(\mathrm{SiMe}_{3}\right)_{3}\right.$ : $2.8638(11), 2.8826(14) \AA),{ }^{[64]}$ and $\mathrm{RBi}(\mathrm{TePh})_{2} \quad\left(\mathrm{R}=o-\mathrm{C}_{6} \mathrm{H}_{4}\left(\mathrm{CH}=\mathrm{NC}_{6} \mathrm{H}_{3}(i-\mathrm{Pr})_{2}-2,6\right)\right.$, 2.8949(3), 2.9545(3) $\AA),{ }^{[57]}$ respectively, but shorter than the shortest Bi-Te distance observed in the crystal of $\mathrm{Bi}_{2} \mathrm{Te}_{3}(3.066(2) \AA) .{ }^{[65]}$ These findings point to substantial intermolecular interactions between the molecules, as was confirmed by an analysis of the packing of $\left(\mathrm{Et}_{2} \mathrm{Bi}\right)_{2} \mathrm{~S},\left(\mathrm{Et}_{2} \mathrm{Bi}\right)_{2} \mathrm{Se}$, and $\left(\mathrm{Et}_{2} \mathrm{Bi}\right)_{2} \mathrm{Te}$. The molecules form distorted diamond-like networks. Even though $\left(\mathrm{Et}_{2} \mathrm{Bi}\right)_{2} \mathrm{~S},\left(\mathrm{Et}_{2} \mathrm{Bi}\right)_{2} \mathrm{Se}$, and $\left(\mathrm{Et}_{2} \mathrm{Bi}\right)_{2} \mathrm{Te}$ form syn-anti conformers in the solid state, they show different intermolecular $\mathrm{Bi} \cdots$ chalcogen contacts, resulting in three-dimensional networks of corner-shared $\mathrm{Bi}_{4} \mathrm{E}$-tetrahedra $(\mathrm{E}=\mathrm{S}, \mathrm{Se}, \mathrm{Te})$. 
Table 4. Interatomic distances $[\AA]$ and angles $\left[^{\circ}\right]$ for bis(dialkylstibanyl)chalcogenanes $\left(\mathrm{R}_{2} \mathrm{Bi}\right)_{2} \mathrm{E}(\mathrm{E}=\mathrm{O}, \mathrm{S}, \mathrm{Se}, \mathrm{Te})$.

\begin{tabular}{|c|c|c|c|c|c|c|c|c|c|c|}
\hline \multirow[t]{2}{*}{$\mathbf{R}$} & \multirow[t]{2}{*}{$\mathbf{E}$} & \multirow[t]{2}{*}{ Conformation } & \multicolumn{2}{|c|}{$\phi$ Bi-E-Bi-lp } & \multirow[t]{2}{*}{ Bi-E-Bi } & \multirow[t]{2}{*}{ C-Bi-C } & \multirow[t]{2}{*}{$\Sigma(\mathrm{X}-\mathrm{Bi}-\mathrm{X})$} & \multirow[t]{2}{*}{ Bi-E } & \multirow[t]{2}{*}{$\mathbf{B i} \cdots \mathbf{B i}^{\mathbf{a}}$} & \multirow[t]{2}{*}{ Ref. } \\
\hline & & & $\phi_{1}$ & $\phi_{2}$ & & & & & & \\
\hline \multirow[t]{2}{*}{ Mesityl } & $\mathrm{O}$ & near $s y n-s y n$ & 86.51 & 92.99 & $124.6(3)$ & 98.3(3) & 294.5(9) & $2.064(7)$ & 3.665 & {$[63]$} \\
\hline & & & & & & 98.4(3) & $295.6(9)$ & $2.075(8)$ & & \\
\hline \multirow[t]{2}{*}{ Mesityl } & $\mathrm{O}^{\mathrm{b}}$ & near $s y n-s y n$ & 84.17 & 86.46 & $117.1(8)$ & $97.4(1)$ & $286(3)$ & $2.095(2)$ & 3.595 & {$[63]$} \\
\hline & & & & & & 98.3(1) & $289(3)$ & $2.117(2)$ & & \\
\hline \multirow[t]{6}{*}{ Et } & $\mathrm{S}$ & near syn-anti & $137.57^{\mathrm{d}}$ & $137.57^{\mathrm{d}}$ & $94.87(15)$ & $94.2(7)^{\mathrm{d}}$ & $281.3(16)^{\mathrm{d}}$ & $2.615(3)^{\mathrm{d}}$ & $3.8516(11)$ & [102] \\
\hline & & & & & & $94.2(7)^{\mathrm{d}}$ & $281.3(16)^{\mathrm{d}}$ & $2.615(3)^{d}$ & & [102] \\
\hline & & & $\begin{array}{l}96.19 / \\
111.58^{\mathrm{c}, \mathrm{d}}\end{array}$ & $\begin{array}{l}96.19 / \\
111.58^{\mathrm{c}, \mathrm{d}}\end{array}$ & $100.97(15)$ & $94.7(8) / 131(2)^{\mathrm{c}, \mathrm{d}}$ & $\begin{array}{l}284.6(18) / \\
323(26)^{\mathrm{c}, \mathrm{d}}\end{array}$ & $2.614(3)^{\mathrm{d}}$ & $4.0331(11)$ & [102] \\
\hline & & & & & & $94.7(8) / 131(2)^{\mathrm{c}, \mathrm{d}}$ & $\begin{array}{l}284.6(18) / \\
323(26)^{\mathrm{c}, \mathrm{d}}\end{array}$ & $2.614(3)^{d}$ & & [102] \\
\hline & & & $\begin{array}{l}98.09 / \\
131.14^{\mathrm{c}}\end{array}$ & 98.09 & $98.58(11)$ & $91.8(11)$ & $283(3) / 284(4)^{c}$ & $2.611(3)$ & $3.9616(8)$ & [102] \\
\hline & & & & & & $93.6(8)$ & $288.8(18)$ & $2.615(3)$ & & [102] \\
\hline \multirow[t]{2}{*}{$\left(\mathrm{Me}_{3} \mathrm{Si}\right)_{2} \mathrm{CH}$} & $\mathrm{S}$ & near $s y n-s y n$ & 21.39 & 59.12 & $92.48(4)$ & $95.74(14)$ & $300.0(4)$ & $2.557(12)$ & 3.705 & {$[63]$} \\
\hline & & & & & & $104.63(15)$ & $301.4(4)$ & $2.572(12)$ & & \\
\hline \multirow[t]{2}{*}{ Mesityl } & $\mathrm{S}$ & near $s y n-s y n$ & 19.47 & 26.3 & $98.7(3)$ & $97.4(1)$ & 294(2) & $2.520(7)$ & 3.844 & {$[63]$} \\
\hline & & & & & & $98.9(9)$ & $295(2)$ & $2.545(6)$ & & \\
\hline
\end{tabular}




\begin{tabular}{|c|c|c|c|c|c|c|c|c|c|c|}
\hline \multirow[t]{2}{*}{$\mathbf{R}$} & \multirow[t]{2}{*}{$\mathbf{E}$} & \multirow[t]{2}{*}{ Conformation } & \multicolumn{2}{|c|}{$\phi$ Bi-E-Bi-lp } & \multirow[t]{2}{*}{ Bi-E-Bi } & \multirow[t]{2}{*}{ C-Bi-C } & \multirow[t]{2}{*}{$\Sigma(\mathrm{X}-\mathrm{Bi}-\mathrm{X})$} & \multirow[t]{2}{*}{ Bi-E } & \multirow[t]{2}{*}{$\mathbf{B} \mathbf{i} \cdots \mathbf{B} \mathbf{i}^{\mathbf{a}}$} & \multirow[t]{2}{*}{ Ref. } \\
\hline & & & $\phi_{1}$ & $\phi_{2}$ & & & & & & \\
\hline \multirow[t]{4}{*}{ Et } & $\mathrm{Se}$ & near syn-anti & 87.62 & $\begin{array}{l}94.09 / \\
128.16^{\mathrm{c}}\end{array}$ & $98.825(16)$ & $97.1(3)$ & $285.5(6)$ & $2.7701(6)$ & $4.2084(4)$ & {$[102]$} \\
\hline & & & & & & $94.8(3) / 97.3(3)^{\mathrm{c}}$ & $280.4(7) / 281.9(7)^{\mathrm{c}}$ & $2.7716(5)$ & & {$[102]$} \\
\hline & & & 136.52 & 141.05 & $91.689(16)$ & $93.0(2)$ & $279.6(5)$ & $2.7608(5)$ & $3.9675(4)$ & {$[102]$} \\
\hline & & & & & & $97.0(3)$ & $271.0(6)$ & $2.7691(6)$ & & {$[102]$} \\
\hline Mesityl & $\mathrm{Se}$ & Near $s y n-s y n$ & 22.14 & 22.14 & $91.2(1)$ & $100.6(3)$ & $295.8(7)$ & $2.651(1)$ & 3.791 & {$[63]$} \\
\hline \multirow[t]{2}{*}{ Et } & $\mathrm{Te}$ & near syn-anti & $138.33^{\mathrm{d}}$ & $138.33^{\mathrm{d}}$ & $86.606(13)$ & $96.08(18)^{\mathrm{d}}$ & $281.9(4)^{\mathrm{d}}$ & $2.9778(4)^{\mathrm{d}}$ & $4.0847(5)$ & {$[102]$} \\
\hline & & & & & & $96.08(18)^{\mathrm{d}}$ & $281.9(4)^{\mathrm{d}}$ & $2.9778(4)^{\mathrm{d}}$ & & {$[102]$} \\
\hline \multirow[t]{2}{*}{$\left(\mathrm{Me}_{3} \mathrm{Si}\right)_{2} \mathrm{CH}$} & $\mathrm{Te}$ & Near syn-syn & 21.33 & 62.64 & $88.0(7)$ & $97.69(4)$ & $302.4(10)$ & $2.872(3)$ & 4.002 & {$[63]$} \\
\hline & & & & & & $104.96(4)$ & $303.6(10)$ & $2.889(2)$ & & \\
\hline
\end{tabular}

${ }^{\mathrm{a}}$ Intramolecular $\mathrm{Bi} \cdots \mathrm{Bi}$ distance; ${ }^{\mathrm{b}}$ Crystallized with $0.5 \mathrm{EtOH} ;{ }^{\mathrm{c}}$ disorderd $\mathrm{C} \alpha ;{ }^{\mathrm{d}}$ equal because of symmetry equivalence, $\phi$ calculated from Bi-E$\mathrm{Bi}-\mathrm{CT}+180^{\circ}$ where $\mathrm{CT}$ is the centroid of the $\mathrm{C} \alpha$, The vector Bi to CT' (generated from CT by inversion at Bi) corresponds to the assumed direction of the lone pair (lp) if considered stereochemically active; Data of $\mathbf{1}$ is of limited reliability because of low crystal quality 
The intramolecular Bi-E-Bi bond angles diminish while the $\mathrm{Bi} \cdots \mathrm{E} \cdots \mathrm{Bi}$ bond lengths increase with increasing atomic number of the chalcogen. As a result, the diamond-like network becomes more distorted from $\mathrm{S}$ to Te. Pseudo-cubic lattices were observed despite the distortion as illustrated in Figure 18 for $\left(\mathrm{Et}_{2} \mathrm{Bi}\right)_{2} \mathrm{Te}$. Since the space groups of $\left(\mathrm{Et}_{2} \mathrm{Bi}\right)_{2} \mathrm{~S}$, $\left(\mathrm{Et}_{2} \mathrm{Bi}\right)_{2} \mathrm{Se}$, and $\left(\mathrm{Et}_{2} \mathrm{Bi}\right)_{2} \mathrm{Te}\left(P 2_{1} / n, P 4_{3} 2_{1} 2\right)$ are subgroups of the space group of the diamond structure $(F d-3 m)$, the structures are related to diamond also symmetry-wise. A tetrahedral environment of $\mathrm{S}$ is also observed in the packing of $\left(\mathrm{Me}_{2} \mathrm{Sb}\right)_{2} \mathrm{~S},{ }^{[88]}$ even though the resulting network is not related to diamond or any other simple structure type involving tetrahedral coordination.

Table 5. Geometrical data of intermolecular interactions (in ${ }^{\circ}$ and $\AA$ ) in structures of $\left(\mathrm{Et}_{2} \mathrm{Bi}\right)_{2} \mathrm{E}(\mathrm{E}=\mathrm{S}, \mathrm{Se}, \mathrm{Te}) .{ }^{[102]}$

\begin{tabular}{llll}
\hline & $\mathbf{E} \cdots \mathbf{B i}$ & $\mathbf{B i} \cdots \mathbf{E} \cdots \mathbf{B i}$ & \\
\hline$\left(\mathrm{Et}_{2} \mathrm{Bi}\right)_{2} \mathrm{~S}$ molecule "S1" & $3.381(3)^{\mathrm{a}}$ & $94.87(15)$ & $110.07(13)$ \\
$\left(\mathrm{Et}_{2} \mathrm{Bi}\right)_{2} \mathrm{~S}$ molecule "S2" & $3.423(2)^{\mathrm{a}}$ & $112.72(2)^{\mathrm{a}}$ & $112.90(2)^{\mathrm{a}}$ \\
& & $100.98(15)$ & $121.38(13)$ \\
$\left(\mathrm{Et}_{2} \mathrm{Bi}\right)_{2} \mathrm{~S}$ molecule "S3" & $3.436(4)$ & $105.52(2)^{\mathrm{a}}$ & $110.82(2)^{\mathrm{a}}$ \\
& $3.439(4)$ & $98.58(11)$ & $107.04(11)$ \\
& & $108.41(12)$ & $111.98(11)$ \\
$\left(\mathrm{Et}{ }_{2} \mathrm{Bi}\right)_{2} \mathrm{Se}$ molecule "Se1" & $3.2795(6)$ & $112.03(12)$ & $117.24(9)$ \\
& $3.3103(5)$ & $98.83(2)$ & $101.13(1)$ \\
& & $107.90(1)$ & $108.31(2)$ \\
$\left(\mathrm{Et}{ }_{2} \mathrm{Bi}\right)_{2} \mathrm{Se}$ molecule "Se11" & $3.2706(5)$ & $108.54(1)$ & $128.13(2)$ \\
& $3.2770(6)$ & $91.69(2)$ & $108.63(2)$ \\
& & $109.24(1)$ & $110.03(1)$ \\
& & $113.21(2)$ & $120.26(2)$ \\
$\left(\mathrm{Et}{ }_{2} \mathrm{Bi}\right)_{2} \mathrm{Te}$ & $3.3894(3)^{\mathrm{a}}$ & $86.61(2)$ & $103.27(1)^{\mathrm{a}}$ \\
& & $104.10(1)^{\mathrm{a}}$ & $142.06(2)$
\end{tabular}

${ }^{\mathrm{a}}$ value appears twice because of a special position, i.e. symmetry equivalent bonds or angles. Data of $\left(\mathrm{Et}_{2} \mathrm{Bi}\right)_{2} \mathrm{~S}$ is of limited reliability due to the low crystal quality. 


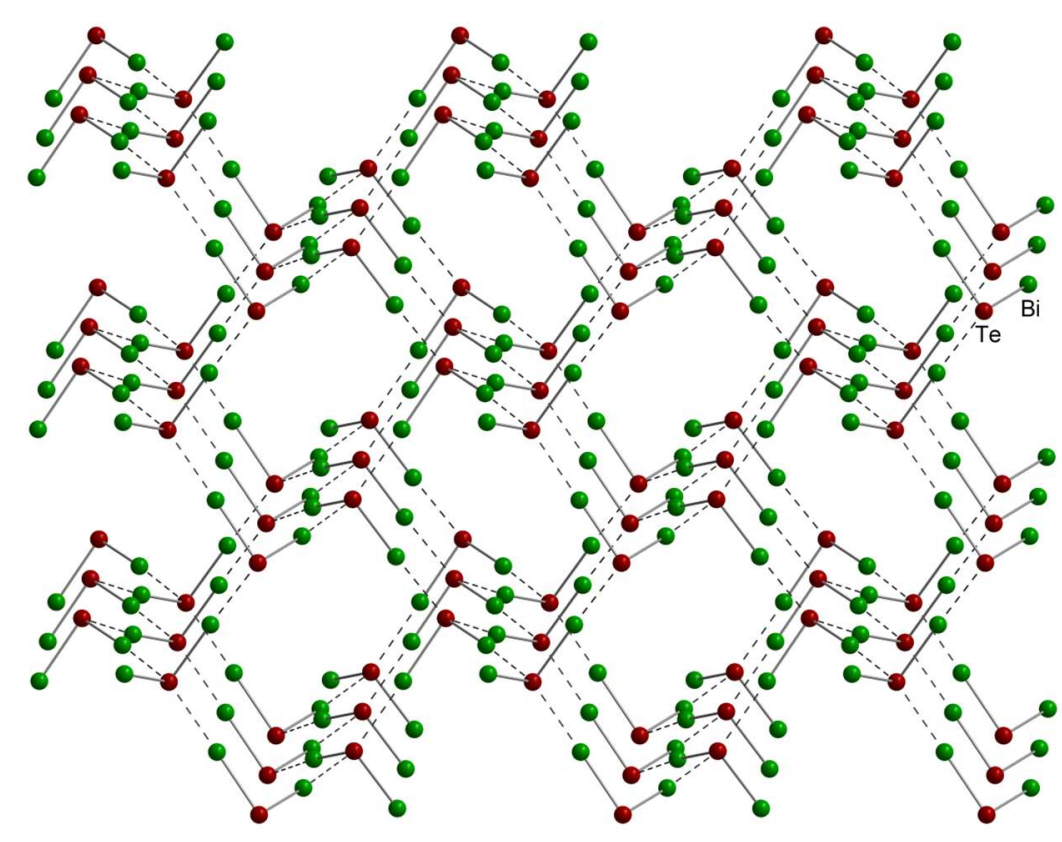

Figure 18. Diamond-like network as observed for $\left(\mathrm{Et}_{2} \mathrm{Bi}\right)_{2} \mathrm{Te}^{[102]}$

\section{Synthesis and Solid State Structures of Group 15 Chalcogenides containing terminal}

\section{Sb-E bonds}

Compounds of the heaviest group 15 (Sb, Bi) and group 16 elements $(\mathrm{S}, \mathrm{Se}$, or $\mathrm{Te}$ ) containing a terminal M-E bond, formally a M-E double bond, have attracted much attention in the last decades. ${ }^{[23,24]}$ They are typically stabilized by sterically demanding organic substituents (kinetical stabilization) to avoid ring formation or polymerization of the molecules or by the introduction of additional donor sites, which coordinate to the group 15 metal center and hence electronically stabilize these compounds. Two types of compounds, $\mathrm{R}_{3} \mathrm{ME}$ and RME, have recently been reported and their solid state structures have been determined.

\section{$4.1 R_{3} \operatorname{SbE}(E=S, S e, T e)$}

Solid state structures of organoantimony $(\mathrm{V})$ and organobismuth $(\mathrm{V})$ chalcogenides of the general type $\mathrm{R}_{3} \mathrm{ME}(\mathrm{M}=\mathrm{Sb}, \mathrm{Bi}, \mathrm{E}=\mathrm{S}, \mathrm{Se}, \mathrm{Te})$ with an unsupported terminal $\mathrm{Sb}=\mathrm{E}$ double bond are almost completely unknown, to date. This is a rather surprising finding, since chalcogenostiboranes $\mathrm{R}_{3} \mathrm{SbE}(\mathrm{E}=\mathrm{O}, \mathrm{S}, \mathrm{Se} ; \mathrm{R}=$ alkyl, aryl) have been initially prepared more than 150 years ago by Carl Jakob Löwig and Eduard Schweizer, who reported on the reaction of $\mathrm{Et}_{3} \mathrm{Sb}$ with elemental sulfur and selenium. ${ }^{[27]}$ Even though several trialkylthio- and selenostiboranes have been synthesized since then, ${ }^{[106,107,108,109]} \mathrm{Ph}_{3} \mathrm{SbS}$, initially prepared by 
Kaufmann 100 years ago, ${ }^{[28,29]}$ and p-Tol ${ }_{3} \mathrm{SbS}$ represent the only structurally characterized triorganylthiostiborane $\mathrm{R}_{3} \mathrm{SbS}^{[30,31,32]}$ In addition, transition metal and main group metal compounds of $\mathrm{R}_{3} \mathrm{SbS}$ were reported. ${ }^{[10,111]}$ In contrast, solid state structures of selenostiboranes $\mathrm{R}_{3} \mathrm{SbSe}$ remained unknown, except for a single report, that describes their capability to serve as ligand in coordination chemistry. ${ }^{[112]} \mathrm{Ph}_{3} \mathrm{SbS}(2.244(1) \AA$ ) exhibits a short Sb-S bond, ${ }^{[113]}$ which was described by Pebler as partial double bond due to $\mathrm{d} \pi-\mathrm{p} \pi$ interaction. In contrast, Otera et al. described the bonding situation in $\mathrm{Me}_{3} \mathrm{SbS}$ as polar single bond with some ionic stabilization. ${ }^{[33]}$ The bonding situation in these type of compounds was also studied by vibrational spectroscopy. Calculations using Gordys rule ${ }^{[114]}$ gave Sb-E stretching vibration frequencies for a Sb-E single bond (Sb-S $338 \mathrm{~cm}^{-1} ; \mathrm{Sb}-\mathrm{Se} 234 \mathrm{~cm}^{-1}$ ) and $\mathrm{Sb}=\mathrm{E}$ double bond $\left(\mathrm{Sb}=\mathrm{S} 485 \mathrm{~cm}^{-1} ; \mathrm{Sb}=\mathrm{Se} 333 \mathrm{~cm}^{-1}\right)$, which were compared with experimental values as reported for $\mathrm{Me}_{3} \mathrm{SbS}\left(431 \mathrm{~cm}^{-1}, \mathrm{KBr}\right.$ pellet), ${ }^{[115]} \mathrm{Et}_{3} \mathrm{SbS}$ (439 $\mathrm{cm}^{-1}$, $\mathrm{CCl}_{4}$ solution), $422 \mathrm{~cm}^{-1}$ (KBr pellet) and $\mathrm{Et}_{3} \mathrm{SbSe}\left(272 \mathrm{~cm}^{-1}, \mathrm{KBr}\right.$ pellet), ${ }^{[108]}$ respectively. The experimental values fall in between the calculated values, hence a clear distinction between both bonding situations was not possible. Therefore, it is still unclear whether the Sb$\mathrm{E}$ bond in $\mathrm{Sb}(\mathrm{V})$ chalcogenides should be rather described as a real double bond with $\mathrm{p}$ bonding contribution or as a polar single bond with ionic contribution (Scheme 6).

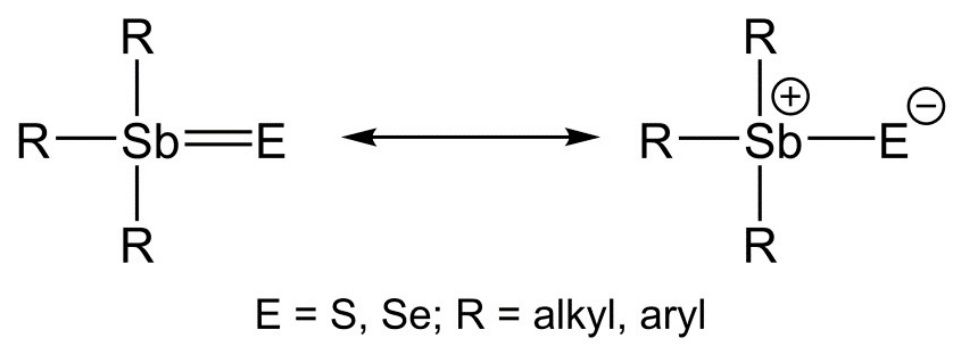

Scheme 6. Possible description of the bonding situation in triorganothio- and selenostiboranes $\mathrm{R}_{3} \mathrm{SbE}$ with and without $\pi$-bonding contribution.

We recently reported on the synthesis and solid state structures of $\mathrm{Et}_{3} \mathrm{SbS}$ and $\mathrm{Et}_{3} \mathrm{SbSe}$ (Fig. 19), which were obtained from the oxidative addition of the respective elemental chalcogen to $\mathrm{Et}_{3} \mathrm{Sb}^{[116]}$ The $\mathrm{Sb}$ atoms adopt slightly distorted tetrahedral coordination spheres. The $\mathrm{Sb}-\mathrm{S}$ bond length of $\mathrm{Et}_{3} \mathrm{SbS}$ (2.381(7) $\AA$ ), which is in between the calculated values for a Sb-S single bond $\left(\sum_{\operatorname{cov}}(\mathrm{Sb}, \mathrm{S})=2.43 \AA\right)^{[59]}$ and a $\mathrm{Sb}=\mathrm{S}$ double-bond $\left(\sum \operatorname{cov}(\mathrm{Sb}, \mathrm{S})=2.27 \AA\right),{ }^{[117]}$ is significantly longer than that observed in $\mathrm{Ph}_{3} \mathrm{Sb}=\mathrm{S}(2.244(1) \AA) .{ }^{[30,31]}$ Moreover, $\left(\mathrm{Me}_{3} \mathrm{SbS}\right)_{2} \mathrm{Me}_{2} \mathrm{SnCl}_{2}\left(2.230(3 \AA)^{[110]}\right.$ as well as three recently structurally characterized copper complexes of $\mathrm{Ph}_{3} \mathrm{SbS}(2.2735(9), 2.2812(7), 2.2832(7) \AA)^{[111]}$ show significantly shorter Sb-S bonds. 


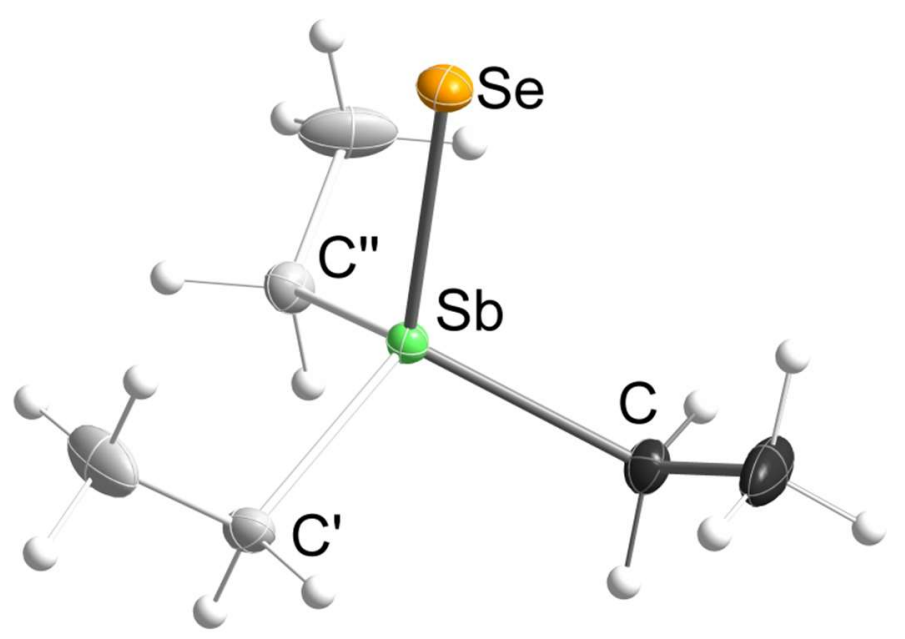

Figure 19. Solid state structure of $\mathrm{Et}_{3} \mathrm{SbSe}^{[116]}$

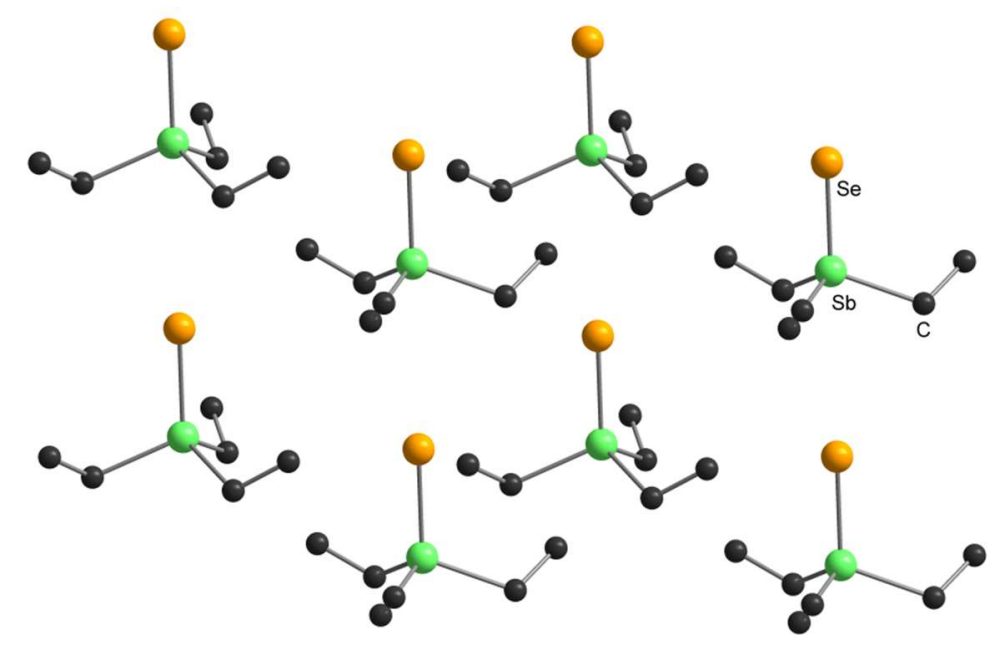

Figure 20. Packing of $\mathrm{Et}_{3} \mathrm{SbSe}$ in the solid state. ${ }^{[116]}$

The Sb-Se bond length $(2.4062(8) \AA)$ in $\mathrm{Et}_{3} \mathrm{SbSe}$, the only structurally characterized trialkylselenostiborane, represents the shortest Sb-Se bond observed, to date. The bond is significantly shorter than the calculated value for a respective $\mathrm{Sb}-\mathrm{Se}$ single bond $\left(\sum_{\mathrm{cov}}(\mathrm{Sb}, \mathrm{Se})\right.$ $=2.56 \AA)^{[59]}$ and agrees perfectly with the calculated value of a $\mathrm{Sb}=\mathrm{Se}$ double bond $\left(\sum_{\operatorname{cov}}(\mathrm{Sb}, \mathrm{Se})=2.40 \AA\right)$, respectively. ${ }^{[17]} \mathrm{Sb}(\mathrm{III})-\mathrm{Se}$ compounds such as (MeSe $)_{3} \mathrm{Sb}(2.568(1)$ $-2.588(1) \AA)^{[80]}$ as well as mixed-valent selenidoantimonates(III,V) polyanions such as $\left[\mathrm{Sb}_{4} \mathrm{Se}_{9}\right]^{4-}(2.4232(9)-2.5154(9) \AA)^{[118]}$ show also longer Sb-Se bond lengths. Based on the structural data available, the presence of a $\mathrm{Sb}=\mathrm{E}$ double bond in $\mathrm{Et}_{3} \mathrm{SbSe}$ was reliable.

$\mathrm{Et}_{3} \mathrm{SbS}$ and $\mathrm{Et}_{3} \mathrm{SbSe}$ do not show any intermolecular $\mathrm{Sb} \cdots \mathrm{E}$ close contacts. Even though both molecules are almost perfectly linearly packed in the crystal as is shown in figure 20 exemplarily for $\mathrm{Et}_{3} \mathrm{SbSe}$, the intermolecular $\mathrm{Sb} \cdots \mathrm{S}(3.955(6) \AA)$ and $\mathrm{Sb} \cdots \mathrm{Se}$ bond distances (4.1227(10) $\AA)$ clearly exceed the sum of the van-der-Waals $\operatorname{radii}\left(\sum_{\mathrm{vdW}}(\mathrm{Sb}, \mathrm{E})=3.86(\mathrm{E}=\mathrm{S})\right.$, $3.96 \AA(\mathrm{E}=\mathrm{Se})) \cdot{ }^{[3]}$ 
Table 6. Bond lengths $(\AA)$ and angles $\left(^{\circ}\right)$ of thio- and selenostiboranes

$\begin{array}{llll} & \text { Ph}_{3} \mathbf{S b S}^{[31]} & \mathbf{E t}_{3} \mathbf{S b S}^{[116]} & \mathbf{E t}_{3} \mathbf{S b S e}^{[116]} \\ \mathrm{Sb}-\mathrm{E}[\AA] & 2.244(1) & 2.381(7) & 2.4062(8) \\ \mathrm{Sb}-\mathrm{C}[\AA] & \text { av. } 209.8(3) & 2.130(13) & 2.142(4) \\ \text { av. } 4 \mathrm{C}-\mathrm{Sb}-\mathrm{C}\left[^{\circ}\right] & 106.4(1) & 107.8(5) & 106.58(14) \\ \text { av. } 4 \mathrm{C}-\mathrm{Sb}-\mathrm{E}\left[^{\circ}\right] & 112.4(1) & 111.1(5) & 112.23(13)\end{array}$

The bonding situation in $\mathrm{Et}_{3} \mathrm{SbS}$ and $\mathrm{Et}_{3} \mathrm{SbSe}$ was further investigated using quantum chemical calculations. Geometry optimizations gave a Sb-S bond length of $2.257 \AA$, notably shorter than the value observed in the crystal structure, and a Sb-Se bond length of $2.393 \AA$, which agrees almost perfectly (within $0.02 \AA$ ) with the solid state structure. In order to get an idea of the packing effects within the linear chains of $\mathrm{Et}_{3} \mathrm{SbS}$ and $\mathrm{Et}_{3} \mathrm{SbSe}$, geometry optimizations of linear aggregates of three monomers with $C_{3}$ symmetry constraints were performed. The bond lengths of the central monomer (Sb-S 2.270 $\AA$; Sb-Se $2.406 \AA$ ) change only slightly with respect to the gas phase monomers. The intermolecular $\mathrm{Sb} \cdots \mathrm{S}$ distance involving the $\mathrm{Sb}$ atom of the central monomer was calculated as $4.051 \AA$, that involving the $\mathrm{S}$ atom of the central monomer as $4.093 \AA$. They deviate by less than $0.14 \AA$ from the crystal structure value of $\mathrm{Et}_{3} \mathrm{SbS}$. The corresponding Sb ${ }^{\cdots}$ Se intermolecular distances $(4.219,4.255$ $\AA$ ) also deviate by less than $0.14 \AA$ from the crystal structure value of Et 3 SbSe. According to natural population analyses (NPA) the sulfur atom in the monomeric structure of $\mathrm{Et}_{3} \mathrm{SbS}$ bears a charge of $-0.73 \mathrm{e}$ and the $\mathrm{Sb}$ atom one of $+1.53 \mathrm{e}$, which even increase for the central molecule in the trimeric aggregate ( $\mathrm{S}:-0.83 \mathrm{e} ; \mathrm{Sb}: 1.57 \mathrm{e})$. The partial charges on $\mathrm{Se}$ for the monomeric structure (S: $-0.64 \mathrm{e} ; \mathrm{Sb}:+1.43 \mathrm{e}$ ) as well as for central monomer in the trimeric structire ( $\mathrm{S}:-0.74 \mathrm{e} ; \mathrm{Sb}:+1.48 \mathrm{e}$ ) in $\mathrm{Et}_{3} \mathrm{Sb}=\mathrm{Se}$ are slightly smaller. Obviously, the bond polarity decreases with an increasing chalcogen atomic number as was observed before. ${ }^{[25,119]}$ Natural bond orbital (NBO) analysis of $\mathrm{Et}_{3} \mathrm{SbS}$ and $\mathrm{Et}_{3} \mathrm{SbSe}$ suggests the presence of three lone pair orbitals on the chalcogen atoms, from which one consists of the valence shell $\mathrm{s}$ orbital $\left(\mathrm{Et}_{3} \mathrm{Sb}=\mathrm{S}: 89 \%\right.$; $\left.\mathrm{Et}_{3} \mathrm{Sb}=\mathrm{Se}: 92 \%\right)$ and the remaining two are pure valence shell $\mathrm{p}$ orbitals. These are orthogonally oriented to the Sb-E bond, thus precluding the existence of a Sb-E double bond in both cases. The remaining $\mathrm{p}$ orbital is involved in a single covalent bond between $\mathrm{Sb}$ and $\mathrm{E}$. A glance at the canonical molecular orbitals confirms this picture: the degenerate HOMO/HOMO-1 pair is strongly localized on the E atom, while HOMO-20 mainly consists of a deformed s orbital on E (Fig. 21). Electron localization function (ELF) also didn't support the presence of any double bond character in the Sb-E bonds, hence the 
ylide form with one covalent and one ionic bond (cf. scheme 6) is the dominant mesomeric structure in both compounds and the short $\mathrm{Sb}-\mathrm{Se}$ bond results from the strong ionic contribution to the overall bond.

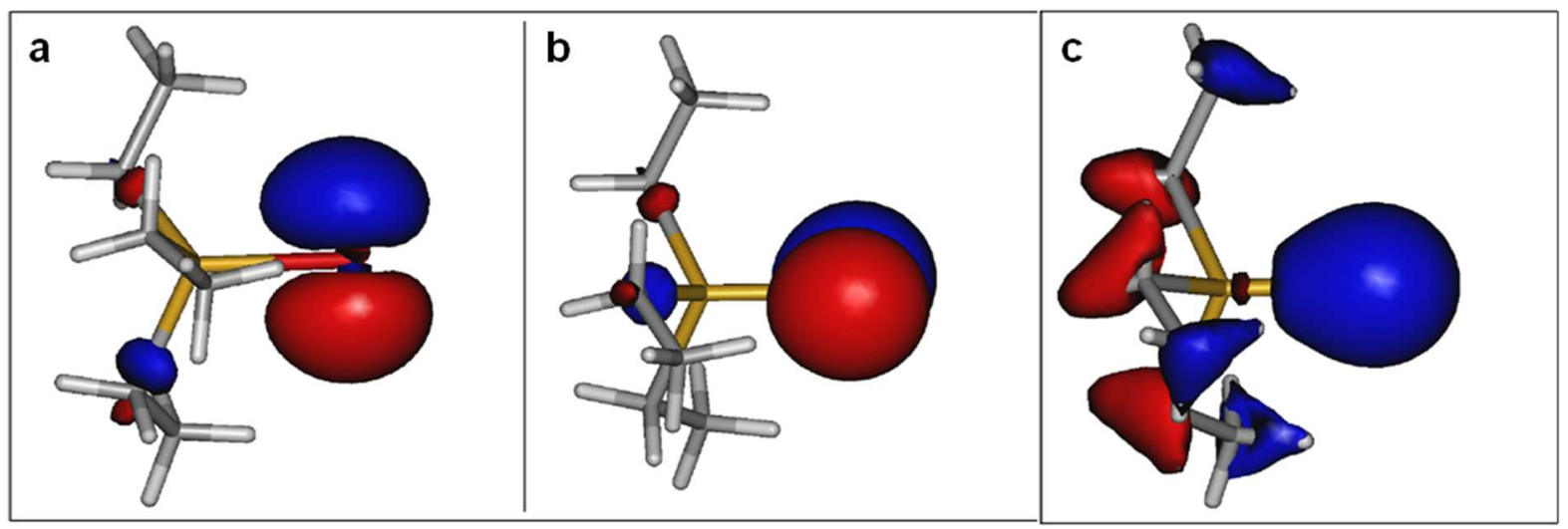

Figure 21. HOMO (a), HOMO-1 (b) and HOMO-20 (c) of Et $3 \mathrm{SbSe}^{[116]}$

\subsection{Synthesis and Solid State Structures of intramolecular-stabilized RSbE (E=S, Se, Te)}

Compounds of the type $\mathrm{RME}(\mathrm{M}=\mathrm{Sb}, \mathrm{Bi} ; \mathrm{E}=\mathrm{S}, \mathrm{Se}, \mathrm{Te})$ containing the group 15 element in the formal oxidation state III typically form chalcogen-bridged dimers $[\mathrm{RM}-\mu-\mathrm{E}]_{2}$ in the solid state. ${ }^{[13,120,121,122,123,124,125,126]}$ In contrast, compounds containing a terminal M-E bond are still very rare $(\mathrm{M}=\mathrm{Sb})$ or even completely unknown $(\mathrm{M}=\mathrm{Bi})$. Breunig et al. suggested the presence of a terminal $\mathrm{Sb}-\mathrm{Se}$ double bond in the tungsten complex $\left[\left(\mathrm{Me}_{3} \mathrm{Si}\right)_{2} \mathrm{CHSbW}(\mathrm{CO})_{5}-\mu-\right.$ $\mathrm{Se}]_{2}$ in benzene solution, but this compound was later shown to be dimeric in the solid state with a central $\mathrm{Sb}_{2} \mathrm{Se}_{2}$ core. ${ }^{[63]}$ Comparable findings were observed for the corresponding dimeric sulfide complex $\left[\left(\mathrm{Me}_{3} \mathrm{Si}\right)_{2} \mathrm{CHSbW}(\mathrm{CO})_{5}-\mu-\mathrm{S}\right]_{2} \cdot\left[{ }^{127}\right]$ Aside from these four-membered rings, Tokitoh et al. reported on the structures of a very few selena- and telluradibismiranes. ${ }^{[62,128]}$

Very recently, Dostál et al. firstly succeeded in the stabilization of monomeric antimony(III) chalcogenides of the general type $\operatorname{ArSbE}(\mathrm{E}=\mathrm{S}, \mathrm{Se})$ containing a terminal Sb-E bond. The introduction of specific N,C,N-pincer-type ligands containing either amine or imine donor sides was found to be essential. ${ }^{[25,26]}$ The new compounds were obtained by reaction of the monovalent organoantimony(I) compound $\mathrm{Ar}_{4} \mathrm{Sb}_{4}\left(\mathrm{Ar}=\mathrm{C}_{6} \mathrm{H}_{3}-2,6-\left(\mathrm{CH}_{2} \mathrm{NMe}_{2}\right)_{2}\right)$ ) with elemental chalcogens, which occurred with oxidation of the $\mathrm{Sb}(\mathrm{I})$ centers and breakage of the $\mathrm{Sb}-\mathrm{Sb}$ bond and subsequent formation of monomeric compounds $\mathrm{ArSbE}(\mathrm{E}=\mathrm{Se}, \mathrm{Te})$ as shown in scheme 7. 

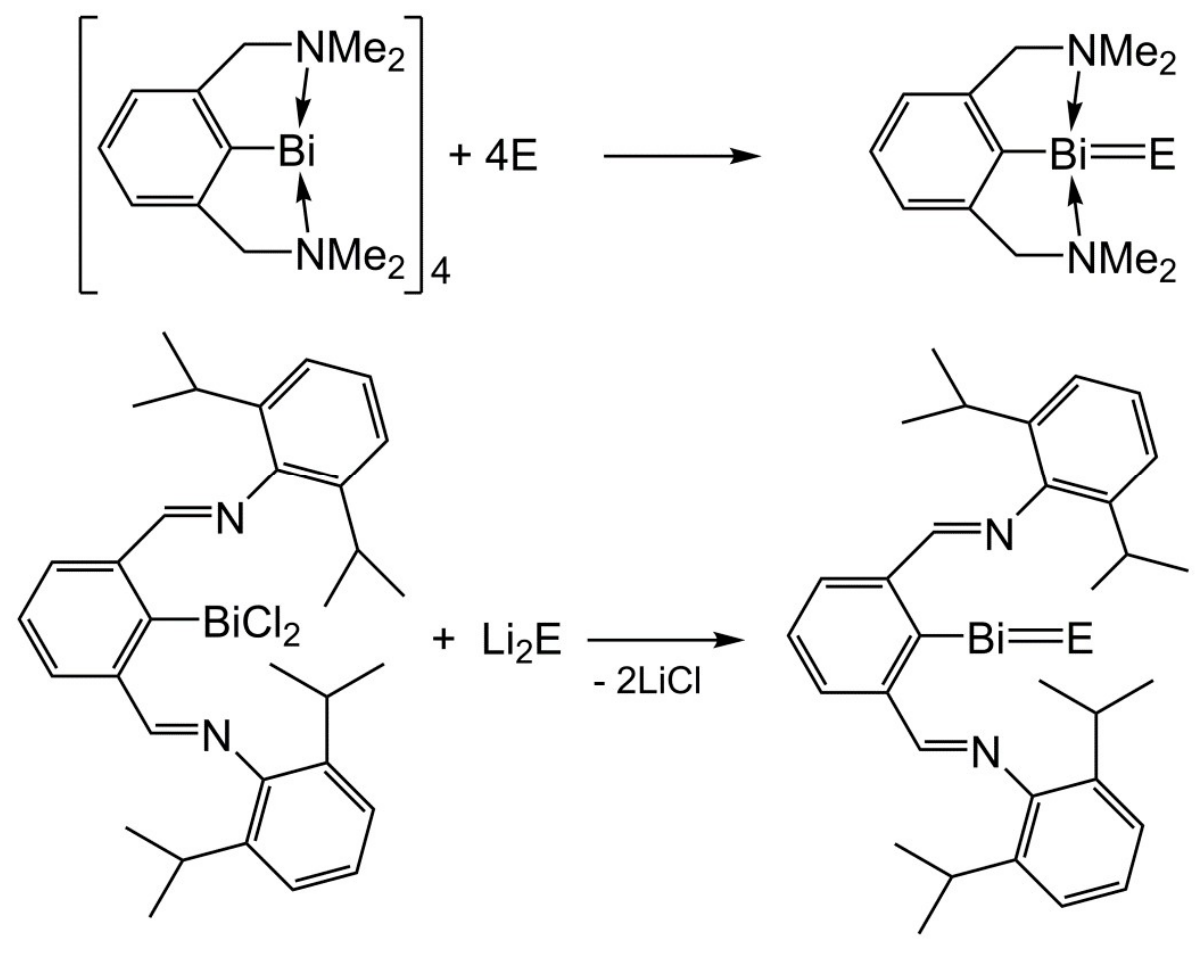

Scheme 7. Synthesis of compounds RME containing terminal M-E bonds.

In contrast, the analogous reaction with sulfur yielded a dimeric sulfide (ArSbS) 2 containing a $\mathrm{Sb}_{2} \mathrm{~S}_{2}$ core. ${ }^{[26]}$ A slight modification of the pincer-type ligand gave also access to monomeric organoantimony sulfides and selenides $\operatorname{Ar} \operatorname{SbE}\left(\mathrm{E}=\mathrm{S}, \mathrm{Se}, \mathrm{Ar}^{\prime}=2,6-\mathrm{bis}\left[\mathrm{N}-\left(2^{\prime}, 6^{\prime}-\right.\right.\right.$ dimethylphenyl)ketimino]phenyl), which were synthesized by reaction of $\mathrm{Ar}^{\prime} \mathrm{SbCl}_{2}$ with in situ prepared $\mathrm{Li}_{2} \mathrm{~S}$ and $\mathrm{Li}_{2} \mathrm{Se}$, respectively. ${ }^{[25]}$

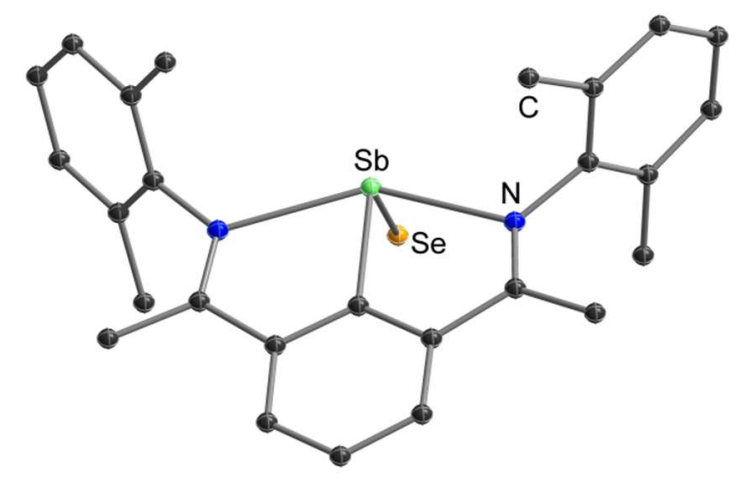

Figure 22. Solid state structure of Ar'SbSe $\left(\operatorname{Ar}^{\prime}=2,6-b i s\left[N-\left(2^{\prime}, 6^{\prime}-\right.\right.\right.$ dimethylphenyl)ketimino]phenyl). ${ }^{[25]}$ 


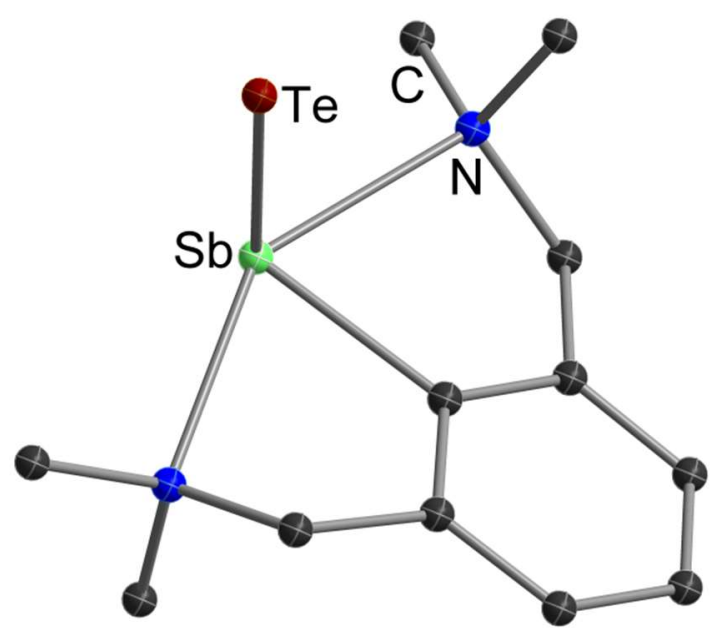

Figure 23. Solid state structure of $\left.\mathrm{ArSbTe}\left(\mathrm{Ar}=\mathrm{C}_{6} \mathrm{H}_{3}-2,6-\left(\mathrm{CH}_{2} \mathrm{NMe}_{2}\right)_{2}\right)\right)$. ${ }^{[26]}$

The compounds are monomeric in solution, as was shown by ${ }^{1} \mathrm{H}$ NMR spectroscopy, and in the solid state, and don't exhibit any short intermolecular contacts (Figs. 22, 23). The Sb-S bond length of Ar'SbS (2.2929(17) $\AA$ ) is significantly shorter than those reported for dimeric antimony sulfides of the type $(\operatorname{ArSbS})_{2}(2.4875(10), 2.4790(11) \AA) \cdot{ }^{[120,129,130]}$ The almost identical Sb-Se bond lengths in $\operatorname{Ar} \operatorname{SbSe}(2.4329(5) \AA)$ and $\mathrm{ArSb}=\mathrm{Se}(2.4396(7) \AA)$ as well as the $\mathrm{Sb}-\mathrm{Te}$ in ArSbTe bond distance are slightly shorter than those reported for selena- and telluradistiborane containing three-membered $\mathrm{Sb}_{2} \mathrm{E}$ rings $(\mathrm{E}=\mathrm{Se}, \mathrm{Te})^{[123,124,131]}$ and for $\mathrm{Et}_{3} \mathrm{SbSe}(2.4062(8)) .{ }^{[116]}$ Moreover, the Sb-E bonds in the monomeric compounds ArSbE (E $=\mathrm{Se}, \mathrm{Te})$ and $\operatorname{Ar}{ }^{\prime} \mathrm{SbE}(\mathrm{E}=\mathrm{S}, \mathrm{Se})$ are significantly shorter than the calculated Sb-E single bond values $\left(\sum_{\operatorname{cov}}(\mathrm{Sb}, \mathrm{E}) 2.43 \AA(\mathrm{E}=\mathrm{S}), 2.56 \AA(\mathrm{E}=\mathrm{Se}), 2.93 \AA(\mathrm{E}=\mathrm{Te})\right),{ }^{[59]}$ but are only slightly enlarged compared to the calculated value of a $\mathrm{Sb}=\mathrm{E}$ double bond $\left(\sum_{\mathrm{cov}}(\mathrm{Sb}, \mathrm{E}) 2.27\right.$ $\AA(\mathrm{E}=\mathrm{S}), 2.40 \AA(\mathrm{E}=\mathrm{Se}), 2.61 \AA(\mathrm{E}=\mathrm{Te})) \cdot{ }^{[117]}$ These structural findings point to either a high double-bonding character or a highly polarized single bond within these compounds.

Table 7. Selected structural parameters of the studied compounds (bond lengths $[\AA]$ and bonding angles $\left.\left[{ }^{\circ}\right]\right)$

\begin{tabular}{lllll}
\hline Compound & Sb-N & N-Sb-N & Sb-E & Ref. \\
\hline $\mathrm{Ar} ' \mathrm{Sb}=\mathrm{S}$ & $2.415(5), 2.416(4)$ & $144.55(16)$ & $2.2929(17) ; 2.292^{\mathrm{a}}$ & {$[25]$} \\
$\mathrm{Ar}{ }^{\prime} \mathrm{Sb}=\mathrm{Se}$ & $2.395(2), 2.393(2)$ & $145.01(8)$ & $2.4329(5) ; 2.437^{\mathrm{a}}$ & {$[25]$} \\
$\mathrm{ArSb}=\mathrm{Se}$ & $2.461(2), 2.518(3)$ & $145.14(12)$ & $2.4396(7) ; 2.430^{\mathrm{a}}$ & {$[25]$} \\
$\mathrm{ArSb}=\mathrm{Te}$ & $2.448(5), 2.526(5)$ & $145.70(18)$ & $2.6620(1) ; 2.639^{\mathrm{a}}$ & {$[26]$} \\
$(\mathrm{ArSbS})_{2}$ & $2.761(3), 2.756(3)$ & $115.39(10)$ & $2.4875(10) ; 2.4790(11)$ & {$[26]$} \\
$\mathrm{PhSbS}$ & - & - & $2.246^{\mathrm{a}}$ & {$[25]$}
\end{tabular}




\begin{tabular}{lllll}
\hline Compound & Sb-N & N-Sb-N & Sb-E & Ref. \\
\hline PhSbSe & - & - & $2.378^{\mathrm{a}}$ & {$[25]$} \\
$\mathrm{PhSbTe}$ & - & - & $2.577^{\mathrm{a}}$ & {$[25]$} \\
\hline
\end{tabular}

${ }^{a}$ Calculated value of terminal Sb-E bond length; $\mathrm{Ar}=\mathrm{C}_{6} \mathrm{H}_{3}-2,6-\left(\mathrm{CH}_{2} \mathrm{NMe}_{2}\right)_{2}, \mathrm{Ar}{ }^{\prime}=2,6-$ bis[N-(2',6'-dimethylphenyl)ketimino]phenyl.

The bonding situation of $\operatorname{ArSbE}(\mathrm{E}=\mathrm{Se}, \mathrm{Te})$ and $\operatorname{Ar} \operatorname{SbE}(\mathrm{E}=\mathrm{S}, \mathrm{Se})$ was also studied using quantum chemical calculations to gain a deeper understanding on the nature of the M-E bond in these type of compounds. Geometry optimizations gave $\mathrm{Sb}-\mathrm{S}$ (2.292 Ar'Sb=S), Sb-Se (2.437 $\mathrm{Ar}$ 'Sb=Se; $2.430 \AA \mathrm{ArSb}=\mathrm{Se}$ ) and $\mathrm{Sb}-\mathrm{Te}$ bond lengths $(2.639 \AA \mathrm{ArSb}=\mathrm{Te})$, which agree well with the experimental findings (Table 7). The molecular orbitals describing the $\mathrm{Sb}-\mathrm{Se}(\mathrm{ArSbSe})$ and $\mathrm{Sb}-\mathrm{Te}(\mathrm{ArSbTe})$ terminal bonds are directly below the highest occupied molecular orbital, and the electron density distribution shows $\pi$ symmetry in these bonds. NBO analysis yielded positive charges on the central $\mathrm{Sb}$ atom $(+1.170 \mathrm{Ar}$ 'SbS, +1.070 Ar'SbSe, +0.999 ArSbSe, +0.854 ArSbTe) and negative charges on S (-0.878 Ar'SbS), Se (-0.777 Ar'SbSe, -0.788 ArSbSe) and Te (-0.658 ArSbTe), respectively, indicating a high polarity of the respective $\mathrm{Sb}-\mathrm{E}$ bonds. The polarity decreases with increasing atomic number of the chalcogen atom as was expected. Moreover, a back-donation of the chalcogen electron lone-pair orbitals in ArSbSe and ArSbTe (Se contains 1.738 electrons; Te contain 1.727 electrons) into the empty $\mathrm{Sb}$ orbital (electron lone p orbital on $\mathrm{Sb}$ contains 0.513 (ArSbSe) and 0.531 (ArSbTe)) points to substantial double bonding character. Wiberg bond orders for the Sb-E bonds (1.305 Ar'SbS, 1.316 Ar'SbSe, 1.4099 ArSbSe, 1.426 ArSbTe), which are in between the expected values for perfectly covalent single (1) and double bonds (2), slightly increase with increasing atomic number of the chalcogen atom, pointing to a slightly decreasing bond polarity. ${ }^{[119]}$ These results imply that the M-E bonds between Sb on one hand and Se or Te on the other hand lie in between a single and a double bond. From this analysis, it can thus be concluded that the nature of the bonding between $\mathrm{Sb}$ and the chalcogen atoms ( $\mathrm{Se}, \mathrm{Te}$ ) can be described as intermediate between a polarized single bond and a double bond. According to these computational calculations, the terminal Sb-E bonds show a high polar bonding character, $\mathrm{Sb}^{\delta+}-\mathrm{E}^{\delta^{-}}(\mathrm{E}=\mathrm{Se}, \mathrm{Te})$, resulting from the donation of electron density from the $\mathrm{N}$ atoms to the $\mathrm{Sb}$ atom, and the $\mathrm{Sb}$-E bonds are best described as having appreciable double-bond character, although the electron density is strongly polarized in the chalcogen atom direction as would be expected due to the rather large electronegativity differences. 
A hypothetical set of molecules, $\operatorname{PhSbE}(E=\mathrm{S}, \mathrm{Se}, \mathrm{Te})$, was also included in the computational studies. They exhibit generally shorter Sb-E bond lengths $(2.246 \AA(\mathrm{E}=\mathrm{S})$, $2.378 \AA(\mathrm{E}=\mathrm{Se})$ and $2.577 \AA(\mathrm{E}=\mathrm{Te}))$ compared to those observed in $\mathrm{ArSbE}(\mathrm{E}=\mathrm{Se}, \mathrm{Te})$ and $\operatorname{Ar} \operatorname{SbE}(\mathrm{E}=\mathrm{S}, \mathrm{Se})$ and show a lower $\mathrm{Sb}-\mathrm{E}$ bond polarity and higher $\mathrm{Sb}-\mathrm{E}$ bond orders. The $\mathrm{Sb}$ atom charge was found to steadily decrease [S +1.036 , $\mathrm{Se}+0.906$, $\mathrm{Te}+0.721]$, while the negative charge on the chalcogen atoms steadily decreases $[\mathrm{S}-0.647, \mathrm{Se}-0.518, \mathrm{Te}$ $-0.343]$. The bond orders increase from $1.757(\mathrm{~S})$ over $1.830(\mathrm{Se})$ to $1.902(\mathrm{Te})$. Form these results it becomes clear, that aditional donor sites, which are neccessary for the kinetic stabilization of the molecules, are somewhat contraindicative for the formation of $\mathrm{M}=\mathrm{E}$ double bonds.

\subsection{Synthesis and Solid State Structures of Donor-Acceptor Compounds of heavy Group 15}

\section{/ 16 Elements}

Aside from neutral compounds as described before, cationic species containing group 15-16 dative bonds have also been investigated. Stibenium $\left(\mathrm{R}_{2} \mathrm{Sb}^{+}\right)$and bismuthenium ions $\left(\mathrm{R}_{2} \mathrm{Bi}^{+}\right)$, which are six-valence-electron species such as silylenes $\left(\mathrm{R}_{2} \mathrm{Si}\right)$ or N-heterocyclic carbenes (NHCs), have a vacant $\mathrm{p}$ orbital and one electron lone pair, hence are able to react as Lewis acid and base as was initially shown in homoleptic ([ $\left.\left.\mathrm{Me}_{2} \mathrm{Sb}\left(\mathrm{SbMe}_{3}\right)\right] \mathrm{MeSbBr}_{3},{ }^{[132]}\right)$ and heteroleptic 1:1 complexes of the type $\left[\mathrm{Ph}_{2} \mathrm{E}\left(\mathrm{PPh}_{3}\right)\right] \mathrm{PF}_{6}(\mathrm{E}=\mathrm{As}, \mathrm{Sb}, \mathrm{Bi}) .{ }^{[133,134,135,136]} \mathrm{In}$ addition, 1:2 complexes such as $\left[\mathrm{Ph}_{2} \mathrm{E}\left(\mathrm{PPh}_{3}\right)_{2}\right] \mathrm{PF}_{6}(\mathrm{E}=\mathrm{Sb}, \mathrm{Bi})$ were synthesized for the heavier pnictogens. ${ }^{[133,134,135,136]}$

Tellurenyl ions $\left(\mathrm{RTe}^{+}\right)$, which are similar to these compounds since they are also unsaturated six-valence-electron species with one vacant $\mathrm{p}$ orbital as well as two electron lone pairs, have been obtained as intramolecular $\sigma$-donor-stabilized complexes. For instance, di- and trinuclear tellurium compounds $\left[\mathrm{MesTe}\left(\mathrm{TeMes}_{2}\right)_{n}\right] \mathrm{SbF}_{6}(n=1,2)$, in which the mesityltellurenyl cation $\left(\mathrm{MesTe}^{+}\right)$is coordinated by the Lewis base Mes2 Te (Mes $\left.=2,4,6-\mathrm{Me}_{3} \mathrm{C}_{6} \mathrm{H}_{2}\right)$, as well as mesityltellurenyl cations stabilized by trialkylphosphine selenides [MesTe(SeP- $t$-Bu $\mathrm{Bu}_{2}-i$ $\left.\operatorname{Pr})_{n}\right] \mathrm{SbF}_{6}(n=1,2)$ were synthesized, but no structural information was given. ${ }^{[137,138]}$ Very recently, Beckmann et al. reported on a synthesis of a series of archetypical $\sigma$-donor-stabilized complexes of the types $\left[\mathrm{MesTe}\left(\mathrm{EPh}_{3}\right)\right] \mathrm{O}_{3} \mathrm{SCF}_{3}(\mathrm{E}=\mathrm{P}, \mathrm{As})$ and $\left[\mathrm{MesTe}\left(\mathrm{SbPh}_{3}\right)\right]\left[\mathrm{Ph}_{2} \mathrm{Bi}\left(\mathrm{O}_{3} \mathrm{SCF}_{3}\right)_{2}\right]$, which were obtained from the reactions of $\left[\mathrm{MesTe}\left(\mathrm{TeMes}_{2}\right)\right] \mathrm{O}_{3} \mathrm{SCF}_{3}$ with $\mathrm{Ph}_{3} \mathrm{E}^{[139]}\left[\mathrm{MesTe}\left(\mathrm{SbPh}_{3}\right)\right]\left[\mathrm{Ph}_{2} \mathrm{Bi}\left(\mathrm{O}_{3} \mathrm{SCF}_{3}\right)_{2}\right]$ was also obtained from the one-pot reaction of $\mathrm{Mes}_{2} \mathrm{Te}, \mathrm{Ph}_{3} \mathrm{Sb}$, and $\mathrm{HO}_{3} \mathrm{SCF}_{3}$. Single crystal X-ray diffraction 
studies revealed the ionic nature of these compounds, each containing the triphenylpnicogenstabilized tellurenyl cations $\left[\mathrm{MesTe}\left(\mathrm{EPh}_{3}\right)\right]^{+}(\mathrm{E}=\mathrm{P}, \mathrm{As}, \mathrm{Sb})$.

The cations $\left[\mathrm{MesTe}\left(\mathrm{EPh}_{3}\right)\right]^{+}$exhibit $\mathrm{T}$-shaped structures with $\mathrm{C}-\mathrm{Te}-\mathrm{E}$ bond angles of 91.29(9) $\left(\left[\mathrm{MesTe}\left(\mathrm{PPh}_{3}\right)\right]^{+}\right)$and $92.10(6)^{\circ}\left(\left[\mathrm{MesTe}\left(\mathrm{AsPh}_{3}\right)\right]^{+}\right)$. The Te-E bond lengths $\left(2.467(1) \AA\left[\mathrm{MesTe}\left(\mathrm{PPh}_{3}\right)\right]^{+} ; 2.5799(6) \AA\left[\mathrm{MesTe}\left(\mathrm{AsPh}_{3}\right)\right]^{+} ; 2.708(1) \AA\left[\mathrm{MesTe}\left(\mathrm{SbPh}_{3}\right)\right]^{+}\right)$ are close to the sum of covalent radii $(2.45 \AA, E=P ; 2.57 \AA, E=A s ; 2.77 \AA, E=S b) .{ }^{[140]}$ The cation [MesTe $\left.\left(\mathrm{SbPh}_{3}\right)\right]^{+}$interacts in the trans position with the $\pi$ system of the mesityl group of an adjacent cation $\left[\mathrm{MesTe}\left(\mathrm{SbPh}_{3}\right)\right]^{+}$as was observed for $\left[\mathrm{Cl}_{2} \mathrm{Bi}\left(\mathrm{SbPh}_{3}\right)\right] \mathrm{AlCl}_{4} \cdot$ toluene, in which the toluene molecule coordinates to the $\mathrm{Bi}$ atom in the trans position of $\mathrm{Ph}_{3} \mathrm{Sb}$ (Fig. 24). ${ }^{[141]}$

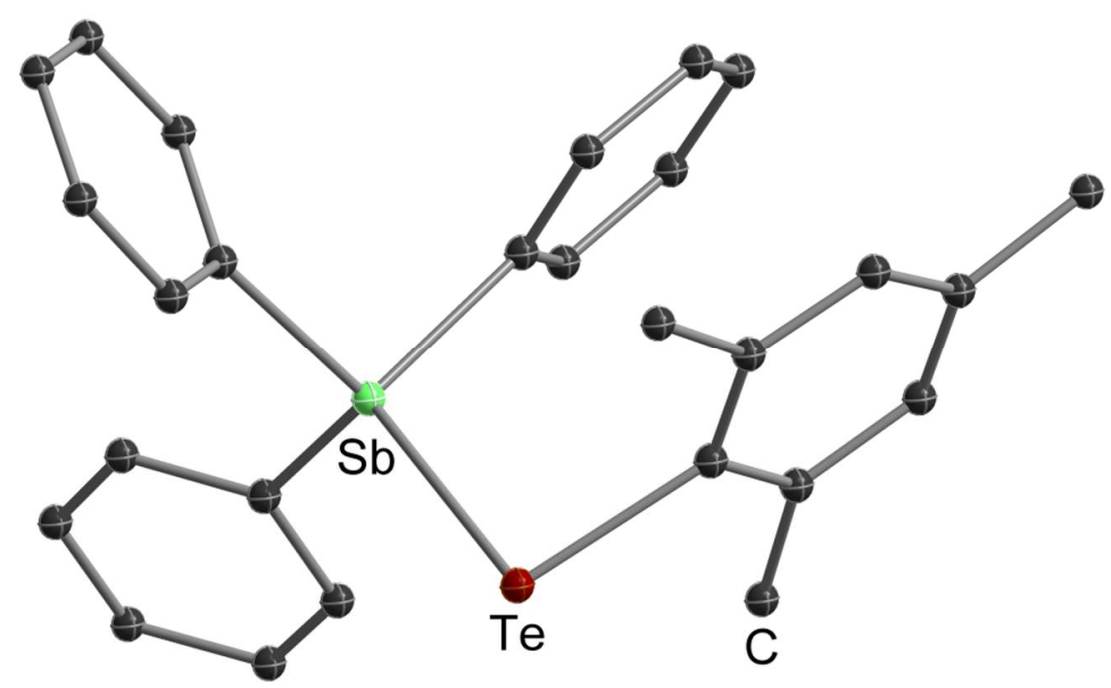

Figure 24. Solid state structure of the cation [MesTe-SbPh 3$]^{+}$. 139$]$

According to DFT calculations, $\left[\mathrm{MesTe}\left(\mathrm{EPh}_{3}\right)\right]^{+}(\mathrm{E}=\mathrm{P}, \mathrm{As}, \mathrm{Sb})$ contain polar covalent Te-E bonds, in which the bond dissociation energies of the cations increases in the order $\left[\operatorname{MesTe}\left(\mathrm{SbPh}_{3}\right)\right]^{+}\left(289.3 \mathrm{~kJ} \mathrm{~mol}^{-1}\right)<\left[\operatorname{MesTe}\left(\mathrm{AsPh}_{3}\right)\right]^{+}\left(303.4 \mathrm{~kJ} \mathrm{~mol}^{-1}\right)<\left[\operatorname{MesTe}\left(\mathrm{PPh}_{3}\right)\right]^{+}$ $\left(322.6 \mathrm{~kJ} \mathrm{~mol}^{-1}\right)$. The highest occupied molecular orbital $(\mathrm{HOMO})$ in $\left[\mathrm{MesTe}\left(\mathrm{EPh}_{3}\right)\right]^{+}(\mathrm{E}=\mathrm{P}$, $\mathrm{As}, \mathrm{Sb})$ is a p-type electron lone pair at the Te cation and the lowest unoccupied molecular orbital is an antibonding combination of $\mathrm{p}$ orbitals at the donor atoms $\mathrm{E}$ and the acceptor atom Te. A number of MOs indicating the binding character of the Te-E bond was observed rather than a single MO for the Te-E bond. The $\rho\left(r_{\mathrm{bcp}}\right)$ values of all Te-E bonds show a trend of decreasing density, which is essentially related to the increasing bond lengths. Upon complex formation, all $\mathrm{E}-\mathrm{C}(\mathrm{E}=\mathrm{P}, \mathrm{As}, \mathrm{Sb})$ and $\mathrm{Te}-\mathrm{C}$ bonds become shorter, thus leading to higher $\rho\left(r_{\mathrm{bcp}}\right)$ values. The large bond ellipticities of the Te-E bonds $(0.21-0.25)$ reflect their diffuse and delocalized nature. In terms of AIM partitioning, the positive charge of the free 
mesityltellurenyl cation is to $61 \%$ located at the Te atom. Upon complex formation, $0.67-0.83$ e are transferred from $\mathrm{Ph}_{3} \mathrm{E}(\mathrm{E}=\mathrm{P}, \mathrm{As}, \mathrm{Sb})$ to the mesityltellurenyl cation, resulting in a less positive Te atom of the cation and a slightly negative mesityl group, while the donor atoms (E $=\mathrm{P}, \mathrm{As}, \mathrm{Sb}$ ) become more positively charged due to the electron loss, which leads to a strong charge polarization between the Te atom of the cation and the donating pnictogen atoms, resulting in the formation of polar covalent Te-E bonds. Therefore, the complexes are best described as phosponium $\left[\mathrm{MesTe}\left(\mathrm{PPh}_{3}\right)\right]^{+}$, arsonium $\left[\mathrm{MesTe}\left(\mathrm{AsPh}_{3}\right)\right]^{+}$, and stibonium cations $\left[\mathrm{MesTe}\left(\mathrm{SbPh}_{3}\right)\right]^{+}$.

\section{Application in Material Sciences}

The use of single-source precursors for the synthesis of nanostructured $\mathrm{M}_{2} \mathrm{E}_{3}$ material films is still very much unexplored and only a few reports are available, to date. ${ }^{[46,47,48,49,50]}$ This is rather disappointing since binary and ternary group $15 / 16$ chalcogenides of the type $\mathrm{M}_{2} \mathrm{E}_{3}(\mathrm{M}$ $=\mathrm{Sb}, \mathrm{Bi} ; \mathrm{E}=\mathrm{S}, \mathrm{Se}, \mathrm{Te}$ ) with tetradymite structure are of high interest in technical applications such as sensitized solar cells (SSCs), ferroelectric phase transition materials, battery materials as well as photovoltaic materials. Moreover, they belong to the most powerful topological insulators as well as thermoelectric materials. ${ }^{[142,143]}$

Thermoelectric materials allow the interchange of thermal energy and electricity for the utilization of waste heat and for cooling. The figure of merit zT of a thermoelectric material is defined as $z T=S^{2} \sigma \mathrm{T} / \kappa$, where $\mathrm{S}$ is the Seebeck coefficient, $\sigma$ the electrical conductivity, $\kappa$ the thermal conductivity, and $\mathrm{T}$ the temperature in Kelvin, respectively. Efficient thermoelectric materials need high Seebeck coefficient (S) and electrical conductivity $(\sigma)$, whereas the thermal conductivity $(\kappa)$ should be as low as possible. Unfortunately, these central parameters are not independent from each other, since the Seebeck coefficient (S) decreases with increasing carrier density, whereas the electrical conductivity $(\sigma)$ and thermal conductivity $(\kappa)$ both increase with increasing carrier density. State-of-the-art bulk thermoelectric materials used in devices have a zT $\approx 1,{ }^{[144,145]}$ while it is assumed that $z T \cong 1.5$ is necessary for future technical applications. ${ }^{[146]}$ Although many promising thermoelectric materials have been discovered in recent years, antimony and bismuth chalcogenide-based materials are still the most widely used.

Nanostructuring is a promising approach for realizing a high thermoelectric figure of merit zT since the thermal and electrical conductivity can be decoupled due to the different lengths scales of the mean free path of electrons and phonons. ${ }^{[147]}$ In addition, the figure of merit zT 
of the binary materials can be increased by doping of the material with additional group 16 elements as was demonstrated for sulfur-doped $\mathrm{Bi}_{2} \mathrm{Te}_{3}$, quarternary $(\mathrm{Sb}, \mathrm{Bi})_{2}(\mathrm{Se}, \mathrm{Te})_{3}$ nanocrystals and others $\mathrm{M}_{2} \mathrm{E}_{3}$ materials. ${ }^{[148,149,150,151,152]}$ In addition, nanostructured $\mathrm{Bi}_{2} \mathrm{Te}_{3} / \mathrm{Bi}_{2} \mathrm{~S}_{3}$ and $\mathrm{Bi}_{2} \mathrm{Te}_{3} / \mathrm{Bi}_{2} \mathrm{Se}_{3}$ heterocomposites showed improved thermoelectric properties. ${ }^{[153,154]}$ Bottom-up chemistry approaches, including those using molecular single source precursors, offer the possibility for generating property-defined phase separation of multicomponents on multiple length scales as well as the simultaneous generation of two different nanomaterials in order to create bulk thermoelectric materials. Due to these promising properties, they have received increasing interest in recent years. ${ }^{[155,156,157]}$

\subsection{Synthesis of Binary Nanomaterials $\mathrm{Sb}_{2} E_{3}(E=S, S e, T e)$ in Solution}

Several synthetic pathways have been established over the years for the generation of binary $\mathrm{Sb}_{2} \mathrm{E}_{3}$ and $\mathrm{Bi}_{2} \mathrm{E}_{3}(\mathrm{E}=\mathrm{S}, \mathrm{Se}, \mathrm{Te})$ nanoparticles such as polyol processes, ${ }^{[158]}$ solvothermal routes, ${ }^{[149,159,160,161,162,163]}$ glucose-assisted reduction routes, ${ }^{[164]}$ and gas-induced reduction routes. ${ }^{[165]}$ These general approaches have in common, that they typically use two different precursors as group 15 and group 16 element source. In contrast, the use of tailor-made single-source precursors, in which the desired group 15 and group 16 elements are connected by a stable chemical bond and the material composition is ideally pre-formed on the molecular level, for the synthesis of nanostructured $\mathrm{M}_{2} \mathrm{E}_{3}$ materials has only been recently demonstrated. ${ }^{[46,47,48,49,50]}$ These studies clearly showed the strong influence of the organic substituents on the decomposition mechanism and formation of the desired material. For instance, Bochmann et al. investigated the thermal decomposition of tris-selenolato-stibines and bismuthines of the type $\mathrm{M}(\mathrm{SeR})_{3}$. While $\left(2,4,6-t-\mathrm{Bu}_{3} \mathrm{C}_{6} \mathrm{H}_{2} \mathrm{Se}\right)_{3} \mathrm{Sb}$ and $(2,4,6-t$ $\left.\mathrm{Bu}_{3} \mathrm{C}_{6} \mathrm{H}_{2} \mathrm{Se}\right)_{3} \mathrm{Bi}$ were found to decompose at $200{ }^{\circ} \mathrm{C}$ with elimination of the selenane $\mathrm{R}_{2} \mathrm{Se}$ and subsequent formation of either $\mathrm{Sb}_{2} \mathrm{Se}_{3}$ or a mixture of elemental bismuth and $\mathrm{Bi}_{2} \mathrm{Se}_{3}$, the analogous compounds $\left(2,4,6-\mathrm{Me}_{3} \mathrm{C}_{6} \mathrm{H}_{2} \mathrm{Se}\right)_{3} \mathrm{Sb}$ and $\left(2,4,6-\mathrm{Me}_{3} \mathrm{C}_{6} \mathrm{H}_{2} \mathrm{Se}\right)_{3} \mathrm{Bi}$ containing the sterically less demanding selenolato group decomposed with formation of elemental $\mathrm{Sb}$ and $\mathrm{Bi}$ as well as the diselenane $\mathrm{R}_{2} \mathrm{Se}_{2}{ }^{[46]}$

Despite several compounds of the types as-summarized in scheme 1 that have been mentioned as single source precursors for the formation of $\mathrm{M}_{2} \mathrm{E}_{3}$ materials in the past, systematic studies on their use in material sciences including state-of-the-art characterization of the resulting materials have rather been recently performed. In the following, the promising potential of 
several compounds of types I, III, IV and $\mathbf{V}$ for the synthesis of high-quality, nanoscalic $\mathrm{M}_{2} \mathrm{E}_{3}$ materials via solution-based and gas phase-based routes will be summarized.

\subsubsection{Single source precursors of the general type $R_{2} M E R^{\prime}$}

Kim et al. recently investigated the thermal decomposition of $\left.\mathrm{Ph}_{2} \mathrm{SbTeR}_{(\mathrm{R}}=\mathrm{Et}, \mathrm{Ph}\right)$ in oleylamine. In case of $\mathrm{Ph}_{2} \mathrm{SbTeEt}$, high-quality $\mathrm{Sb}_{2} \mathrm{Te}_{3}$ nanoplates were obtained after heating at $300{ }^{\circ} \mathrm{C}$ for $2 \mathrm{~h}$, whereas lower reaction temperatures $\left(250^{\circ} \mathrm{C}\right)$ and shorter reaction times $(1$ h) resulted in the formation of a mixture of $\mathrm{Sb}_{2} \mathrm{Te}$ as major component and $\mathrm{Sb}_{2} \mathrm{Te}_{3}$ powders, indicating rather complex decomposition mechanism. ${ }^{[166]}$ In contrast, pure $\mathrm{Sb}_{2} \mathrm{Te}_{3}$ nanoplates of hexagonal shape were obtained using $\mathrm{Ph}_{2} \mathrm{SbTePh}$ at $250{ }^{\circ} \mathrm{C}$ for $1 \mathrm{~h}$, whereas an increasing reaction time $(2 \mathrm{~h})$ and reaction temperature $\left(300{ }^{\circ} \mathrm{C}\right)$ yielded shape-distorted $\mathrm{Sb}_{2} \mathrm{Te}_{3}$ nanoplates. The authors suggested that the decomposition of $\mathrm{Ph}_{2} \mathrm{SbTePh}$ proceeds with formation of $\mathrm{Ph}-\mathrm{Ph}$ (Scheme 8), but no experimental details on the formation of this compound are given. Surprisingly, when the decompositon was performed in a closed glass ampoule, reduction of $\mathrm{Sb}^{3+}$ to elemental $\mathrm{Sb}$ by ligand elimination was observed. These results clearly demonstrate that the decomposition pathway of the precursor in the absence of a solvent can significantly differ from that in a solvent medium.

$$
3 \mathrm{Ph}_{2} \mathrm{SbTePh} \underset{\text { oleylamine }}{\stackrel{300{ }^{\circ} \mathrm{C}}{\longrightarrow}} \mathrm{Sb}_{2} \mathrm{Te}_{3}+\mathrm{Ph}_{3} \mathrm{Sb}+3 \mathrm{Ph}-\mathrm{Ph}
$$

Scheme 8. Thermal decomposition of $\mathrm{Ph}_{2} \mathrm{SbTePh}$.

Both single source precursors yielded phase-pure, highly stoichiometric $\mathrm{Sb}_{2} \mathrm{Te}_{3}$ nanoplates at decomposition temperatures between 250 and $300{ }^{\circ} \mathrm{C}$ as was shown by XRD, EDX, SEM and TEM (Fig. 25).

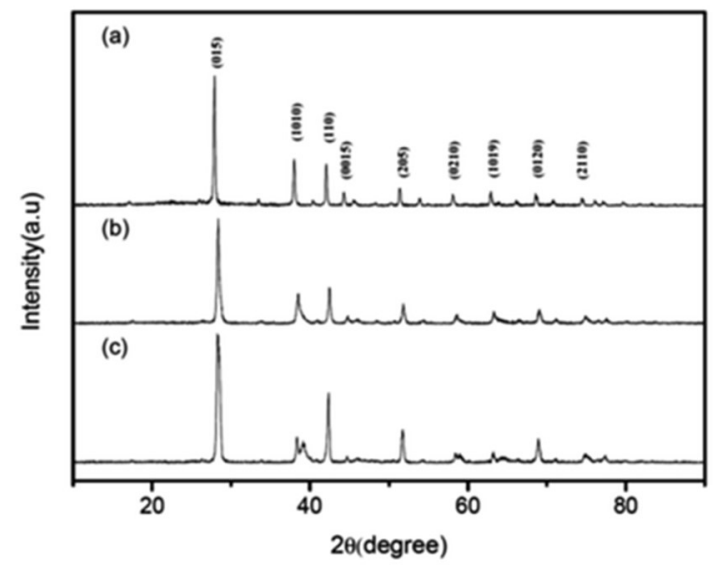

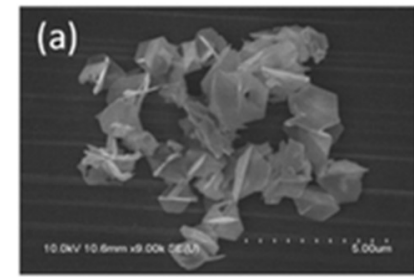

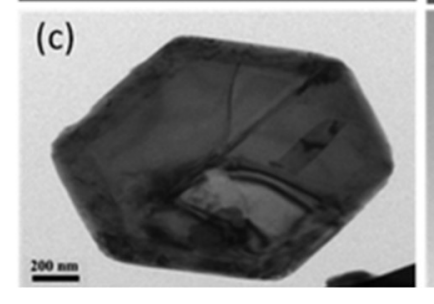

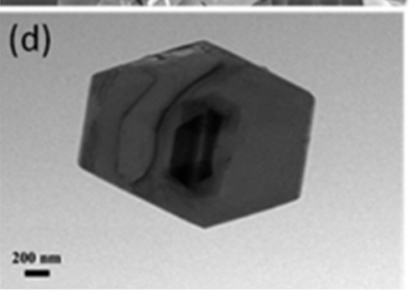

Figure 25. XRD pattern of $\mathrm{Sb}_{2} \mathrm{Te}_{3}$ obtained from $\mathrm{Ph}_{2} \mathrm{SbTePh}$ at $250{ }^{\circ} \mathrm{C}$ as well as $\mathrm{SEM}$ and TEM photographs synthesized from $\mathrm{Ph}_{2} \mathrm{SbTeEt}$ at $300{ }^{\circ} \mathrm{C}$ for $2 \mathrm{~h}(\mathrm{a}, \mathrm{c})$ and $\mathrm{Ph}_{2} \mathrm{SbTePh}$ at 250 
${ }^{\circ} \mathrm{C}$ for $1 \mathrm{~h}$ (b, d). (Reproduced from G. Gupta, J. Kim, Dalton Trans. 2013, 42, 8209 with permission of The Royal Society of Chemistry. ${ }^{[166]}$ )

The hexagonal $\mathrm{Sb}_{2} \mathrm{Te}_{3}$ nanoparticles showed an edge length of $0.4-2.0 \mu \mathrm{m}$ and a thickness of 20-50 $\mathrm{nm}$. The specific precursor molecules and the reaction temperature was found to strongly influence the formation of the nanocrystals. For instance, decomposition of $\mathrm{Ph}_{2} \mathrm{SbTeEt}$ at $250{ }^{\circ} \mathrm{C}$ yielded a mixture of $\mathrm{Sb}_{2} \mathrm{Te}$ (major component) and $\mathrm{Sb}_{2} \mathrm{Te}_{3}$, whereas increasing the temperature to $300{ }^{\circ} \mathrm{C}$ gave phase pure hexagonal $\mathrm{Sb}_{2} \mathrm{Te}_{3}$ nanoplates. Obviously, $\mathrm{Sb}_{2} \mathrm{Te}$ can be formed at relatively low temperature, but disappeared at elevated temperature. In remarkable contrast, the thermal decomposiiton of $\mathrm{Ph}_{2} \mathrm{SbTePh}$ at $250{ }^{\circ} \mathrm{C}$ for 1 $h$ only yielded hexagonal $\mathrm{Sb}_{2} \mathrm{Te}_{3}$ plates. The shape of the $\mathrm{Sb}_{2} \mathrm{Te}_{3}$ plates became irregular with increasing reaction time $(2 \mathrm{~h})$ and reaction temperature $\left(300^{\circ} \mathrm{C}\right)$.

Kim et al. suggested, that the growth mechanism of the $\mathrm{Sb}_{2} \mathrm{Te}_{3}$ nanoplates is strongly influenced by the crystal structure of rhombohedral $\mathrm{Sb}_{2} \mathrm{Te}_{3} . \mathrm{Sb}_{2} \mathrm{Te}_{3}$ exhibits a layered anisotropic lattice structure with infinite $-\mathrm{Te}_{1}-\mathrm{Sb}-\mathrm{Te}_{2}-\mathrm{Sb}-\mathrm{Te}_{1}-$ chains, the so-called quintuple layer structure, along the c-axis. These quintuple layers are attached through weak Te $\cdots$ Te van der Waals contacts. The authors expected a faster growth rate perpendicular to the c-axis than along the c-axis of the $\mathrm{Sb}_{2} \mathrm{Te}_{3}$ crystal due to the higher free energy of a broken covalent bond compared to that of a dangling van der Waals bond. Consequently, the inherent crystal structure of $\mathrm{Sb}_{2} \mathrm{Te}_{3}$ forced the anisotropic growth of the $\mathrm{Sb}_{2} \mathrm{Te}_{3}$ hexagons.

\subsubsection{Single source precursors of the general type $M\left(E R^{\prime}\right)_{3}$}

Sharma et al. reported on the thermal decomposition of several homoleptic tris-2-pyridyl selenolate compounds of the type $\left[\mathrm{M}\left\{\mathrm{Se}-\mathrm{C}_{5} \mathrm{H}_{3}(\mathrm{Me}-3) \mathrm{N}\right\}_{3}\right](\mathrm{M}=\mathrm{Sb}, \mathrm{Bi})$ in a simple furnace at 400 and $450{ }^{\circ} \mathrm{C}$, yielding crystalline orthorhombic $\mathrm{Sb}_{2} \mathrm{Se}_{3}$ and a hexagonal phase of BiSe according to XRD and EDX studies. ${ }^{[167]}$ The morphology of the materials was investigated by SEM, demonstrating the formation of monodisperse $\mathrm{Sb}_{2} \mathrm{Se}_{3}$ nanorods (Fig. 26) with a width of $250 \mathrm{~nm}$ and length of few microns as well as uniform flower like BiSe nanoparticles (Fig. 27). 


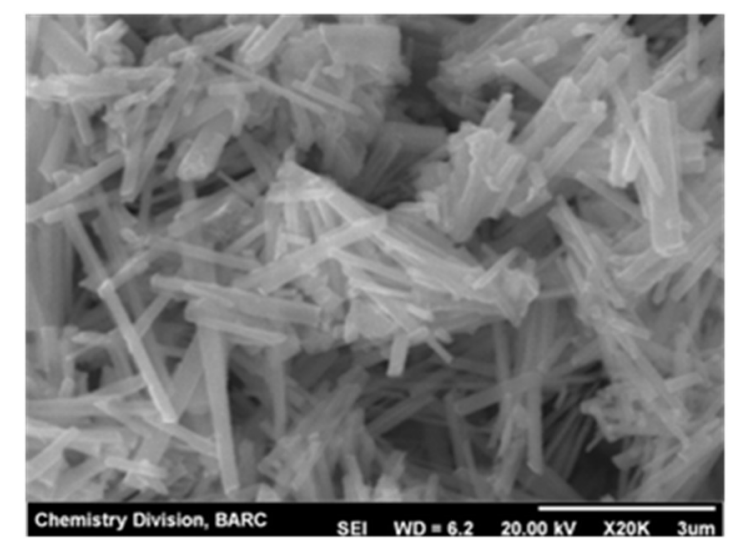

Figure 26. SEM photographs of $\mathrm{Sb}_{2} \mathrm{Se}_{3}$ nanorods formed by pyrolysis of $\left[\mathrm{Sb}\left\{\mathrm{Se}-\mathrm{C}_{5} \mathrm{H}_{3}(\mathrm{Me}-\right.\right.$ 3)N $\}_{3}$ ] at $400{ }^{\circ}$ C. (Reproduced from R. K. Sharma, G. Kedarnath, V. K. Jain, A. Wadawale, M. Nalliath, C. G. S. Pillai and B. Vishwanadh, Dalton Trans., 2010, 39, 8779 with permission of The Royal Society of Chemistry. ${ }^{[167]}$ )

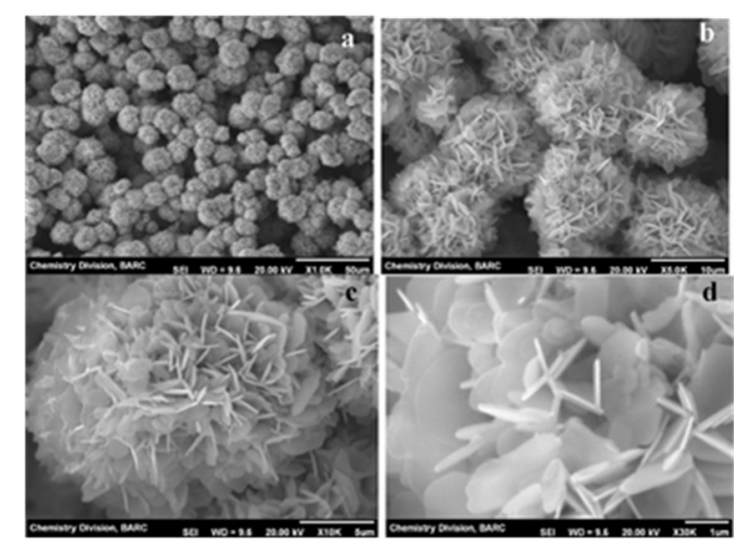

Figure 27. SEM photographs of BiSe flower-like structures as formed by pyrolysis of $\left[\mathrm{Bi}\left\{\mathrm{Se}-\mathrm{C}_{5} \mathrm{H}_{3}(\mathrm{Me}-3) \mathrm{N}\right\}_{3}\right]$ at $450{ }^{\circ} \mathrm{C}$. (Reproduced from R. K. Sharma, G. Kedarnath, V. K. Jain, A. Wadawale, M. Nalliath, C. G. S. Pillai and B. Vishwanadh, Dalton Trans., 2010, 39, 8779 with permission of The Royal Society of Chemistry. ${ }^{[167]}$ )

In contrast, thermal decomposition of $\left[\mathrm{Sb}\left\{\mathrm{Se}-\mathrm{C}_{5} \mathrm{H}_{3}(\mathrm{Me}-3) \mathrm{N}\right\}_{3}\right]$ and $\left[\mathrm{Bi}\left\{\mathrm{Se}-\mathrm{C}_{5} \mathrm{H}_{3}(\mathrm{Me}-3) \mathrm{N}\right\}_{3}\right]$ in an organic solvent (HDA) at lower temperatures $\left(200-230{ }^{\circ} \mathrm{C}\right)$ yielded $\mathrm{M}_{2} \mathrm{Se}_{3}$ nanoparticles $(\mathrm{M}=\mathrm{Sb}$ or $\mathrm{Bi})$ with average sizes of 47 and $13 \mathrm{~nm}$, respectively. All reflections in the XRD pattern could be indexed to orthorhombic $\mathrm{Sb}_{2} \mathrm{Se}_{3}$ and rhombohedral $\mathrm{Bi}_{2} \mathrm{Se}_{3}$. SEM and TEM studies showed the formation of $\mathrm{Sb}_{2} \mathrm{Se}_{3}$ nanorods of 40-60 nm width (diameter) and 0.6-1.4 $\mu$ in length. A bright dot like pattern in the SAED spectra showed their single crystalline nature. The $\mathrm{Bi}_{2} \mathrm{Se}_{3}$ flakes with an average width of $30 \mathrm{~nm}$ and average length of $760 \mathrm{~nm}$ are also single crystalline as shown by SAED. The SAED pattern displayed (101), (0012) and (1013) lattice planes of rhombohedral $\mathrm{Bi}_{2} \mathrm{Se}_{3}$. 


\subsubsection{Single source precursors of the general type $\left(R_{2} M\right)_{2} E$}

We investigated recently the capability of compounds of the general type $\left(\mathrm{Et}_{2} \mathrm{Sb}\right)_{2} \mathrm{E}(\mathrm{E}=\mathrm{S}$, $\mathrm{Se}, \mathrm{Te})$ to serve as single source precursors for the synthesis of highly stoichiometric, crystalline $\mathrm{Sb}_{2} \mathrm{Te}_{3}$ nanoparticles in different organic solvents in the presence of PVP* as capping agent at temperatures below $170{ }^{\circ} \mathrm{C} .\left[{ }^{168},{ }^{169}\right]$

DSC experiments proved that $\left(\mathrm{Et}_{2} \mathrm{Sb}\right)_{2} \mathrm{Te}$ decomposes upon heating in a stoichiometric reaction at temperatures starting at $140{ }^{\circ} \mathrm{C}$ with exclusive formation of $\mathrm{Sb}_{2} \mathrm{Te}_{3}$ and $\mathrm{Et}_{3} \mathrm{Sb}$, which is thermally stable up to almost $300{ }^{\circ} \mathrm{C}$ (Scheme 9). ${ }^{[168]}$ In contrast, the decomposition pathways of $\left(\mathrm{Et}_{2} \mathrm{Sb}\right)_{2} \mathrm{E}(\mathrm{E}=\mathrm{S}, \mathrm{Se})$ are more complex. As was previously observed, ${ }_{7}{ }^{7}$ $\left(E t_{2} \mathrm{Sb}\right)_{2} \mathrm{~S}$ decompose with formation of $\mathrm{SbR}_{3}$ und $\mathrm{Sb}_{2} \mathrm{~S}_{3}$. In addition, we observed the formation of $\mathrm{SEt}_{2}$. Analogous findings were observed for $\left(\mathrm{Et}_{2} \mathrm{Sb}\right)_{2} \mathrm{Se}$, which decomposes with formation of $\mathrm{Sb}_{2} \mathrm{Se}_{3}, \mathrm{SbEt}_{3}$ and $\mathrm{SeEt}_{2}$, respectively.

$$
\begin{aligned}
& 3\left(\mathrm{Et}_{2} \mathrm{Sb}\right)_{2} \mathrm{E} \stackrel{160{ }^{\circ} \mathrm{C}}{\longrightarrow} \mathrm{Sb}_{2} \mathrm{Te}_{3}+4 \mathrm{SbEt}_{3}+\mathrm{EEt}_{2} \\
& \mathrm{E}=\mathrm{S}, \mathrm{Se} \\
& 3\left(\mathrm{Et}_{2} \mathrm{Sb}\right)_{2} \mathrm{Te} \stackrel{160^{\circ} \mathrm{C}}{\longrightarrow} \mathrm{Sb}_{2} \mathrm{Te}_{3}+4 \mathrm{SbEt}_{3}
\end{aligned}
$$

Scheme 9. Thermal decomposition of $\left(\mathrm{Et}_{2} \mathrm{Sb}\right)_{2} \mathrm{Te}$

$\mathrm{The}_{2} \mathrm{Sb}_{3}(\mathrm{E}=\mathrm{S}, \mathrm{Se}, \mathrm{Te})$ materials consist of crystalline nanoparticles. All reflection peaks with a significant intensity in the XRD patterns can be indexed on the basis of the structure of orthorhombic $\mathrm{Sb}_{2} \mathrm{E}_{3}(\mathrm{E}=\mathrm{S}, \mathrm{Se})$ and rhombohedral $\mathrm{Sb}_{2} \mathrm{Te}_{3}$, respectively. EDX analyses showed the formation of slightly Sb-rich materials $\left(\mathrm{Sb}_{2} \mathrm{~S}_{3}, \mathrm{Sb}_{2} \mathrm{Se}_{3}\right)$, which is typically observed in these materials due to their tendency to form antisite defects. In contrast, highlystoichiometric $\mathrm{Sb}_{2} \mathrm{Te}_{3}$ nanoparticles were obtained from $\left(\mathrm{Et}_{2} \mathrm{Sb}\right)_{2} \mathrm{Te}$. The morphology of the materials differed significantly: $\mathrm{Sb}_{2} \mathrm{~S}_{3}$ was obtained as nanobundles and flower-like structures as was previously reported by Wang et al. and Pei et al., ${ }^{[164,170]}$ whereas $\mathrm{Sb}_{2} \mathrm{Se}_{3}$ formed nanowires and $\mathrm{Sb}_{2} \mathrm{Te}_{3}$ was obtained as hexagonal nanoplates (Fig. 28).
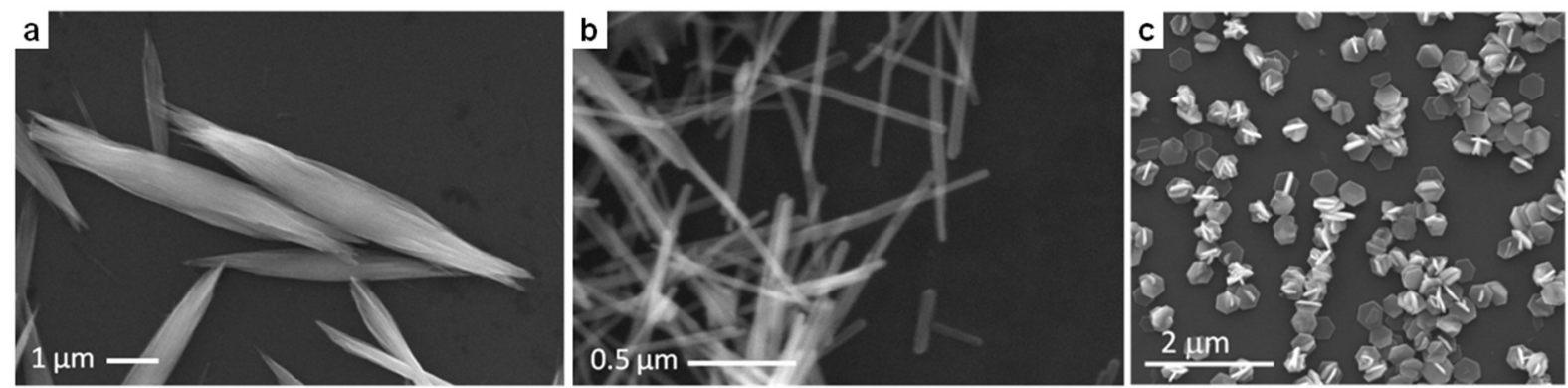
Figure 28. $\mathrm{SEM}$ photographs of $\mathrm{Sb}_{2} \mathrm{~S}_{3}$ nanobundles (a), $\mathrm{Sb}_{2} \mathrm{Se}_{3}$ nanowires (b) and $\mathrm{Sb}_{2} \mathrm{Te}_{3}$ nanoplates (c) synthesized with $\left(\mathrm{Et}_{2} \mathrm{Sb}\right)_{2} \mathrm{E}(\mathrm{E}=\mathrm{S}, \mathrm{Se}, \mathrm{Te})$ at $170{ }^{\circ} \mathrm{C} .{ }^{[168,169]}$

According to TEM studies, the crystalline $\mathrm{Sb}_{2} \mathrm{~S}_{3}$ nanobundles and $\mathrm{Sb}_{2} \mathrm{Te}_{3}$ nanowires are as long as $5 \mu \mathrm{m}$ and show diameters below $150 \mathrm{~nm}$ in the middle (Fig. 29). The nanobundles grew in [001] direction, which most likely results from the preferential binding of PVP molecules to the (010) facets of the initially formed $\mathrm{Sb}_{2} \mathrm{~S}_{3}$ crystal seeds, hence enhancing the anisotropic growth in [001] direction as Chem et al. postulated. ${ }^{[171]}$ In contrast, $\mathrm{Sb}_{2} \mathrm{Te}_{3}$ rather forms hexagonal, almost monodisperse, crystalline nanoplates of roughly $400 \mathrm{~nm}$ in diameter and $35 \mathrm{~nm}$ in thickness (Fig. 28c; 29c,d). Heterodisperse $\mathrm{Sb}_{2} \mathrm{Te}_{3}$ nanoplates were previously solvothermally synthesized by reaction of $\mathrm{SbCl}_{3}$, elemental Te powder and $\mathrm{NaBH}_{4}$ in the presence of a suitable reducing agent. ${ }^{[172,173]}$ The formation of hexagonal $\mathrm{Sb}_{2} \mathrm{Te}_{3}$ nanoplates is based on the anisotropic structure of rhombohedral $\mathrm{Sb}_{2} \mathrm{Te}_{3}$, which forms a layered lattice structure with infinite -Te1-Sb-Te2-Sb-Te1-chains along the c-axis direction and van der Waals bonds between adjacent Te1 layers. ${ }^{[174]}$ As was shown for $\mathrm{Bi}_{2} \mathrm{Te}_{3}$ nanoplates, ${ }^{[175]}$ which adopt the same crystal structure as $\mathrm{Sb}_{2} \mathrm{Te}_{3}$, the formation of $\mathrm{Sb}_{2} \mathrm{Te}_{3}$ nanoplate seeds is the initial step on their formation. Since the free energy of a broken covalent bond is higher than that of a dangling van der Waals bond, the growth process along the top-bottom crystalline plane is expected to occur faster than along the c-axis.
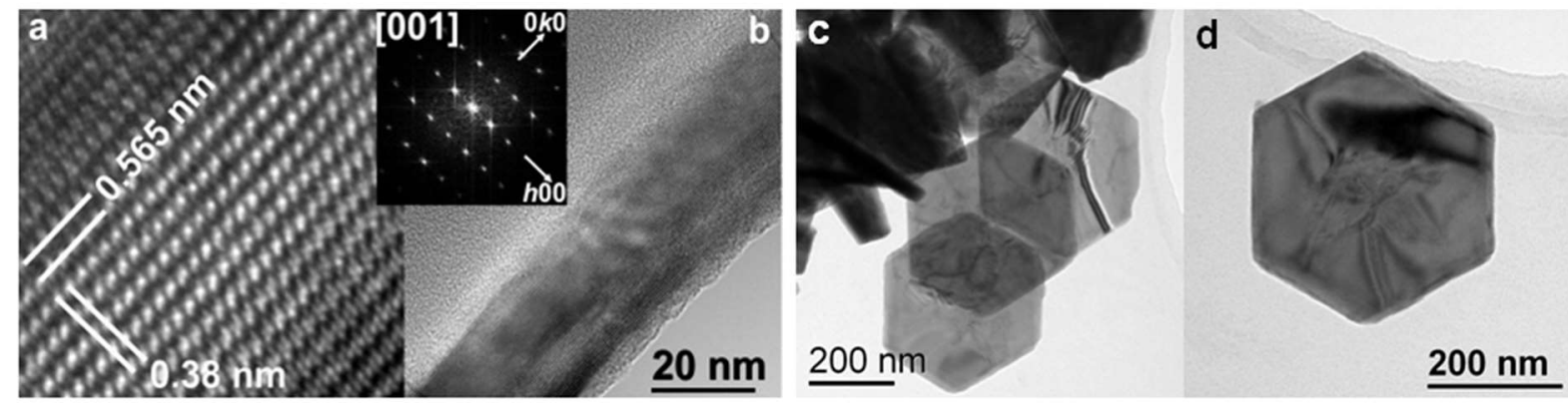

Figure 29. ( $a, b)$ Zoom and amplitude of FFT as inset of the HRTEM image of a single $\mathrm{Sb}_{2} \mathrm{~S}_{3}$ nanowire formed with $\left(\mathrm{Et}_{2} \mathrm{Sb}\right)_{2} \mathrm{~S}$ in DIPP/PVP* solution at $170{ }^{\circ} \mathrm{C}$ in [001] orientation. $(\mathrm{c}, \mathrm{d})$ TEM photographs of $\mathrm{Sb}_{2} \mathrm{Te}_{3}$ nanoplates formed with $\left(\mathrm{Et}_{2} \mathrm{Sb}\right)_{2} \mathrm{Te}$ in DIPP/PVP* solution at $170{ }^{\circ} \mathrm{C} \cdot .^{[168,169]}$

Cold pressed pellets of the $\mathrm{Sb}_{2} \mathrm{Te}_{3}$ nanoplates with densities of $5.6 \mathrm{~g} / \mathrm{cm}^{3}$ and $5.75 \mathrm{~g} / \mathrm{cm}^{3}$, corresponding to $85 \%$ and $87 \%$ of the bulk density of $\mathrm{Sb}_{2} \mathrm{Te}_{3}\left(6.57 \mathrm{~g} / \mathrm{cm}^{3}\right)$, showed high Seebeck coefficients $\alpha$ between $145 \mu \mathrm{V} / \mathrm{K}$ and $170 \mu \mathrm{V} / \mathrm{K}$. These values are close to optimized values of bulk materials, ${ }^{[176]}$ hence demonstrating a low defect density and low carrier 
densities in the order of $10^{19}$ to $10^{20} \mathrm{~cm}^{-3}$. The positive sign of the thermopower demonstrates an intrinsic p-type doping of the material. The Seebeck coefficient is the only thermoelectric parameter that solely depends on the material chemistry, i.e. the electrochemical potential. Hence, the high values of the Seebeck coefficient originate from the specific defect chemistry of the material and are a result of the very low antisite defect concentration. This is clear prove that the controlled thermolysis reaction of the tailor-made single source precursor $\left(\mathrm{Et}_{2} \mathrm{Sb}\right)_{2} \mathrm{Te}$ provides ideal pre-conditions for thermoelectricity. While the $\mathrm{Sb}_{2} \mathrm{Te}_{3}$ material showed promising Seebeck coefficients, the specific electrical conductivity $\sigma$ (native sample $<6 \mathrm{~S} / \mathrm{cm}$; annealed sample $<36 \mathrm{~S} / \mathrm{cm}$ ) was rather low. The thermal conductivity $\kappa$ (native sample 0.29 to $0.27 \mathrm{~W} /(\mathrm{m} \cdot \mathrm{K})$; annealed sample 0.51 to $0.46 \mathrm{~W} /(\mathrm{m} \cdot \mathrm{K}))$ was much lower compared to that of single crystalline $\mathrm{Sb}_{2} \mathrm{Te}_{3}$, for which values of $1.6 \mathrm{~W} /(\mathrm{m} \cdot \mathrm{K})$ and 5.6 $\mathrm{W} /(\mathrm{m} \cdot \mathrm{K})$ at ambient temperature have been reported, depending on the crystallographic axis. $^{[177]}$ The reduced thermal conductivity was attributed to the nanostructuring and the high porosity of the pellets (Fig. 30). The over-all figure of merit zT was 0.08 at $180{ }^{\circ} \mathrm{C}$ for the 'native' sample and 0.11 at $195^{\circ} \mathrm{C}$ for the annealed powder.
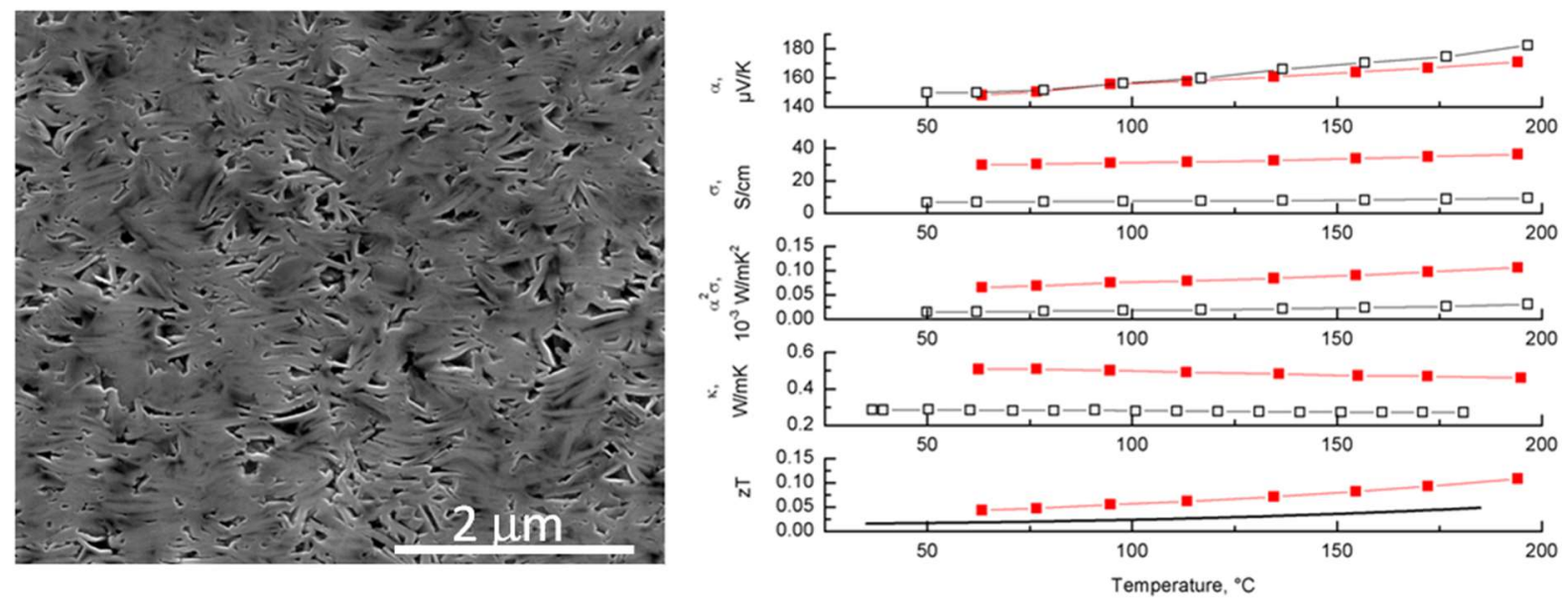

Figure 30. Cross-section SEM photograph of the "native" cold-pressed $\mathrm{Sb}_{2} \mathrm{Te}_{3}$ pellet and thermoelectric transport characterization of cold-pressed nanoplates in the temperature range between $25^{\circ} \mathrm{C}$ and $200{ }^{\circ} \mathrm{C}$. A "native" sample, cold-pressed pellets without any temperature annealing (black open squares), and a powder exposed to a rapid thermal annealing (RTA; red filled squares) are shown. ${ }^{[168]}$

According to these results, further improvement of the thermoelectric properties of the material was required. While the use of a single source precursor allowed the careful control of the charge carrier concentration by providing $\mathrm{Sb}$ and $\mathrm{Te}$ in the correct stoichiometric ratio $\left(\mathrm{Sb}_{2} \mathrm{Te}_{3}\right)$, the second major aspect on optimizing the given thermoelectric material is by 
careful control of the carrier mobility. The electrical mobility of nanocomposites is often compromised not only by the nanostructure itself but by the incorporation of impurities, arising from the use of surfactants which were chosen to stabilize the nanostructure, but are now limiting the carrier mobility, especially at the grain boundaries. Decomposition of the single-source precursor in ionic liquids offers a synthetic route to almost an impurity free, nanoscopic product, since the nanoparticles are sterically and electrostatically shielded by the ionic liquid against agglomeration and further particle growth ${ }^{[178]}$ and the ionic liquid can easily be removed by a simple washing procedure, as they exhibit, compared to standard nanoparticle stabilizers, only weakly coordinating properties. ${ }^{[179]}$ The third central thermoelectric property, the thermal conductivity of the material, was finally tuned by careful adjustment of the porosity of the resulting macroscalic pellet since phonon-boundary scattering at pores is known to effectively reduce the mean free path of phonons.

Microwave-assisted decomposition of the single source precursor $\left(\mathrm{Et}_{2} \mathrm{Sb}\right)_{2} \mathrm{Te}$ in $\left[\mathrm{C}_{4} \mathrm{mim}\right] \mathrm{Br}$ $\left(\mathrm{C}_{4} \mathrm{mim}=1\right.$-butyl-3-methylimidzolium $)$ as the ionic liquid produced phase pure $\mathrm{Sb}_{2} \mathrm{Te}_{3}$ nanoparticle-agglomerates of high thermoelectric performances. ${ }^{[180]}$ IR and EDX proved that the particle surface was free from any contaminations such as oxygen and carbon. Thermoelectric transport properties of different samples yielded excellent Seebeck coefficients of $180 \mu \mathrm{V} / \mathrm{K}$ at room temperature, which clearly prove the formation of a highly stoichiometric $\mathrm{Sb}_{2} \mathrm{Te}_{3}$ material with very low anti-site defect concentrations as was intended by the use of the single source precursor. High electrical conductivities were observed for samples prepared in rather short reaction times, since with increasing reaction time the incorporation of impurities such as oxygen or carbon (decomposition of as-formed $\mathrm{SbEt}_{3}$ ) becomes more likely resulting in a reduced electrical conductivity. As a consequence, high power factors of $>2 \times 10^{-3} \mathrm{~W} / \mathrm{m}-\mathrm{K}^{2}$ were obtained for an optimized sample. Moreover, the thermal conductivity was found to correlate with the porosity of the samples: The higher the porosity, the lower the thermal conductivity (Fig. 31). 

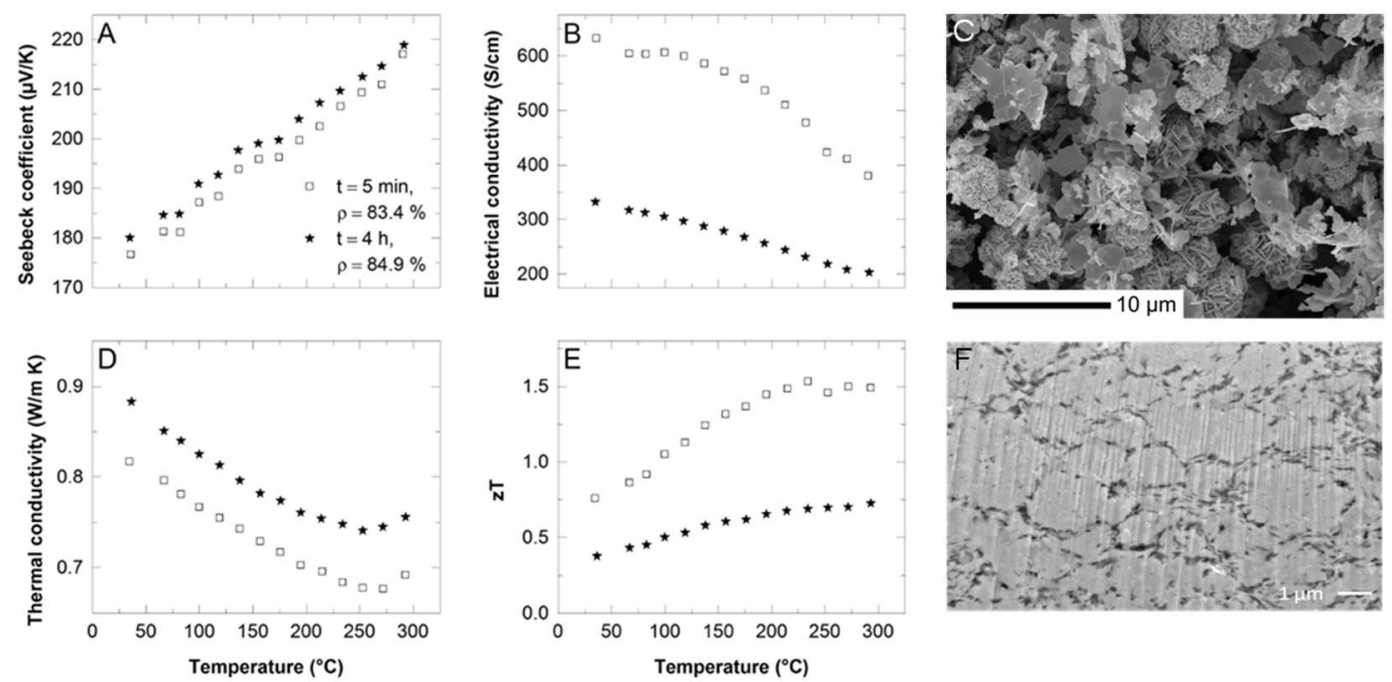

Figure 31. Thermoelectric transport properties (a, b, d, e) of two different $\mathrm{Sb}_{2} \mathrm{Te}_{3}$ nanoporous bulk samples, synthesized at $170{ }^{\circ} \mathrm{C}$ either within 5 minutes in IL using a microwave reactor (sample I) or within 4 hours by thermal decomposition in an oil bath (sample II) as well as SEM pictures (c, cross-section $\mathrm{f}$ ) of the sample obtained in the IL. ${ }^{[180]}$

The results clearly demonstrate the efficiency of the decoupling of electronic and phononic transport properties, resulting in a dramatic enhancement of the figure of merit of up to 1.5 at $300{ }^{\circ} \mathrm{C}$. While the thermal decomposition of $\left(\mathrm{Et}_{2} \mathrm{Sb}\right)_{2} \mathrm{Te}$ in the presence of organic capping agents resulted in high Seebeck coefficients but a disappointing figure of merit (below 0.1 due to low electrical conductivity), fast microwave-assisted decomposition of the single source precursor in an ionic liquid substantially improved the electrical conductivity, hence improving the powder factors and the figure of merit of up to 1. Finally, controlling the porosity of the nanostructured material yielded record high $z T$ values of up to 1.5 , without the need of alloying or electronic doping.

\subsubsection{Single source precursors of the general type $R_{3} M E$}

$\mathrm{Et}_{3} \mathrm{SbS}$ and $\mathrm{Et}_{3} \mathrm{SbSe}$ start to decompose almost immediately after melting $\left(130{ }^{\circ} \mathrm{C}\right)$ with formation of black solids as well as $\mathrm{SbEt}_{3}, \mathrm{SEt}_{2}$ and $\mathrm{SeEt}_{2}$, respectively. For the resulting $\mathrm{Sb}_{2} \mathrm{~S}_{3}$ nanoparticles, an amorphous-to-crystalline phase transition as indicated by a color change (red/black) at temperatures higher than $140{ }^{\circ} \mathrm{C}$ was observed. ${ }^{[181]}$ The $\mathrm{Sb}_{2} \mathrm{E}_{3}(\mathrm{E}=\mathrm{S}$, $\mathrm{Se}, \mathrm{Te})$ materials are crystalline, highly-stoichiometric $\mathrm{Sb}_{2} \mathrm{~S}_{3}$ nanobundles, which are comparable to those obtained with $\left(\mathrm{Et}_{2} \mathrm{Sb}\right)_{2} \mathrm{E}(\mathrm{E}=\mathrm{S}, \mathrm{Se})$ and as long as $5 \mu \mathrm{m}$ and show 
diameters below $150 \mathrm{~nm}$. They again preferentially grew in [001] direction (c-achsis) as was shown by TEM and SAED (Fig. 32).
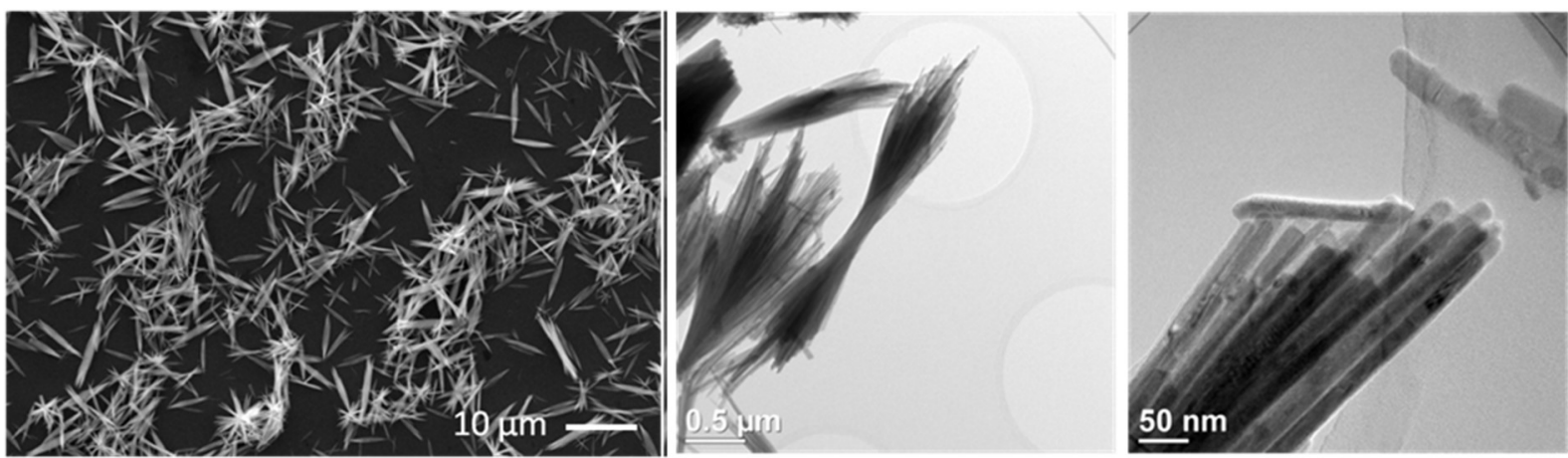

Figure 32. $\mathrm{SEM}$ and TEM photographs of $\mathrm{Sb}_{2} \mathrm{~S}_{3}$ nanobundles formed by thermal decomposition of $\mathrm{Et}_{3} \mathrm{SbS}$ in DIPP/PVP* solution at $170{ }^{\circ} \mathrm{C} .{ }^{[169]}$

The material as obtained from thermal decomposition of $\mathrm{Et}_{3} \mathrm{SbSe}$ in DIPB was slightly Sbrich, whereas that obtained by thermal decomposition in oleylamine at $150{ }^{\circ} \mathrm{C}$ contained phase pure $\mathrm{Sb}_{2} \mathrm{Se}_{3}$ nanowires. The nanowires are up to $5 \mu \mathrm{m}$ in length and show diameters between 20 to $100 \mathrm{~nm}$ (Fig. 33).
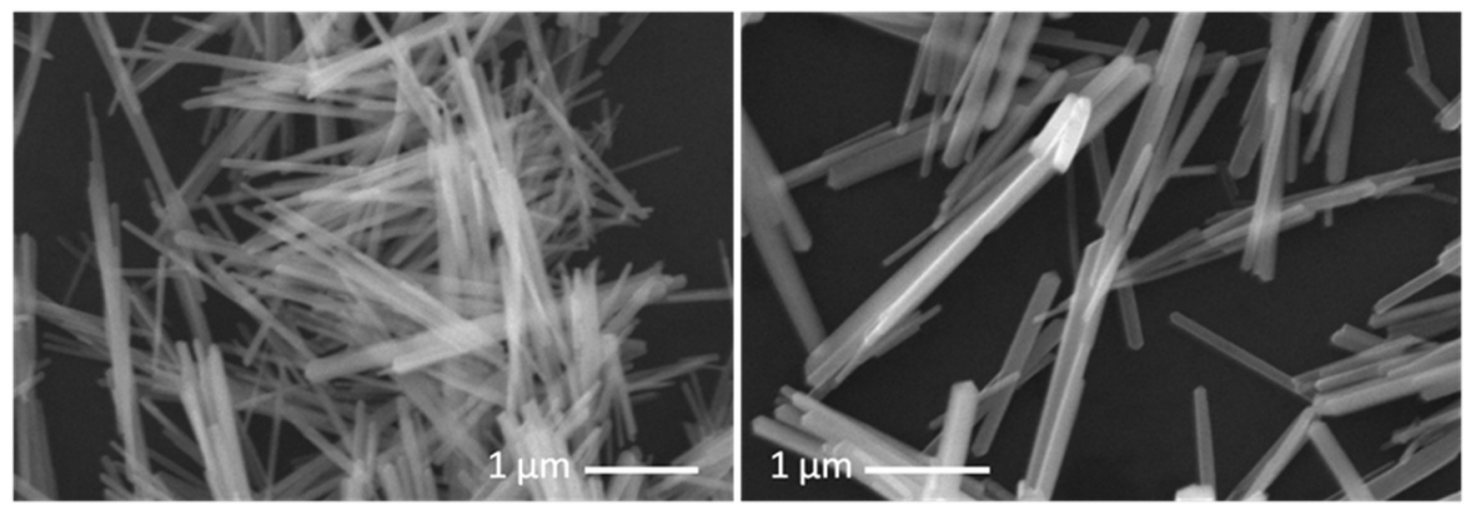

Figure 33. $\mathrm{SEM}$ photographs of $\mathrm{Sb}_{2} \mathrm{Se}_{3}$ nanowires formed with $\mathrm{Et}_{3} \mathrm{SbSe}$ in oleylamine solution at $150{ }^{\circ} \mathrm{C}$ (left) and $170{ }^{\circ} \mathrm{C}$ (right). ${ }^{[169]}$

Fig. 34 shows TEM bright field images of the $\mathrm{Sb}_{2} \mathrm{Se}_{3}$ nanowires, which have a big aspect ratio with lengths up to $5 \mu \mathrm{m}$ and diameters of $20-30 \mathrm{~nm}$. They are covered by an amorphous seam, most likely due to surface oxidation after their synthesis. The growth direction of the $\mathrm{Sb}_{2} \mathrm{Se}_{3}$ nanowires is along the $<010>$ direction of the stibnite structure in Pnma setting. Fig. 34a shows a HRTEM image of $\mathrm{Sb}_{2} \mathrm{Se}_{3}$ with lattice fringes of $(010)$ planes $\left(d_{010}=0.396 \mathrm{~nm}\right)$ perpendicular and spacings of $(200)$ planes $\left(d_{200}=0.5885 \mathrm{~nm}\right)$ parallel to the growth direction. Ring patterns of the diffracted intensity of several crystals (Fig. 34c) are in good agreement with simulated data of $\mathrm{Sb}_{2} \mathrm{Se}_{3}$. 


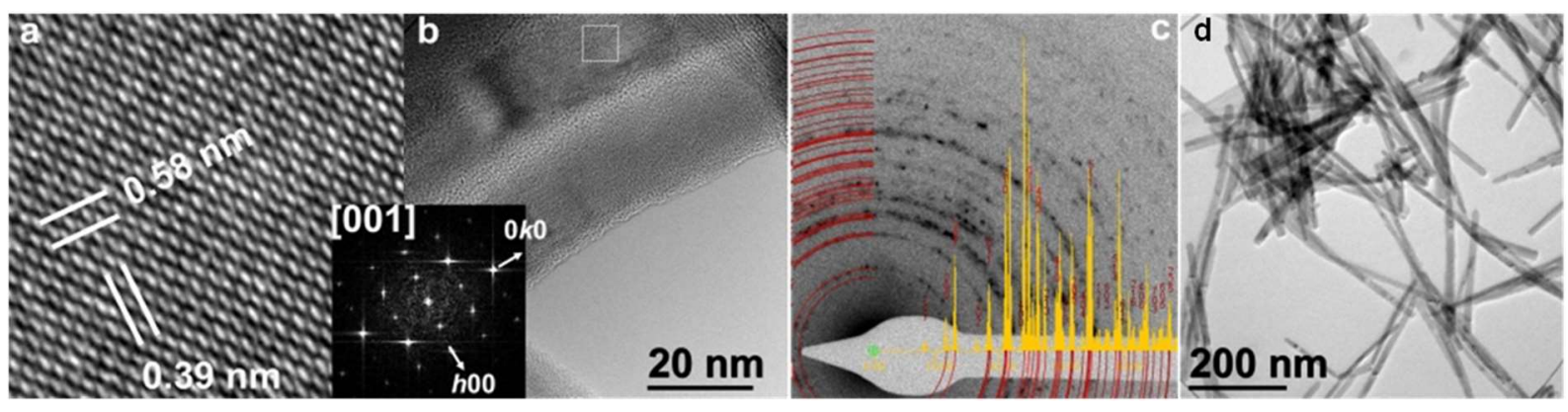

Figure 34. Zoom (a) and amplitude of FFT as inset of the boxed area in the HRTEM image (b) of $\mathrm{Sb}_{2} \mathrm{Se}_{3}$ nanowires formed with $\mathrm{Et}_{3} \mathrm{SbSe}$ in oleylamine solution at $150{ }^{\circ} \mathrm{C}$ in [001] orientation. (c) Debeyogram (inverted) of $\mathrm{Sb}_{2} \mathrm{Se}_{3}$ nanowires with simulation as overlay. (d) TEM micrographs of $\mathrm{Sb}_{2} \mathrm{Se}_{3}$ nanowires. ${ }^{[169]}$

These studies clearly demonstrate the promising potential of chalcogenostiboranes of the general type $\mathrm{R}_{3} \mathrm{ME}$ for the wet-chemical synthesis of high quality, stoichiometric $\mathrm{Sb}_{2} \mathrm{E}_{3}$ materials.

\subsection{Synthesis of Ternary Nanomaterials $\mathrm{Sb}_{2}\left(E, E^{\prime}\right)_{3}$ in Solution}

Simultaneous decomposition of $\left(\mathrm{Et}_{2} \mathrm{Sb}\right)_{2} \mathrm{~S}$ and $\left(\mathrm{Et}_{2} \mathrm{Sb}\right)_{2} \mathrm{Te}$ in DIPB/PVP* at $170{ }^{\circ} \mathrm{C}$ yielded biphasic, heterocomposite materials containing crystalline $\mathrm{Sb}_{2} \mathrm{~S}_{3}$ nanobundles and $\mathrm{Sb}_{2} \mathrm{Te}_{3}$ nanoplates (Figure 35). Rietveld refinement of the powder XRD data showed an almost 1:1 stoichiometric ratio of $\mathrm{Sb}_{2} \mathrm{~S}_{3}$ and $\mathrm{Sb}_{2} \mathrm{Te}_{3}$, which is in reasonable agreement to the EDX results $(\mathrm{Sb}: \mathrm{S}: \mathrm{Te}=45: 31: 24)$.

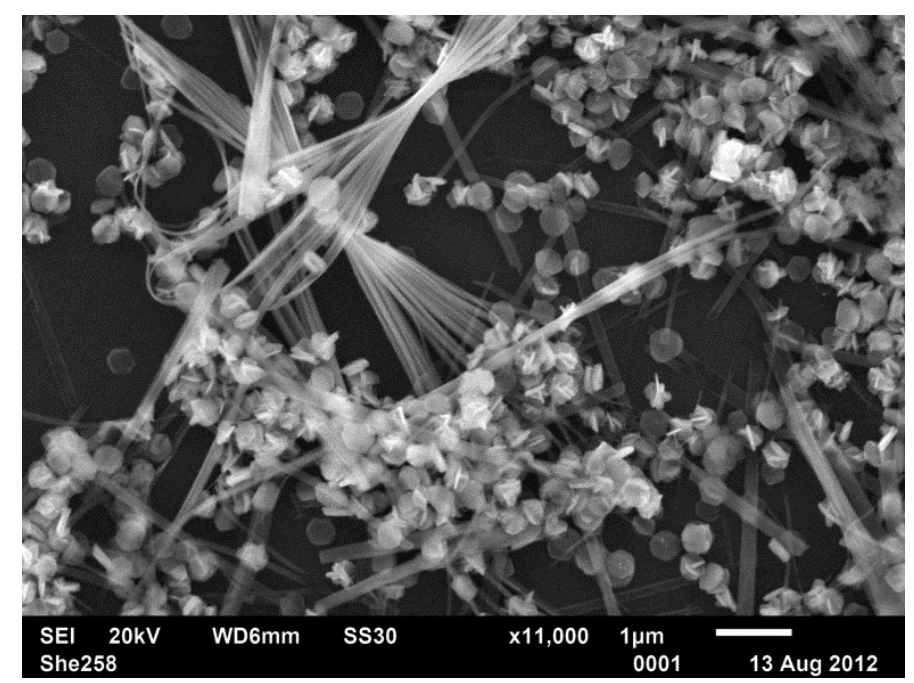

Figure 35. $\mathrm{SEM}$ picture of the $\mathrm{Sb}_{2} \mathrm{~S}_{3} / \mathrm{Sb}_{2} \mathrm{Te}_{3}$ heterocomposite material as-formed by simultaneous thermolysis of $\left(\mathrm{Et}_{2} \mathrm{Sb}\right)_{2} \mathrm{~S}$ and $\left(\mathrm{Et}_{2} \mathrm{Sb}\right)_{2} \mathrm{Te}$ in DIPB/PVP* at $170{ }^{\circ} \mathrm{C} .{ }^{[169]}$ 
In contrast, simultaneous decomposition of $\left(\mathrm{Et}_{2} \mathrm{Sb}\right)_{2} \mathrm{~S}$ and $\left(\mathrm{Et}_{2} \mathrm{Sb}\right)_{2} \mathrm{Se}$ in DIPB/PVP* at $170{ }^{\circ} \mathrm{C}$ gave a black crystalline precipitate, that contains almost equal amounts of sulfur and selenium (EDX analysis: $\mathrm{Sb}: \mathrm{S}: \mathrm{Se}=42: 28: 30$ ) and consist of a ternary $\mathrm{Sb}_{2}(\mathrm{~S}, \mathrm{Se})_{3}$ phase as was proven by X-ray diffraction, according to which the material consists of $51.7 \% \mathrm{Sb}_{2} \mathrm{~S}_{3}$ and $48.3 \%$ $\mathrm{Sb}_{2} \mathrm{Se}_{3}$, respectively.

TEM studies proved the formation of single crystalline nanowires up to $3 \mu \mathrm{m}$ in lengths and $30-50 \mathrm{~nm}$ in diameter (Fig. 36a). Again the growth direction was found to be along the $<010>$ direction $\left(d_{010}=0.39 \mathrm{~nm}\right)$ of the $\mathrm{Sb}_{2}\left(\mathrm{~S}_{2} \mathrm{Se}_{3}\right)$ stibnite structure in space group Pnma. [53] HRTEM images of the $\mathrm{Sb}_{2}\left(\mathrm{~S}_{2} \mathrm{Se}_{3}\right)$ nanowire (Fig. $\left.37 \mathrm{~b}\right)$ show the growth direction as indicated by a double arrow-headed line. The lattice spacings perpendicular to the growth direction as well as the FFT, which can be indexed as [101], prove the growth direction. Spot EDS analyses reveal the presence of $\mathrm{Sb}, \mathrm{S}$ and $\mathrm{Se}$ within the wires and EDS line-scans prove the homogeneous distribution of the elements $(\mathrm{S}, \mathrm{Se}, \mathrm{Sb})$ within the nanowire as would be expected for a ternary material phase.
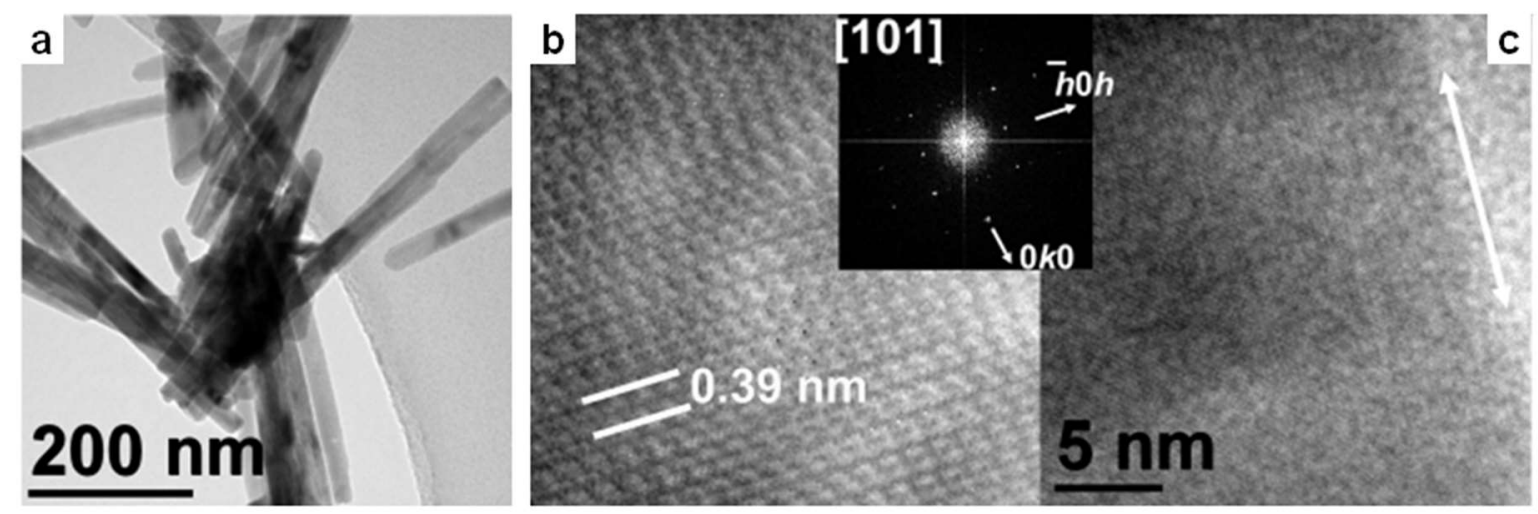

Figure 36. TEM pictures of $\mathrm{Sb}_{2}(\mathrm{~S}, \mathrm{Se})_{3}$ nanowires Zoom (b) and amplitude of FFT as inset of the HRTEM image (c) of $\mathrm{Sb}_{2}\left(\mathrm{~S}_{2} \mathrm{Se}_{3}\right)$ nanowires formed by simultaneous decomposition of of $\left(\mathrm{Et}_{2} \mathrm{Sb}\right)_{2} \mathrm{~S}$ and $\left(\mathrm{Et}_{2} \mathrm{Sb}\right)_{2} \mathrm{Se}$ in DIPB/PVP* at $170{ }^{\circ} \mathrm{C}$ in DIPB/PVP*in [101] orientation. ${ }^{[169]}$

The synthesis of ternary materials from two precursors requires comparable decomposition temperature as was clearly demonstrated. Moreover, the structures of the materials should also be comparable in order to avoid phase separation, which becomes even more important at elevated temperatures. Single source precursors are promising candidates for the generation of ternary materials, since they typically require milder reaction conditions.

\subsection{Synthesis of Binary Nanomaterials $\mathrm{Sb}_{2} \mathrm{E}_{3}(E=S, \mathrm{Se}, \mathrm{Te})$ by MOCVD Process}


Aside from use in wet chemical approaches, single-source precursors offer also several advantages in gas-phase based material synthesis such as MOCVD processes. Compared to simple metal alkyl compounds, which are conventionally applied, they are often less air and moisture sensitive and allow film growth at lower substrate temperatures. Lower substrate temperatures reduce possible incorporations of impurities such as carbon due to uncontrolled decomposition of the precursor as well as interlayer diffusion in superlattices such as $\mathrm{Sb}_{2} \mathrm{Te}_{3} / \mathrm{Bi}_{2} \mathrm{Te}_{3}$ multilayer structures. Moreover, pre-reaction in the gas phase are suppressed and, even more important, the ligand design to some extent allows control over the decomposition mechanism and therefore the level of impurities such as carbon incorporated into the resulting material films. Unfortunately, their high molecular weights typically lower their volatility, which is a major drawback of single-source precursors in conventional atmospheric pressure CVD processes. ${ }^{[182]}$ Since only a few reports on the use of single source precursors for $\mathrm{M}_{2} \mathrm{E}_{3}$ materials exist, ${ }^{[85,183,184]}$ their is a strong demand for new, tailor-made metal organic precursors with suitable vapor pressures and lower decomposition temperatures compared to conventional metal alkyls.

MOCVD growth of $\mathrm{Sb}_{2} \mathrm{Te}_{3}$ films are typically grown in a dual source approach using trialkylstibanes $\mathrm{SbR}_{3}(\mathrm{R}=\mathrm{Me}, \mathrm{Et})$ and dialkyltellanes $\mathrm{TeR}_{2}(\mathrm{R}=\mathrm{Et}, i-\mathrm{Pr}) .{ }^{[185,186,187,188,189,190]}$ In contrast, only a very few reports on the use of suitable single-source precursors for the deposition of $\mathrm{Sb}_{2} \mathrm{Te}_{3}$ films. In the following, the most prominent type of compounds for use in gas-phase based thin film generation will by summarized.

\subsubsection{Single source precursors of the general type $R_{2} M E R^{\prime}$}

In a very early study, Dickson et al. reported almost 20 years ago on their unsuccessful attempts to use of $\mathrm{Et}_{2} \mathrm{SbTeEt}$ for the MOCVD deposition of $\mathrm{Sb}_{2} \mathrm{Te}_{3}$ films using $\mathrm{H}_{2}$ as reactive gas. ${ }^{[191]}$ Unfortunately, these studies only yielded Sb-rich material films due to hydrogenolysis of the precursor and formation of unstable $\mathrm{H}_{2} \mathrm{Te}$ and $\mathrm{Et}_{2} \mathrm{SbH}$.

\subsubsection{Single source precursors of the general type $M\left(E R^{\prime}\right)_{3}$}

Phase pure rhombohedral $\mathrm{Sb}_{2} \mathrm{Te}_{3}$ films were deposited in the temperature range from $375-475$ ${ }^{\circ} \mathrm{C}$ using $\mathrm{Sb}\left[\left(\mathrm{TeP} i-\mathrm{Pr}_{2}\right)_{2} \mathrm{~N}\right]_{3}$ in an aerosol-assisted (AA)CVD process. ${ }^{[183]}$ The calculated lattice values $(a=4.257 \AA, c=30.373 \AA)$ were in good agreement with the reported values $(a$ $=4.264 \AA, c=30.458 \AA$ ). The films consist of hexagonal $\mathrm{Sb}_{2} \mathrm{Te}_{3}$ nanoplates, whose size range from 100 to $200 \mathrm{~nm}$, and also showed some truncated hexagonal-shaped nanoplates 
(Fig. 37). The $20 \mathrm{~nm}$ thick nanoplates are randomly oriented with a preferred orientation along the (003) plane. X-ray photoelectron spectroscopy (XPS) showed different chemical environments of the $\mathrm{Sb}$ atoms, i.e. $\mathrm{Sb}-\mathrm{O}$ and $\mathrm{Sb}-\mathrm{Te}$, indicating surface oxidation of the films after exposure to the atmosphere. Four-point probe resistivity measurements gave conductivity values as high as $180 \Omega-1 \mathrm{~cm}-1$, which are comparable to the literature value $\left(320 \Omega^{-1} \mathrm{~cm}^{-1}\right) .^{[183]}$

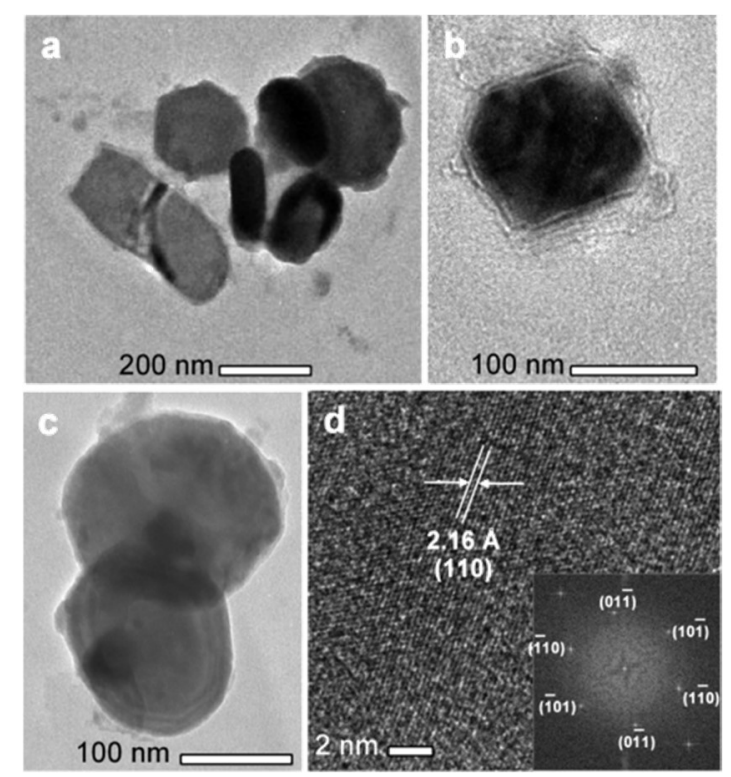

Figure 37. (a) and (c) TEM pictures of $\mathrm{Sb}_{2} \mathrm{Te}_{3}$ nanoplates showing that their planar dimension varies between 100 and $200 \mathrm{~nm}$; (b) a truncated nanoplate and (d) HRTEM and FFT (inset) of the films grown at $475{ }^{\circ} \mathrm{C}$ indicate single crystallinity of the nanoplates. (Reprinted with permission from S. S. Garje, D. J. Eisler, J. S. Ritch, M. Afzaal, P. O’Brien, T. Chivers, J. Am. Chem. Soc. 2006, 128, 3120. Copyright 2014 American Chemical Society. ${ }^{[183]}$ )

In addition, orthorhombic phase $\mathrm{Sb}_{2} \mathrm{Se}_{3}$ thin films were deposited on glass substrates between 375 and $500{ }^{\circ} \mathrm{C}$ using $\left[\mathrm{Sb}\left\{\mathrm{Se}-\mathrm{C}_{5} \mathrm{H}_{3}(\mathrm{Me}-3) \mathrm{N}\right\}_{3}\right] .{ }^{[85]}$ The films grew preferentially in (221) direction and wire-like structures with a diameter in the range of $240-500 \mathrm{~nm}$ and length of several microns were observed by SEM and TEM (Fig. 38), with the length of the wires increasing with increasing temperature and deposition time. Ideal growth conditions are a substrate temperature of $425^{\circ} \mathrm{C}$ and a deposition time of 1 and $2 \mathrm{~h}$. 

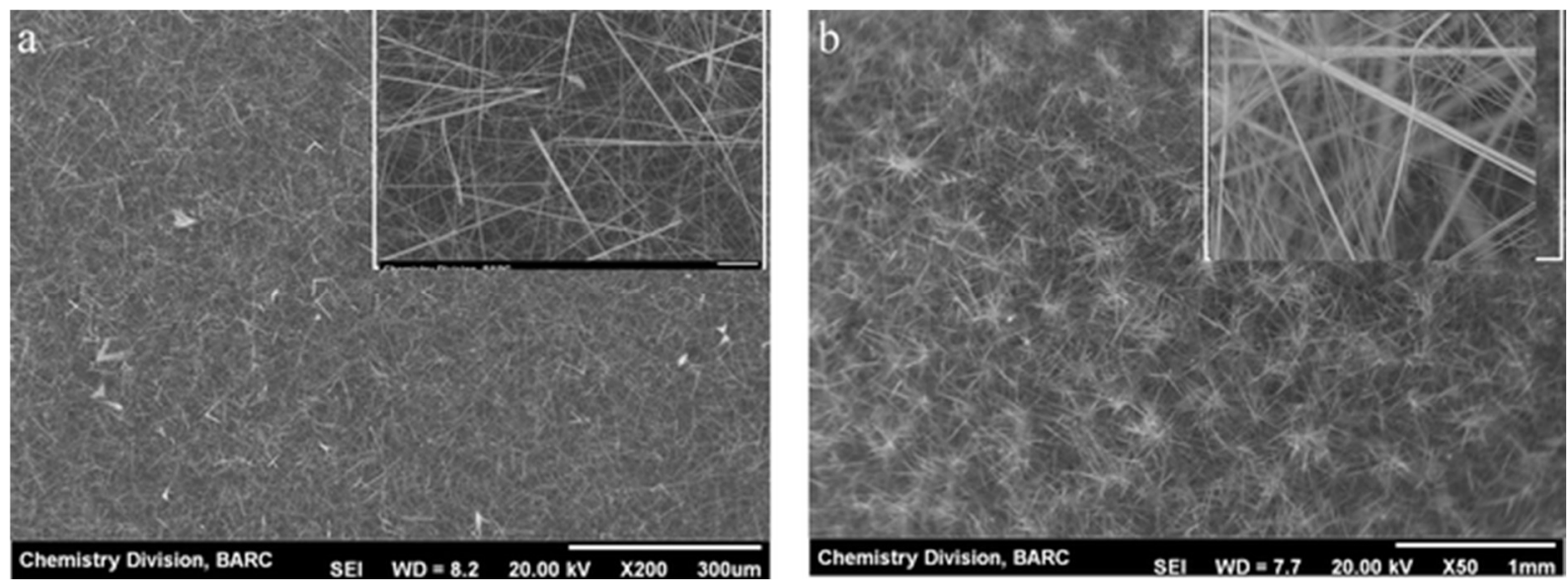

Figure 38. SEM image of $\mathrm{Sb}_{2} \mathrm{Se}_{3}$ films deposited by AACVD of $\left[\mathrm{Sb}\left\{\mathrm{Se}-\mathrm{C}_{5} \mathrm{H}_{3}(\mathrm{Me}-3) \mathrm{N}\right\}_{3}\right]$ at $425^{\circ} \mathrm{C}$ for a) $1 \mathrm{~h}$ and b) $2 \mathrm{~h}$ (inset displays the magnified image of the same). (Reproduced from R. K. Sharma, G. Kedarnath, V. K. Jain, A. Wadawale, M. Nalliath, C. G. S. Pillai and B. Vishwanadh, Dalton Trans., 2010, 39, 8779 with permission of The Royal Society of Chemistry. ${ }^{[85]}$ )

Several attempt to grow phase-pure $\mathrm{Bi}_{2} \mathrm{Se}_{3}$ films by AACVD using [Bi $\left.\left\{\mathrm{Se}-\mathrm{C}_{5} \mathrm{H}_{3}(\mathrm{Me}-3) \mathrm{N}\right\}_{3}\right]$ (4) failed. Instead, mixtures of different bismuth selenide phases were obtained on glass substrates at substrate temperatures between 325 and $475{ }^{\circ} \mathrm{C}$. Thin films deposited at 350 and $475{ }^{\circ} \mathrm{C}$ for $1 \mathrm{~h}$ corresponds to rhombohedral $\mathrm{Bi}_{3} \mathrm{Se}_{4}$ and the hexagonal phase of $\mathrm{Bi}_{3} \mathrm{Se}_{2}$, whereas films deposited between 375 and $425{ }^{\circ} \mathrm{C}$ for $1 \mathrm{~h}$ contained the hexagonal phase of BiSe. Interestingly, films deposited at 400 and $425{ }^{\circ} \mathrm{C}$ for $2 \mathrm{~h}$ mainly contained the bismuthrich rhombohedral $\mathrm{Bi}_{4} \mathrm{Se}_{3}$ phase. Obviously, increasing substrate temperatures resulted in the formation of Se-deficient films, most likely due to sublimation of selenium, which exhibits a relatively high volatility under these conditions.

\subsubsection{Single source precursors of the general type $\left(R_{2} M\right)_{2} E$}

Dickson et al. initially investigated almost 20 years ago the capability of $\left(\mathrm{Et}_{2} \mathrm{Sb}\right)_{2} \mathrm{Te}$ to serve as single source precursor for the MOCVD deposition of $\mathrm{Sb}_{2} \mathrm{Te}_{3}$ films. ${ }^{[191]}$ However, these studies remained unsuccessful since with $\mathrm{H}_{2}$ as reactive gas, only Sb-rich material films were obtained. It was proposed that hydrogenolysis of the precursor resulted in the formation of unstable $\mathrm{H}_{2} \mathrm{Te}$ and $\mathrm{Et}_{2} \mathrm{SbH}$. In addition, with its rather low vapor pressure of $1.3 \times 10^{-4} \mathrm{~mm}$ $\mathrm{Hg}$ at $20^{\circ} \mathrm{C}$, it was concluded that $\left(\mathrm{Et}_{2} \mathrm{Sb}\right)_{2} \mathrm{Te}$ is not a suitable precursor for conventional MOCVD applications. ${ }^{[191]}$ Despite these unsuccessful usage of $\left(\mathrm{Et}_{2} \mathrm{Sb}\right)_{2} \mathrm{Te}$ for the MOCVD deposition of $\mathrm{Sb}_{2} \mathrm{Te}_{3}$ films, we recently re-investigated $\left(\mathrm{Et}_{2} \mathrm{Sb}\right)_{2} \mathrm{Te}$ as single-source precursor for the MOCVD-growth of $\mathrm{Sb}_{2} \mathrm{Te}_{3}$ thin films. ${ }^{[192]}$ In contrast to Dickson et al., we used 
$\left(\mathrm{Et}_{2} \mathrm{Sb}\right)_{2} \mathrm{Te}$ in a home-made cold wall MOCVD reactor at a working pressure of $10^{-1} \mathrm{mbar}, \mathrm{Ar}$ as carrier gas and substrate $(\mathrm{Si}(100))$ temperatures of 200,250 and $300{ }^{\circ} \mathrm{C}$. The film growth rate of approximately $600 \mathrm{~nm} / \mathrm{h}$ at $200{ }^{\circ} \mathrm{C}$ was found to increase with increasing substrate temperature as is typical for a kinetically-controlled growth process. $\mathrm{Sb}_{2} \mathrm{Te}_{3}$ films were obtained between $200{ }^{\circ} \mathrm{C}$ and $220{ }^{\circ} \mathrm{C}$, while higher substrate temperatures resulted in the formation of Sb-rich films as was shown by EDX analysis and X-ray diffraction (Fig. 39). The increasing $\mathrm{Sb}$ concentration results from the thermal decomposition of $\mathrm{SbEt}_{3}$, which is formed as a by-product during decomposition of $\left(\mathrm{Et}_{2} \mathrm{Sb}\right)_{2} \mathrm{Te}$. Since pure $\mathrm{Et}_{3} \mathrm{Sb}$ starts to decompose at about $240{ }^{\circ} \mathrm{C},{ }^{[168]}$ the substrate temperature should not exceed $220{ }^{\circ} \mathrm{C}$. EDX studies also revealed the presence of small amounts of carbon (5-6\%), which are rather located on the substrate surface due to incompletely decomposed precursor residues as was shown by scanning Auger electron microscopy studies (SAM/AES).
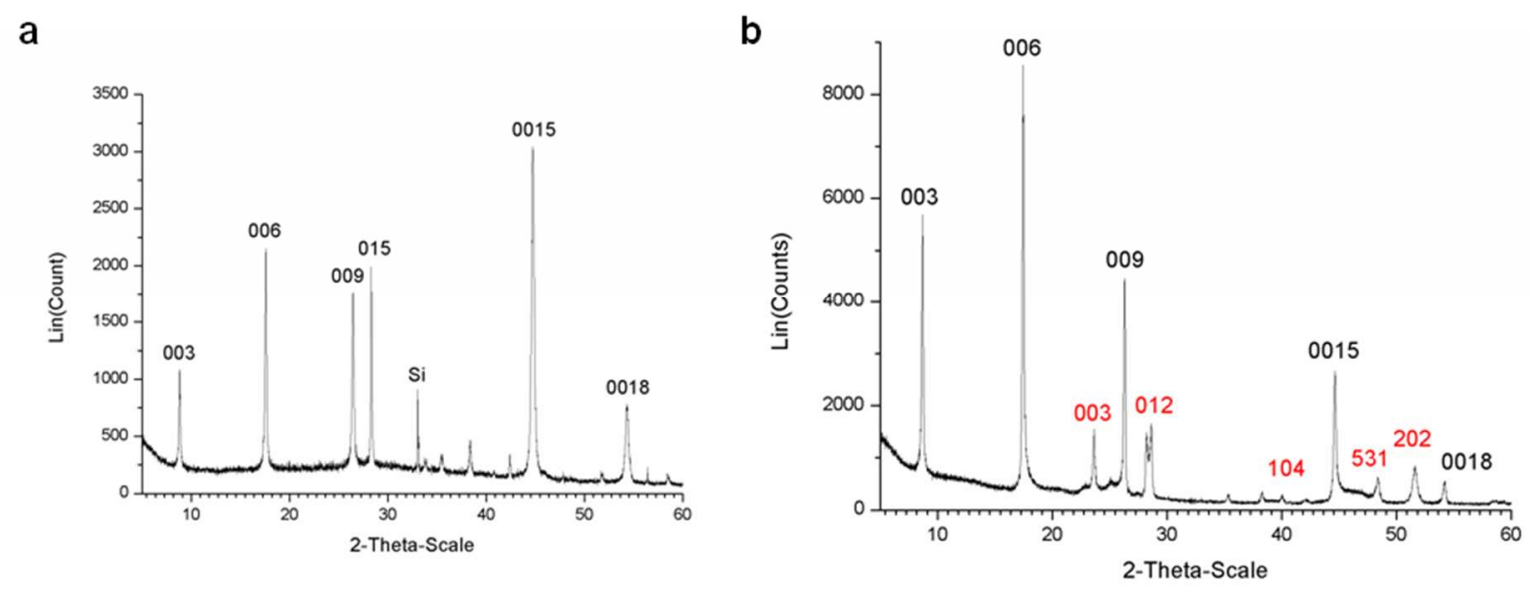

Figure 39. 2- $\theta$ XRD pattern of the film deposited at $200{ }^{\circ} \mathrm{C}$ (a) and $300{ }^{\circ} \mathrm{C}$ (b); peaks of $\mathrm{Sb}_{2} \mathrm{Te}_{3}$ given in black, those of elemental $\mathrm{Sb}$ in red. ${ }^{[192]}$

The powder diffractogram of the film deposited at $200{ }^{\circ} \mathrm{C}$ (Fig. 40a) proved the formation of pure, crystalline $\mathrm{Sb}_{2} \mathrm{Te}_{3}$ films. All reflection peaks with a significant intensity can be assigned to rhombohedral $\mathrm{Sb}_{2} \mathrm{Te}_{3}$. The most intense peaks in the diffractogram correspond to (001) planes, pointing to a preferred c-axis oriented growth as was previously reported for MOCVD grown $\mathrm{Sb}_{2} \mathrm{Te}_{3}$ films. ${ }^{[187,188,189]}$ In contrast, the diffractogram of the film deposited at $300{ }^{\circ} \mathrm{C}$ shows additional reflexes due to the presence of crystalline elemental antimony (Fig. 40b). Quantification of the $\mathrm{Sb}$ reflexes shows an almost 1:1 ratio of $\mathrm{Sb}_{2} \mathrm{Te}_{3}$ and $\mathrm{Sb}$, which agrees with the results from the EDX studies.

The surface morphology of the film deposited at $200{ }^{\circ} \mathrm{C}$ consists of hexagonal $\mathrm{Sb}_{2} \mathrm{Te}_{3}$ nanoplates with a diameter of more than $2 \mu \mathrm{m}$, which are randomly oriented with respect to 
the substrate as was shown by SEM (Fig. 40). Obviously, the low substrate temperature reduces the mobility of the ad atoms on the substrate surface during growth, hence leading to island nucleation and coalescence growth mode instead of step bunching growth process. With increasing temperature, the films become more flat as was expected, but their composition becomes more Sb-rich due to thermal decomposition of $\mathrm{SbEt}_{3}$.

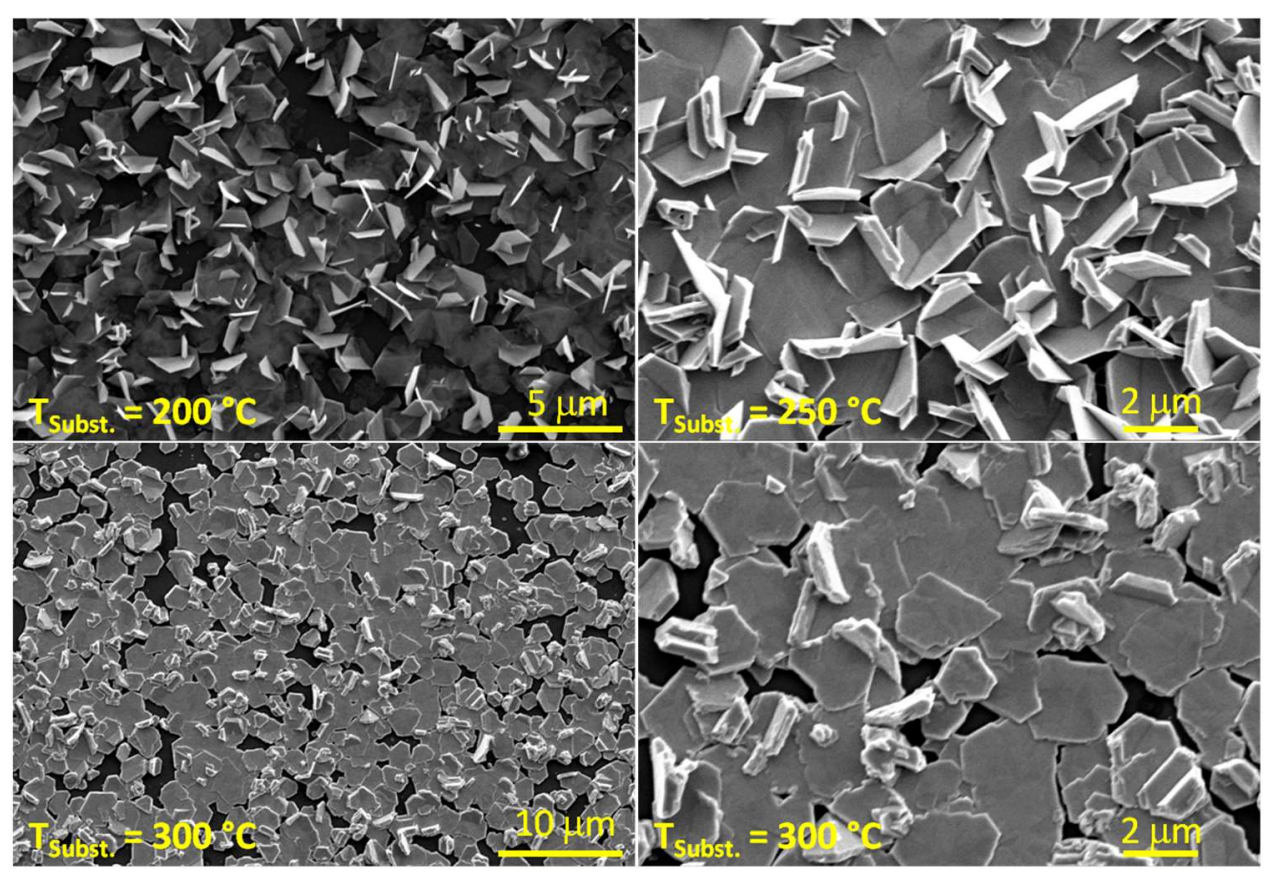

Figure 40. SEM photographs of $\mathrm{Sb}_{2} \mathrm{Te}_{3}$ films deposited on $\mathrm{Si}(100)$ substrates at substrate temperatures of 200,250 and $300{ }^{\circ} \mathrm{C} .{ }^{[192]}$

The average Seebeck value $(153.35 \pm 6.68 \mu \mathrm{V} / \mathrm{K})$ of the film deposited at $200{ }^{\circ} \mathrm{C}$ is higher than that of bulk $\mathrm{Sb}_{2} \mathrm{Te}_{3}$ crystals but corresponds very well to values reported by Yan et al. for $\mathrm{Sb}_{2} \mathrm{Te}_{3}$ films consisting of much smaller $\mathrm{Sb}_{2} \mathrm{Te}_{3}$ particles (100 nm diameter). ${ }^{[193]} \mathrm{A}$ similar Seebeck coefficient $(65 \mu \mathrm{V} / \mathrm{K})$ was found for $\mathrm{Sb}_{2} \mathrm{Te}_{3}$ films which were deposited by coevaporation of elemental $\mathrm{Sb}$ and Te on glass substrates. ${ }^{[194]}$ In contrast, the film deposited at $300{ }^{\circ} \mathrm{C}$ was rather metallic due to the Te-deficiency, leading to a rather broad distribution of the thermoelectric voltage.

These results clearly demonstrate, that the single source approach offers the possibility of $\mathrm{Sb}_{2} \mathrm{Te}_{3}$ film deposition using MOCVD processes at low temperatures, which might become even more important for the deposition of $\mathrm{Sb}_{2} \mathrm{Te}_{3} / \mathrm{Bi}_{2} \mathrm{Te}_{3}$ superlattices in order to avoid interlayer diffusion. However, careful adjustment of the deposition parameters, in particular the decomposition characteristics of possibly formed by-products, is neccessary in order to grow high quality material thin films. 


\section{Acknowledgment}

Financial support by the Mercator Research Center Ruhr (MERCUR), the Deutsche Forschungsgemeinschaft (DFG, priority program 1708) and the University of Duisburg-Essen is gratefully acknowledged.

\section{References}

${ }^{1}$ G. Mundt, O. Becker, J. Baumgarten, H. Riffel, A. Simon, Z. Anorg. Allg. Chem. 632 (2006) 1687-1709.

${ }^{2}$ W. Dukat, F. Gall, C. Meyer, D. Mootz, D. Naumann, G. Nowicki, K. Schulz, Z. Anorg. Allg. Chem. 622 (1996) 617-621.

${ }^{3}$ M. Mantina, A.C. Chamberlin, R. Valero, C.J. Cramer, D.G. Truhlar, J. Phys. Chem. A 113 (2009) 5806-5812.

${ }^{4}$ A. Kuczkowski, S. Heimann, A. Weber, S. Schulz, D. Bläser, C. Wölper, Organometallics 30 (2011) 47304735 .

${ }^{5}$ S. Schulz, S. Heimann, A. Kuczkowski, C. Wölper, D. Bläser, Organometallics 32 (2013) 3391-3394.

${ }^{6}$ A.J. Ashe, III, E.G. Ludwig, Jr., J. Oleksyszyn, J.C. Huffman, Organometallics 3 (1984) 337-338.

${ }^{7}$ H.J. Breunig, H. Jawad, Z. Naturforsch. 37b (1982) 1104-1108.

${ }^{8}$ H.J. Breunig, H. Jawad, J. Organometal. Chem. 277 (1984) 257-260.

${ }^{9}$ H.J. Breunig, T. Krüger, E. Lork, J. Organomet. Chem. 648 (2002) 209-213.

${ }^{10}$ M. Wieber, I. Sauer, Z. Naturforsch. 42b (1987) 695-698.

${ }^{11}$ H.J. Breunig, K.H. Ebert, R.E. Schulz, M. Wieber, I. Sauer, Z. Naturforsch. 50b (1995) 735-744.

${ }^{12}$ X.-W. Li, J. Lorberth, K.H. Ebert, W. Massa, S. Wocadlo, J. Organomet. Chem. 560 (1998) 211-215.

${ }^{13}$ H.J. Breunig, L. Königsmann, E. Lork, M. Nema, N. Philipp, C. Silvestru, A. Soran, R. A. Varga, R. Wagner, J. Chem. Soc., Dalton Trans. 2008, 1831-1842.

${ }^{14}$ H.J. Breunig, S. Gülec, Unkonventionelle Wechselwirkungen in der Chemie Metallischer Elemente, B. Krebs (Ed.), VCH, Weinheim, 1992, 218.

${ }^{15}$ H.J. Breunig, S. Gülec, Z. Naturforsch. 41b (1986) 1387-1390.

${ }^{16}$ R.S. Dickson, K.D. Heazle, J. Organomet. Chem. 493 (1995) 189-197.

${ }^{17}$ S. Schulz, A. Kuczkowski, M. Nieger, J. Organomet. Chem. 604 (2000) 202-207.

${ }^{18}$ P. Dehnert, J. Grobe, W. Hildebrandt, D. le Van, Z. Naturforsch. 34b (1979) 1646-1652.

${ }^{19}$ M. Wieber, I. Sauer, Z. Naturforsch. 39b (1984) 1668-1670.

${ }^{20}$ H.J. Breunig, W.W. du Mont, D. Müller, T. Severengiz, Z. Naturforsch.40b (1985) 848-849.

${ }^{21}$ A.J. Ashe, III, E.G. Ludwig, Jr., J. Organomet. Chem. 308 (1986) 289-296.

${ }^{22}$ F. Calderazzo, A. Morvillo, G. Pelizzi, R. Poli, F. Ungari, Inorg. Chem. 27 (1988) 3730-3733.

${ }^{23}$ R.C. Fischer, P.P. Power, Chem. Rev. 110 (2010) 3877-3923.

${ }^{24}$ P.P. Power, Chem. Rev. 99 (1999) 3463-3504. 
${ }^{25}$ P. Šimon, R. Jambor, A. Růžička, A. Lyčka, F. De Proft, L. Dostál, J. Chem. Soc., Dalton Trans. 41 (2012) $5140-5143$.

${ }^{26}$ L. Dostál, R. Jambor, A. Růžička, A. Lyčka, J. Brus, F. de Proft, Organometallics 27 (2008) 6059-6065.

${ }^{27}$ C. Löwig, E. Schweizer, Liebigs Ann. Chem. 75 (1850) 315-355.

${ }^{28}$ L. Kaufmann, Chem. Ber. 41 (1908) 2762-2766.

${ }^{29}$ W.J. Lile, R.C. Menzies, J. Chem. Soc. 1950, 617-621.

${ }^{30}$ J. Pebler, F. Weller, K. Dehnicke, Z. Anorg. Allg. Chem. 492 (1982) 139-147.

${ }^{31}$ F. Weller, K. Dehnicke, Naturwissenschaften 68 (1981) 523-524.

${ }^{32}$ G.S. Zhdanov, V.A. Pospelov, M.M. Umanski, V.P.Glushkova, Dokl. Akad. Nauk SSSR (Russ.) (Proc. Nat. Acad. Sci. USSR) 92 (1953) 983-985.

33 J. Otera, R. Okawara, Inorg. Nucl. Chem. Lett. 6 (1970) 855-857.

${ }^{34}$ J.A. Chang, J.H. Rhee, S.H. Im, Y.H. Lee, H.-J. Kim, S.I. Seok, M.K. Nazeeruddin, M. Grätzel, Nano Lett. 10 (2010) 2609-2612.

${ }^{35}$ S.H. Im, C.-S. Lim, J.A. Chang, Y.H. Lee, N. Maiti, H.-J. Kim, M.K. Nazeeruddin, M. Grätzel, S.I. Seok, Nano Lett. 11 (2011) 4789-4793.

${ }^{36}$ N. Maiti, S.H. Im, C.-S. Lim, S.I. Seok, J. Chem. Soc., Dalton Trans. 41 (2012) 11569-11572

${ }^{37}$ J. Grigas, Microwave dielectric spectroscopy of ferroelectrics and related materials; Gordon and Breach Publishers: Amsterdam, 1996, Vol. 9.

${ }^{38}$ D.Y.W. Yu, H.E. Hoster, S.K. Batabyal, Sci. Rep. 4 4562; DOI:10.1038/srep04562 (2014).

${ }^{39}$ P.V. Prikhodchenko, J. Gun, S. Sladkevich, A.A. Mikhaylov, O. Lev, Y. Yan Tay, S.K. Batabyal, D.Y.W. Yu, Chem. Mater. 24 (2012) 4750-4757.

${ }^{40}$ D.Y.W. Yu, P.V. Prikhodchenko, C.W. Mason, S.K. Batabyal, J. Gun, S. Sladkevich, A.G. Medvedev, O. Lev, Nature Comm. 4, 2922; 10.1038/ncomms3922 (2013).

${ }^{41}$ R. Venkatasubramanian, E. Siivola, T. Colpitts, B. O'Quinn, Nature 413 (2001) 597-602.

42 T.C. Harman, P.J. Taylor, M.P. Walsh, B.E. LaForge, Science 297 (2002) 2229-2232.

${ }^{43}$ D. Hsieh, Y. Xia, D. Qian, L. Wray, F. Meier, J. H. Dil, J. Osterwalder, L. Patthey, A. V. Fedorov, H. Lin, A. Bansil, D. Grauer, Y. S. Hor, R. J. Cava and M. Z. Hasan, Phys. Rev. Lett. 103 (2009) 146401-4.

${ }^{44}$ A.I.; Boukai, Y.; Bunimovich, J.; Tahir-Kheli, J.K.; Yu, W.A.; Goddard, J.R. Heath, Nature 451 (2008) 168171.

${ }^{45}$ H. Zhang, C.-X. Liu, X.-L. Qi, X. Dai, Z. Fang, S.-C. Zhang, Nat. Phys. 5 (2009) 438-442.

${ }^{46}$ M. Bochmann, X. Song, M. B. Hursthouse, A. Karaulov, J. Chem. Soc., Dalton Trans. (1995) 1649-1652;

${ }^{47}$ F.T.F. O'Mahony, U.B. Cappel, N. Tokmoldin, T. Lutz, R. Lindblad, H. Rensmo, S.A. Haque, Angew. Chem. Int. Ed. 52 (2013) 12047-12051; Angew. Chem. 125 (2013) 12269-12273.

48 J.R. Castro, K.C. Molloy, Y. Liu, C.S. Lai, Z. Dong, T.J. White, E.R. T. Tiekink, J. Mater. Chem. 18 (2008) 5399-5405.

${ }^{49}$ H.-W. Chang, B. Sarkar, C.W. Liu, Cryst. Growth Des. 7 (2007) 2691-2695. 
${ }^{50}$ W. Lou, M. Chen, X. Wang, W. Liu, Chem. Mater. 19 (2007) 872-878.

${ }^{51}$ A.G. Davies, S.C.W. Hook, J. Chem. Soc. B (1970) 735-737

${ }^{52}$ M. Wieber, U. Baudis, Z. Anorg. Allg. Chem. 436 (1977) 101-104

${ }^{53}$ M. Wieber, U. Baudis, Z. Anorg. Allg. Chem. 439 (1978) 134-138

${ }^{54}$ D.N. Kravtsov, B.A. Kvasov, S.I. Pombrik, E.I. Fedin, J. Organomet. Chem. 86 (1975) 383-395;

${ }^{55}$ G.G. Briand, A. Decken, N.M. Hunter, G.M. Lee, J.A. Melanson, Polyhedron 31 (2012) 796-800.

${ }^{56}$ T. Arnold, D.H.R. Barton, J.-F. Normant, J. Org. Chem. 64 (1999) 3722-3725.

${ }^{57}$ P. Šimon, R. Jambor, A. Růžička, L. Dostál, Organometallics 32 (2013) 239-248.

${ }^{58}$ G. Mugesh, B.H. Singh, R.J. Butcher, J. Chem. Res. (1999) 416-417.

${ }^{59}$ P. Pyykkö, M. Atsumi, Chem.-Eur. J. 15 (2009) 186-197.

${ }^{60}$ Landolt-Börnstein - Group III Condensed Matter C 41 (1998) 1-4.

${ }^{61}$ S. Heimann, A. Kuczkowski, D. Bläser, C. Wölper, R. Haak, G. Jansen, S. Schulz, Eur. J. Inorg. Chem. (2014) 4858-4864.

${ }^{62}$ T. Sasamori, E. Mieda, N. Takeda, N. Tokitoh, Angew. Chem. Int. Ed. 44 (2005) 3717-3720; Angew. Chem. 117 (2005) 3783-3786.

${ }^{63}$ H.J. Breunig, I. Gheşner, E. Lork, J. Organomet. Chem. 664 (2002) 130-135.

${ }^{64}$ S. Traut, A.P. Hähnel, C. von Hänisch, J. Chem. Soc., Dalton Trans. 40 (2011) 1365-1371.

${ }^{65}$ Y. Feutelais, B. Legendre, N. Rodier, V. Agafonov, Mater. Res. Bull. 28 (1993) 591-596.

${ }^{66}$ H.M. Hoffmann, M. Dräger, J. Organomet. Chem. 329 (1987) 51-56.

${ }^{67}$ H.M. Hoffmann, M. Dräger, J. Organomet. Chem. 320 (1987) 273-282.

${ }^{68}$ H.M. Hoffmann, M. Dräger, J. Organomet. Chem. 295 (1985) 33-46.

${ }^{69}$ M. Dräger, B.M. Schmidt, J. Organomet. Chem. 290 (1985) 133-145.

${ }^{70}$ P. Singh, S. Singh, V.D. Gupta, H. Nöth, Z. Naturforsch. 53b (1998) 1475-1483.

${ }^{71}$ N. Avarvari, M. Fourmigue, Organometallics 22 (2003) 2042-2049.

72 N. Avarvari, M. Fourmigue, E. Canadell, Eur. J. Inorg. Chem. (2004) 3409-3414.

${ }^{73}$ N. Avarvari, E. Faulques, M. Fourmigue, Inorg. Chem. 40 (2001) 2570-2577.

${ }^{74}$ A.J. Blake, M. Pearson, D.B. Sowerby, P.P. Woodhead, Acta Cryst. C 53 (1997) 583-585.

${ }^{75}$ N. Tokitoh, Y. Arai, J. Harada, R. Okazaki, Chem. Lett. 24 (1995) 959-960.

${ }^{76}$ K.R. Chaudhari, A.P. Wadawale, V.K. Jain, N. Yadav, R. Bohra, Indian J. Chem. A 49 (2010) 34-39.

${ }^{77}$ H. Preut, F. Huber, K.-H. Hengstmann, Acta Cryst. C 44 (1988) 468-469.

${ }^{78}$ K.-H. Hengstmann, F. Huber, H. Preut, Acta Cryst. C 47 (1991) 2029-2032.

${ }^{79}$ P. Šimon, R. Jambor, A. Rủžička, L. Dostál, J. Organomet. Chem. 740 (2013) 98-103.

${ }^{80}$ H.J. Breunig, S. Gülec, B. Krebs, M. Dartmann, Z. Naturforsch. 44b (1989) 1351-1354.

${ }^{81}$ H. Sommer, A. Eichhöfer, D. Fenske, Z. Anorg. Allg. Chem. 634 (2008) 436-440.

${ }^{82}$ H.J. Breunig, S. Gülec, Z. Naturforsch. 43b (1988) 998-1002. 
${ }^{83}$ L.Y. Pech, Y.A. Bankovskii, V.K. Bel'sky, E. Ya. Silin', Y.V. Ashaks, V.E. Zavodnik, Zh. Neorg. Khim. (Russ. J. Inorg. Chem.) 45 (2000) 843-849.

${ }^{84}$ E. Silina, S. Belyakov, J. Ashaks, L. Pecha, D. Zaruma, Acta Cryst. C 63 (2007) m62-m64.

${ }^{85}$ R.K. Sharma, G. Kedarnath, V.K. Jain, A. Wadawale, M. Nalliath, C.G.S. Pillai, B. Vishwanadh, J. Chem. Soc., Dalton Trans. 39 (2010) 8779-8787.

${ }^{86}$ M.W. DeGroot, J.F. Corrigan, J. Chem. Soc., J. Chem. Soc., Dalton Trans. (2000) 1235-1236.

${ }^{87}$ E. Silina, J. Ashaks, S. Belyakov, A. Tokmakov, L. Pech, D. Zaruma, Khim. Get. Soedin., SSSR (Chem. Heterocycl. Compd.) (2007) 1866-1874.

${ }^{88}$ H. J. Breunig, E. Lork, R. Rösler, G. Becker, O. Mundt, W. Schwarz, Z. Anorg. Allg. Chem. 626 (2000) 1595-1607.

${ }^{89}$ L.M. Opris, A.M. Preda, R.A. Varga, H.J. Breunig, C. Silvestru, Eur. J. Inorg. Chem. (2009) 1187-1193.

${ }^{90}$ R. Qiu, Z. Meng, S. Yin, X. Song, N. Tan, Y. Zhou, K. Yu, X. Xu, S. Luo, C.-T. Au, W.-Y. Wong, ChemPlusChem 77 (2012) 404-410.

${ }^{91}$ H.J. Breunig, M. Jönsson, R. Rösler, E. Lork, Z. Anorg. Allg. Chem. 625 (1999) 2120-2124.

92 M. Wieber, N. Graf, Z. Anorg. Allg. Chem. 619 (1993) 1991-1997.

${ }^{93}$ H.J. Breunig, E. Lork, O. Moldovan, R. Wagner, Z. Anorg. Allg. Chem. 634 (2008) 1397-1402.

${ }^{94}$ A. Haaland, V.I. Sokolov, H.V. Volden, H.J. Breunig, M. Denker, R. Rösler, Z. Naturforsch. 1997, 52b, 296 300.

${ }^{95}$ A. Haaland, D. J. Shorokhov, H. V. Volden, H. J. Breunig, M. Denker, R. Rösler, Z. Naturforsch. 53b (1998) $381-385$.

96 A. Haaland, D.J. Shorokhov, V.I. Sokolov, H.V. Volden, H.J. Breunig, M. Denker, R. Rösler, Phosphorous Sulfur Silicon Relat. Elem. 136-138 (1998) 463-466.

97 S. Heimann, S. Schulz, D. Bläser, C. Wölper, Eur. J. Inorg. Chem. (2013) 4909-4915.

${ }^{98}$ R. Boese, M. Nussbaumer, "In Situ Crystallisation Techniques", in: "Organic Crystal Chemistry", Ed. D. W. Jones, Oxford University Press, Oxford, England, (1994) 20-37.

${ }^{99}$ C.J. Warren, D.M. Ho., R.C. Haushalter, A.B. Bocarsly, Angew. Chem. Int. Ed. 32 (1993) 1646-1649; Angew. Chem. 105 (1993) 1684-1687.

100 C.J. Warren, S.S. Dhingra, D.M. Ho, R.C. Haushalter, A.B. Bocarsly, Inorg. Chem. 33 (1994) 2709-2710.

101 J.L. Shreeve-Keyer, R.C. Haushalter, Polyhedron 15 (1996) 1213-1215.

102 S. Heimann, D. Bläser, C. Wölper, S. Schulz, Organometallics 33 (2014) 2295-2300.

103 S. Schulz, A. Kuczkowski, D. Bläser, C. Wölper, G. Jansen, R. Haack, Organometallics 32 (2013) 54455450 .

104 A. Kuczkowski, S. Heimann, A. Weber, S. Schulz, D. Bläser, C. Wölper, Organometallics 30 (2011) 47304735 .

${ }^{105} \mathrm{Bi}-\mathrm{S}$ distances $(31$ hits for $\mathrm{Bi}-\mathrm{S}$ with bonding single bond and coordination numbers c.n. $(\mathrm{Bi})=3$, c.n. $(\mathrm{S})=$ 2) range from 2.450 to 2.727 (mean value 2.584(50) $\AA$ ); Bi-Se distances (7 hits containing a Bi-Se bond 
(2.569 - 2.717; mean value 2.676(35) $\AA$ ) and four compounds with a Bi-Te bond of the desired type (2.8382.889; mean value 2.866(16) $\AA$ )

106 A. Hantzsch, H. Hibbert, Ber. Dtsch. Chem. Ges. 40 (1907) 1508-1519.

107 W.J.C. Dyke, W.J. Jones, J. Chem. Soc. (1930) 1921-1927.

108 R.A. Zingaro, A. Merijanian, J. Organomet. Chem. 1 (1964) 369-372.

109 G.N. Chremos, R.A. Zingaro, J. Organomet. Chem. 22 (1970) 637-646.

110 J. Beckmann, D. Dakternieks, A. Duthie, R.C. Foitzik, Z. Anorg. Allg. Chem. 629 (2003) 1508-1510.

111 L. Yang, J. Tehranchi, W.B. Tolman, Inorg. Chem. 50 (2011) 2606-2612.

112 N. Kuhn, H. Schumann, J. Organomet. Chem. 288 (1985) c51-c52.

${ }^{113}$ Unfortunately, structural data of $\mathrm{p}-\mathrm{Tol}_{3} \mathrm{SbS}$ are not available in the Cambridge structure database.

114 W. Gordy, J. Chem. Phys., 14 (1946) 305-320.

115 M. Shindo, Y. Matsumura, R. Okawara, J. Organometal. Chem. 11 (1968) 299-305.

116 S. Heimann, D. Bläser, C. Wölper, R. Haack, G. Jansen, S. Schulz, J. Chem. Soc., Dalton Trans. 43 (2014) 14772-14777.

117 P. Pyykkö, M. Atsumi, Chem.-Eur. J. 15 (2009) 12770-12779.

118 D. Jia, Y. Zhang, Q. Zhao, J. Deng, Inorg. Chem. 45 (2006) 9812-9817.

${ }^{119}$ U. Herzog, G. Rheinwald, Organometallics 20 (2001) 5369-5374.

${ }^{120}$ L. Dostál, R. Jambor, A. Růžička, R. Jirásko, V. Lochar, L. Benes, F. de Proft, Inorg. Chem. 48 (2009) 10495-10497.

${ }^{121}$ L.M. Opris, A. Silvestru, C. Silvestru, H. J. Breunig, E. Lork, J. Chem. Soc., Dalton Trans. (2004) 35753585 .

122 J. Vrana, R. Jambor, A. Růžička, A. Lyčka, L. Dostál, J. Organomet. Chem. 718 (2012) 78-81.

123 T. Sasamori, E. Mieda, N. Takeda, N. Tokitoh, Chem.Lett. 33 (2004) 104-105.

124 T. Sasamori, E. Mieda, N. Tokitoh, Bull. Chem. Soc. Jpn. 80 (2007) 2425-2435.

125 T. Tanabe, Y. Mizuhata, N. Takeda, N. Tokitoh, J. Organomet. Chem. 694 (2009) 353-35.

${ }^{126}$ M. Chovancova, R. Jambor, A. Růžička, R. Jirasko, I. Cisarova, L. Dostál, Organometallics 28 (2009) 19341943.

${ }^{127}$ H.J. Breunig, I. Ghesner, E. Lork, Appl. Organomet. Chem. 16 (2002) 547-549.

128 T. Sasamori, N. Takeda, N. Tokitoh, J. Phys. Org. Chem. 16 (2003) 450-462.

${ }^{129}$ L. Dostál, R. Jambor, A. Růžička, R. Jirásko, E. Černošková, L. Beneš, F. de Proft, Organometallics 29 (2010) 4486-4490.

${ }^{130}$ L. Dostál, R. Jambor, M. Erben, A. Růžička, Z. Anorg. Allg. Chem. 638 (2012) 614-616.

${ }^{131}$ N. Tokitoh, Y. Arai, T. Sasamori, R. Takeda, R. Okazaki, Heteroat. Chem. 12 (2001) 244-249.

132 H. Althaus, H.J. Breunig, E. Lork, J. Chem. Soc, Chem. Commun. (1999) 1971-1973.

${ }^{133}$ K.A. Porter, A.C. Willis, J. Zank, S.B. Wild, Inorg. Chem. 41 (2002) 6380-6386. 
${ }^{134}$ N. Burford, P.J. Ragogna, K. Sharp, R. McDonald, M.J. Ferguson, Inorg. Chem. 44 (2005) 9453-9460.

135 J.W. Wielandt, N.L. Kilah, A.C. Willis, S.B. Wild, J. Chem. Soc, Chem. Commun. (2006) 3679-3680.

${ }^{136}$ N.L. Kilah, S. Petrie, R. Stranger, J.W. Wielandt, A.C. Willis, S.B. Wild, Organometallics 26 (2007) 61066113.

${ }^{137}$ J. Jeske, W.-W. du Mont, P.G. Jones, Angew. Chem., Int. Ed. 36 (1997) 2219-2221; Angew. Chem. 109 (1997) 2304-2306.

138 J. Jeske, W.-W. du Mont, F. Ruthe, P.G. Jones, L.M. Mercuri, P. Deplano, Eur. J. Inorg. Chem. (2000) 1591-1599.

${ }^{139}$ J. Beckmann, J. Bolsinger, A. Duthie, P. Finke, E. Lork, C. Lüdtke, O. Mallow, S. Mebs, Inorg. Chem. 51 (2012) 12395-12406.

${ }^{140}$ B. Cordero, V. Gómez, A.E. Platero-Prats, M. Revés, J. Echeverría, E. Cremades, F. Barragán, S. Alvarez, J. Chem. Soc., Dalton Trans. (2008) 2832-2838.

${ }^{141}$ E. Conrad, N. Burford, R. McDonald, M.J. Ferguson, J. Chem. Soc, Chem. Commun. 46 (2010) 4598-4600

142 A.J. Minnich, M.S. Dresselhaus, Z.F. Ren, G. Chen, Energy Environ. Sci. 2 (2009) 466-479.

143 M.S. Dresselhaus, G. Chen, M.Y. Tang, R.G. Yang, H. Lee, D.Z. Wang, Z.F. Ren, J.P. Fleurial, P. Gogna, Adv. Mater. 19 (2007) 1043-1053.

144 T. M. Tritt, Annual Review of Materials Research; Clarke, D. R., Fratzl, P., Eds.; Annual Reviews: Palo Alto, CA, 41 (2011) 433-448.

145 G.S. Nolas, J. Sharp, J. Goldsmid, Thermoelectrics: Basic Principles and New Materials Developments; Springer: New York (2011).

146 L.E. Bell, Science 321 (2008) 1457-1461.

147 A.I. Boukai, Y. Bunimovich, J. Tahir-Kheli, J.K. Yu, W.A. Goddard, J.R. Heath, Nature 451 (2008) 168171.

148 R.J. Mehta, Y. Zhang, C. Karthik, B. Singh, R.W. Siegel, T. Borca-Tasciuc, G. Ramanath, Nature Mater. 11 (2012) 233-240.

${ }^{149}$ R.J. Mehta, C. Karthik, W. Jiang, B. Singh, Y. Shi, R.W. Siegel, T. Borca-Tasciuc, G. Ramanath, Nano Lett. 10 (2010) 4417-4422.

${ }^{150}$ D. Li, X.Y. Qin, Y.F. Liu, N.N. Wang, C.J. Song, R.R. Sun, RSC Adv.3 (2013) 2632-2638.

${ }^{151}$ Y. Zhang, R.J. Mehta, M. Belley, L. Han, G. Ramanath, T. Borca-Tasciuc, Appl. Phys. Lett. 100 (2012) 193113-193115.

152 Z. Lu, L.P. Tan, X. Zhao, M. Layani, T. Sun, S. Fan, Q. Yan, S. Magdassi, H.H. Hng, J. Mater. Chem. C 1 (2013) 6271-6277.

${ }^{153}$ M.K. Han, S. Kim, H.-Y. Kim, S.-J. Kim, RSC Adv. 3 (2013) 4673-4679.

${ }^{154}$ Y. Min, J.W. Roh, H. Yang, M. Park, S.I. Kim, S. Hwang, S.M. Lee, K.H. Lee, U. Jeong, Adv. Mater. 25 (2013) 1425-1429.

155 Y. Zhang, G.D. Stucky, Chem. Mater. 26 (2014) 837-848. 
${ }^{156}$ R. Benoit, V. Hornebecq, F. Weill, L. Lecren, X. Bourrat, M. Tréguer-Delapierrec, J. Mater. Chem. A 1 (2013) 14221-14226.

${ }^{157}$ R.J. Mehta, C. Karthik, B. Singh, R. Teki, T. Borca-Tasciuc, G. Ramanath, ACS Nano 4 (2010) 5055-5060.

${ }^{158}$ G. Shen, D. Chen, K. Tang, X. Jiang, Y. Qian, J. Cryst. Growth 252 (2003) 350-354.

${ }^{159}$ Z. Deng, M. Mansuripur, A.J. Muscat, Nano Lett. 9 (2009) 2015-2020.

${ }^{160}$ Y. Yu, R.H. Wang, Q. Chen, L.-M. Peng, J. Phys. Chem. B 110 (2006) 13415-13419.

161 J. Ma, Y.P.Wang, Y.J. Wang, P. Peng, J.B. Lian, X.C. Duan, Z.F. Liu, X.D. Liu, Q. Chen, T. Kim, G. Yao, W. J. Zheng, Cryst. Eng. Comm. 13 (2011) 2369-2374.

162 W. Tao, J. Wang, D. Wu, J. Chang, F. Wang, Z. Gao, F. Xu, K. Jiang, J. Chem. Soc., Dalton Trans. 42 (2013) 11411-11417.

${ }^{163}$ H. Zhang, M. Ge, L. Yang, Z. Zhou, W. Chen, Q. Li, L. Liu, J. Phys. Chem. C 117 (2013) 10285-10290

${ }^{164}$ R. Jin, G. Chen, C. Yan, D. Chen, H. Xu, J. Pei, Cryst. Eng. Comm. 14 (2012) 8547-8553.

${ }^{165}$ X. Wang, K. Cai, H. Liu, Cryst. Growth Des. 11 (2011) 4759-4767.

${ }^{166}$ G. Gupta, J. Kim, J. Chem. Soc., Dalton Trans. 42 (2013) 8209-8211.

${ }^{167}$ K. Sharma, G. Kedarnath, V.K. Jain, A. Wadawale, M. Nalliath, C.G.S. Pillai, B. Vishwanadh J. Chem. Soc., Dalton Trans. 39 (2010) 8779-8787.

${ }^{168}$ S. Schulz, S. Heimann, J. Friedrich, M. Engenhorst, G. Schierning, W. Assenmacher, Chem. Mater. 24 (2012) 2228-2234.

${ }^{169}$ S. Heimann, W. Assenmacher, O. Prymak, S. Schulz, in preparation.

${ }^{170}$ D. Wang, C. Song, X. Fu, X. Li, J. Cryst. Growth 281 (2005) 611-615.

${ }^{171}$ G.-Y. Chen, B. Dneg, G.-B. Cai, T.-K. Zhang, W.-F. Dong, W.-X. Zhang, A.-W. Xu, J. Phys. Chem. C 112 (2008) 672-679.

172 W.Z. Wang, B. Poudel, J. Yang, D.Z. Wang, Z.F. Ren, J. Am. Chem. Soc. 127 (2005) 13792-13793.

${ }^{173}$ R. Jin, G. Chen, J. Pei, H. Xu, Z. S. Lv, RSC Adv. 2 (2012) 1450-1456.

${ }^{174}$ W. Shi, L. Zhou, S. Song, J. Yang, H. Zhang, Adv. Mater. 20 (2008) 1892-1897.

175 J.A. Hollingsworth, D.M. Poojary, A. Clearfield, W.E. Buhro, J. Am. Chem. Soc. 122 (2000) 3562-3563.

${ }^{176}$ L.W. da Silva, M. Kaviany, C. Uher, J. Appl. Phys. 97 (2005) 114903-114910.

${ }^{177}$ H. Scherrer, S. Scherrer, Thermoelectrics Handbook, Macro to Nano, Ed. D.M. Rowe, Francis \& Taylor group, Boca Raton, Florida (2006) Chapter 27.

178 J. Dupont, J.D. Scholten, Chem. Soc. Rev. 39 (2010) 1780-1804.

179 J. Cybinska, C. Lorbeer, A.-V. Mudring, J. Mater. Chem. 22 (2012) 9505-9508.

${ }^{180}$ S. Heimann, S. Schulz, J. Schaumann, A. Mudring, J. Stötzel, G. Schierning, in preparation.

${ }^{181}$ E. Diemann, Z. Anorg. Allg. Chem. 433 (1977) 242-246.

182 J.S. Ritch, T. Chivers, M. Afzaal, P. O’Brien, Chem. Soc. Rev. 36 (2007) 1622-1631. 
${ }^{183}$ S.S. Garje, D.J. Eisler, J.S. Ritch, M. Afzaal, P. O’Brien, T. Chivers, J. Am. Chem. Soc. 128 (2006) 3120 3121.

${ }^{184}$ S.L. Benjamin, C.H. de Groot, C. Gurnani, A.L. Hector, R. Huang, E. Koukharenko, W. Levason, G. Reid, J. Mater. Chem. 2 (2014) 4865-4869.

185 J.-H. Kim, S.-D. Kwon, D.-Y. Jeong, B.-K. Ju, S.-J. Yoon, J.-S. Kim, 25th Internat. Conf. on Thermoelectrics, 2006 (ICT '06), 411-413. Doi: 10.1109/ICT.2006.331284.

186 J.S. Lee, S. Brittman, D. Yu, H. Park, J. Am. Chem. Soc. 130 (2008) 6252-6258.

${ }^{187}$ A. Giani, A. Boulouz, F.P. Delannoy, A. Foucaran, A. Boyer, B. Aboulfarah, A. Mzerd, J. Mater. Sci. Lett. 18 (1999) 541-543.

${ }^{188}$ R. Venkatasubramanian, T. Colpitts, B. O’Quinn, S. Liu, N. El-Masry, M. Lamvik, Appl. Phys. Lett. 75 (1999) 1104-1106.

189 J.H. Kim, Y.C. Jung, S.H. Suh, J.S. Kim, J. Nanosci. Nanotechnol. 6 (2006) 3325-3328.

${ }^{190}$ G. Bendt, S. Zastrow, K. Nielsch, P.S. Mandal, J. Sánchez-Barriga, O. Rader, S. Schulz, J. Mater. Chem. A 2 (2014) 8215-8222.

${ }^{191}$ R.S. Dickson, K.D. Heazle, J. Organomet. Chem. 493 (1995) 189-197.

192 G. Bendt, S. Schulz, S. Zastrow, K. Nielsch, Chem. Vap. Deposition 19 (2013) 235-241

193 J. Chen, T. Sun, D.H. Sim, H. Peng, H. Wang, S. Fan, H.H. Hng, J. Ma, F.Y.C. Boey, S. Li, M.K. Samani, G.C.K. Chen, X. Chen, T. Wu, Q. Yan, Chem. Mater. 22 (2010) 3086-3092.

${ }^{194}$ K. Rajasekar, L. Kungumadevi, A. Subbarayan, R. Sathyamoorthy, Ionics 14 (2008) 69-72. 


\section{DuEPublico}

This text is made available via DuEPublico, the institutional repository of the University of Duisburg-Essen. This version may eventually differ from another version distributed by a commercial publisher.

DOI: $\quad 10.1016 /$ j.ccr.2014.11.003

URN： urn:nbn:de:hbz:464-20201125-092121-6

This is the Authors Accepted Manuscript of an article published in:

Coordination Chemistry Reviews 297-298 (2015), 49-76.

The final version may be found at: https://doi.org/10.1016/j.ccr.2014.11.003

This work may be used under a Creative Commons Attribution -

NonCommercial - NoDerivatives 4.0 License (CC BY-NC-ND 4.0) 